US Army Corps of Engineers ${ }_{\circledast}$

Engineer Research and

Development Center

\title{
Red River Structure Physical Model Study
}

Gary L. Bell, Jeremy A. Sharp, Locke M. Williams, Howard E. Park, September 2020 Duncan B. Bryant, and Gaurav Savant

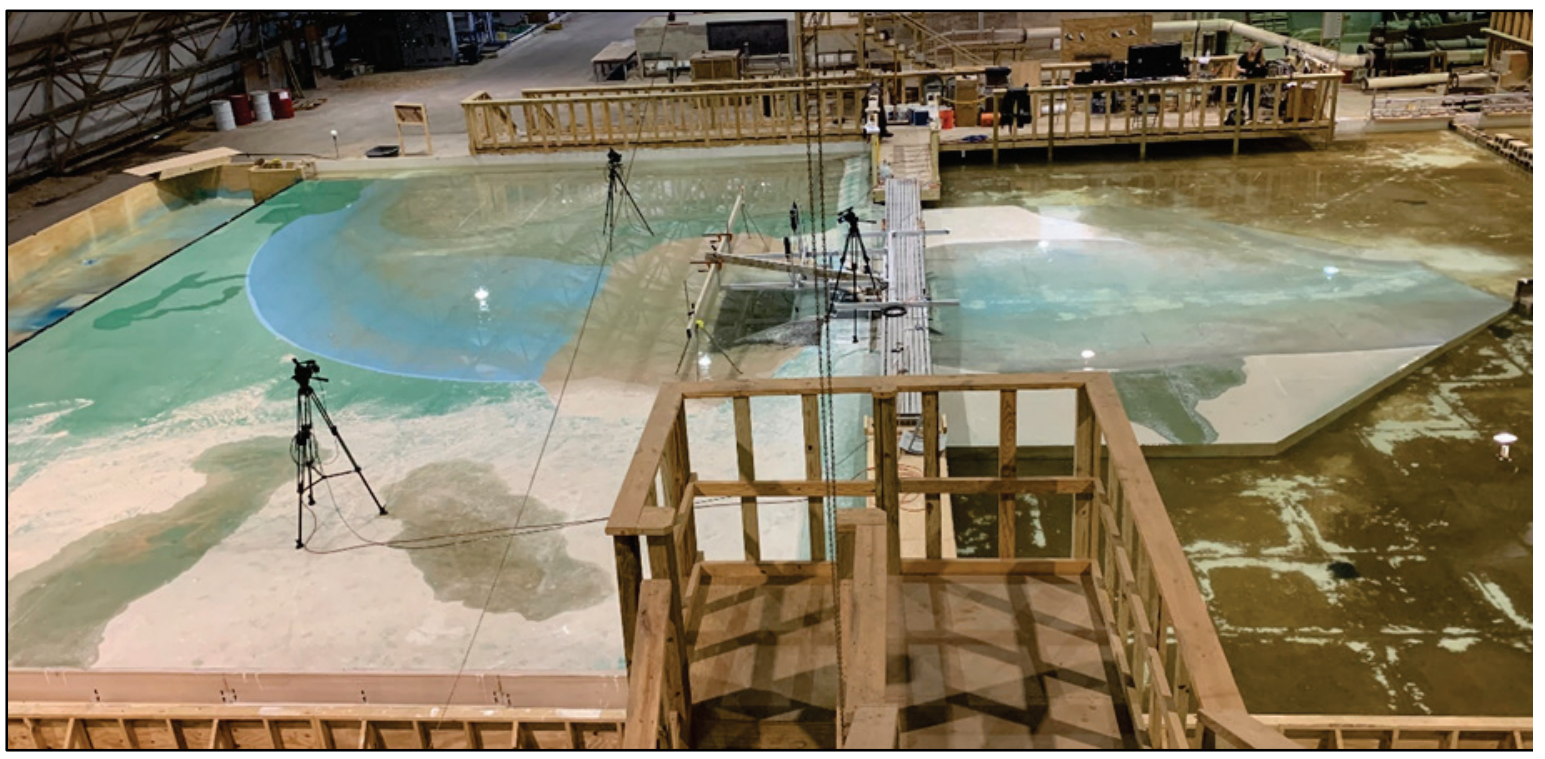


The US Army Engineer Research and Development Center (ERDC) solves the nation's toughest engineering and environmental challenges. ERDC develops innovative solutions in civil and military engineering, geospatial sciences, water resources, and environmental sciences for the Army, the Department of Defense, civilian agencies, and our nation's public good. Find out more at www.erdc.usace.army.mil.

To search for other technical reports published by ERDC, visit the ERDC online library at https://erdclibrary.on.worldcat.org/discovery. 
ERDC/CHL TR-20-20

September 2020

\section{Red River Structure Physical Model Study}

Gary L. Bell, Jeremy A. Sharp, Locke M. Williams, Howard E. Park, Duncan B. Bryant, and Gaurav Savant

Coastal and Hydraulics Laboratory

U.S. Army Engineer Research and Development Center

3909 Halls Ferry Road

Vicksburg, MS 39180-6199

Final report

Approved for public release; distribution is unlimited.

Prepared for U.S. Army Corps of Engineers, St. Paul District

Saint Paul, MN 55101

Under MIPR W81G6591564227, "Fargo-Moorhead Metropolitan Area Flood Risk Management Project: Red River Structure Physical Model Study" 


\section{Abstract}

A proposed Red River Structure (RRS), intended to function as one of three gated structures comprising the Fargo-Moorhead Metropolitan Area Flood Risk Management Project, was tested in a general physical model. A 1:40 Froude-scale was applied to model the structure, engineered channels, existing bathymetry/topography in the Red River and overbank areas, and the proposed Southern Embankment. The physical model was used to ensure that the RRS could pass at least 104,300 cfs during the Probable Maximum Flood while maintaining a maximum pool water surface elevation of $923.5 \mathrm{ft}$. The physical model was also utilized to optimize the approach structure, stilling basin, retaining walls, and erosion protection designs. The physical modeling effort resulted in an optimized stilling basin wall, retaining wall, and end sill geometry/configuration where erosive conditions were not observed outside and adjacent to the stilling basin. Properly designed riprap (St. Paul District's R470 gradation) proved to be successful in protecting the proposed RRS from potential scour downstream. The modified approach wall design proved to be successful in creating safe approach flow conditions as well as acceptable flow separation patterns. It is recommended that Alternative 3 be the design used going forward.

DISCLAIMER: The contents of this report are not to be used for advertising, publication, or promotional purposes. Citation of trade names does not constitute an official endorsement or approval of the use of such commercial products. All product names and trademarks cited are the property of their respective owners. The findings of this report are not to be construed as an official Department of the Army position unless so designated by other authorized documents. 


\section{Contents}

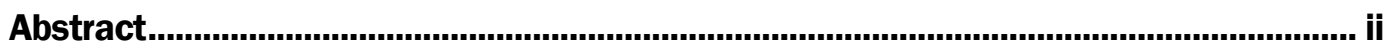

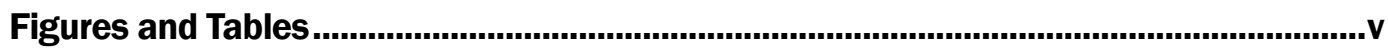

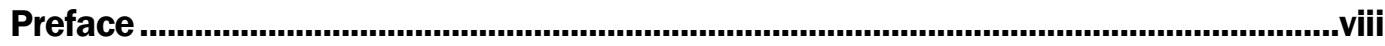

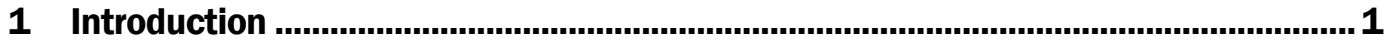

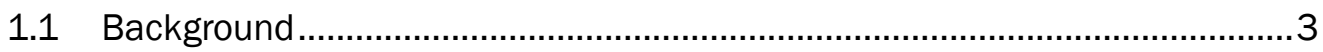

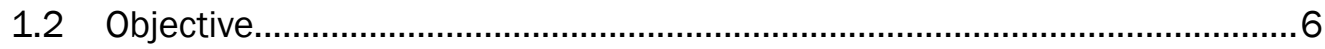

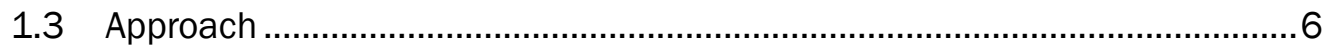

2 Process and Setup ............................................................................................... 7

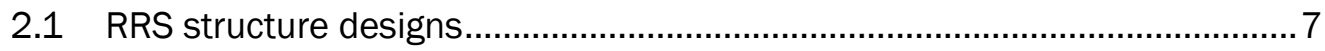

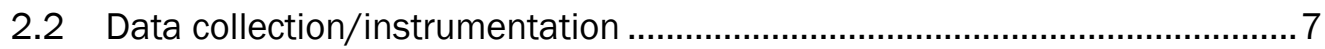

2.3 Boundary conditions and model operation.................................................

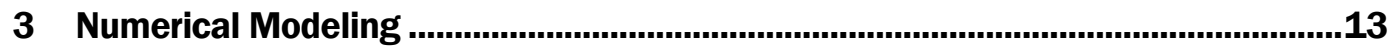

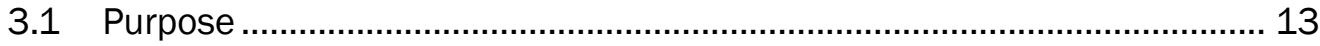

3.2 Model domain/layout ................................................................... 13

4 Physical Model Results ..........................................................................................21

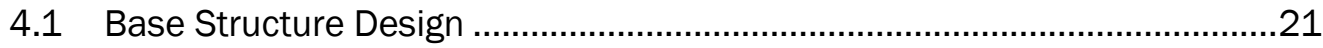

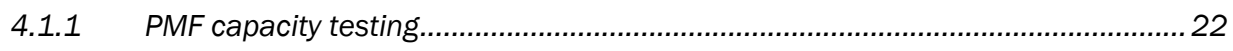

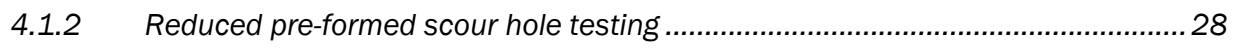

4.1.3 Maximum controlled releases testing............................................................. 30

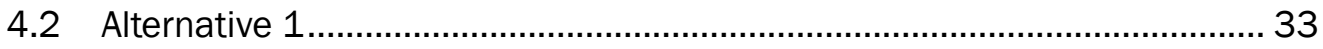

4.2.1 Alternative 1 Design modifications ................................................................... 33

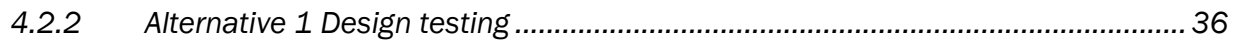

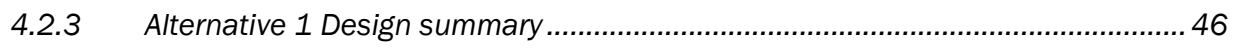

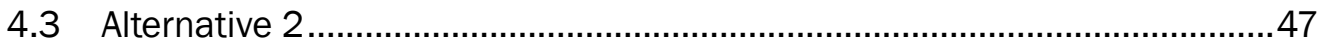

4.3.1 Alternative 2 Design modifications ................................................................... 47

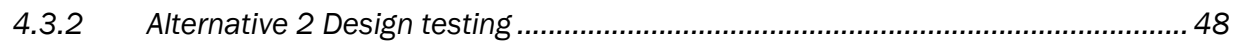

4.3.3 Alternative 2 Design summary ....................................................................... 61

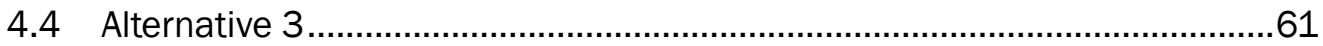

4.4.1 Alternative 3 Design modifications ................................................................... 61

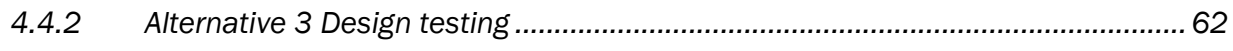

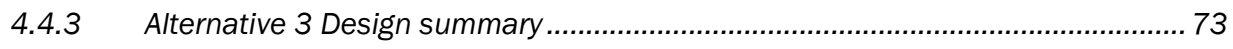

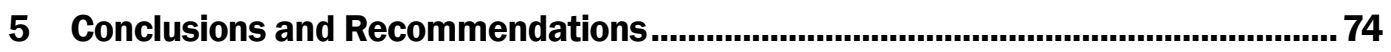

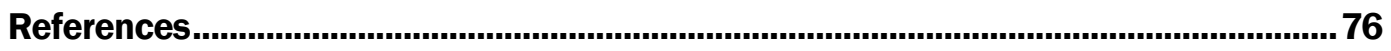

Appendix: ERDC/CHL LR-19-15........................................................................................... 77

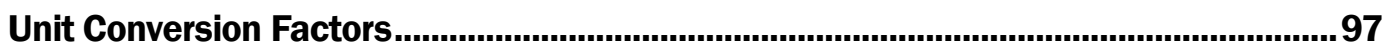




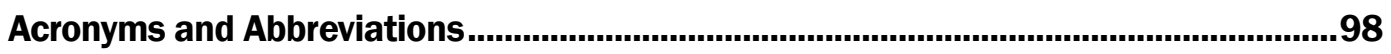
Report Documentation Page 


\section{Figures and Tables}

\section{Figures}

Figure 1. Fargo-Moorhead Metropolitan Area Flood Risk Management Project overview.

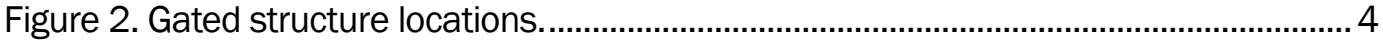

Figure 3. Overview of proposed conditions. ...................................................................... 5

Figure 4. Design concept (left photo looking downstream; right photo looking upstream).

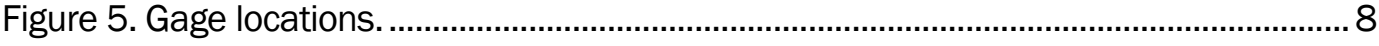

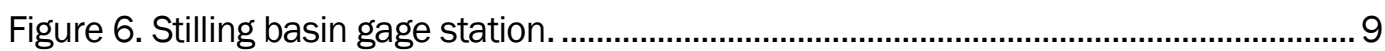

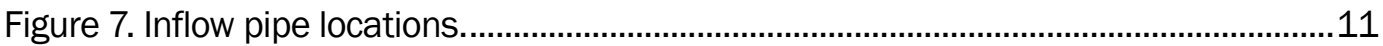

Figure 8. Baffle wall and flow splitter (looking upstream) ....................................................1

Figure 9. Descending right bank flap gate and one of the weirs. .....................................12

Figure 10. Initial AdH model domain outlined in black.........................................................14

Figure 11. Initial (black line) and final (red line upstream and blue line downstream) AdH model extents. The blue line also designates the boundary of the modeled terrain in the physical model while the red line indicates the boundary of space identified to house the physical model.

Figure 12. AdH velocity results from a zoomed-in portion of the initial model domain (left) and final model domain (right).

Figure 13. Difference plot of the final model minus initial model velocities. ......................17

Figure 14. AdH flow trace comparison...............................................................................17

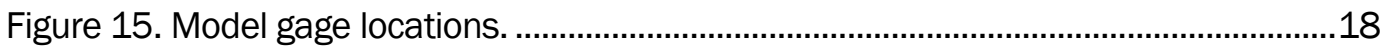

Figure 16. WSE profile comparison between the initial model and final domain AdH models.

Figure 17. Difference plot of the final model minus the initial model WSEs. ......................20

Figure 18. Base Design details (looking downstream).....................................................22

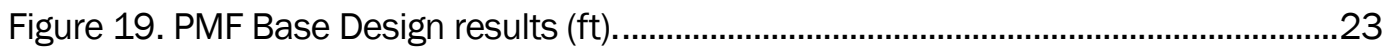

Figure 20. PMF sensitivity Base Design results (ft).........................................................24

Figure 21. Upstream ADV locations (looking downstream). ................................................26

Figure 22. Downstream ADVs (looking upstream).........................................................27

Figure 23. Roaming ADV velocity measurements along the centerline of the pre-formed scour hole for Base Design PMF capacity testing............................................28

Figure 24. Reduced size scour hole viewed from the east. ...............................................29

Figure 25. Reduced size scour hole viewed from the northwest. .....................................30

Figure 26. Maximum controlled releases WSE results (ft). ...................................................

Figure 27. Roaming ADV location and values for Base Design maximum controlled releases testing.

Figure 28. Alternative 1 Design (pre-test for Maximum Controlled Releases scenario), looking at the structure from the east. 
Figure 29. Scaled R470 riprap gradation results................................................................35

Figure 30. Turbulence downstream of gate openings during a PMF resiliency test...........38

Figure 31. Alternative 1 Design velocity measurement locations.......................................39

Figure 32. Upstream velocity results for Alternative 1 Design configuration. .....................40

Figure 33. Downstream velocity results for Alternative 1 Design testing. ...........................42

Figure 34. Downstream velocity results for Alternative 1 Design testing. ...........................43

Figure 35. Alternative 1 Design 5\% AEP event ADV-derived velocity vectors. ......................44

Figure 36. Alternative 1 Design Maximum Controlled Releases ADV-derived

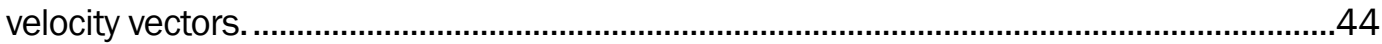

Figure 37. Alternative 1 Design 60,000 cfs releases ADV-derived velocity vectors............45

Figure 38. Alternative 1 Design PMF ADV-derived velocity vectors. ....................................45

Figure 39. Alternative 1 Design PMF resiliency ADV-derived velocity vectors. ....................46

Figure 40. Alternative 2 Design modifications.................................................................... 47

Figure 41. Modified approach wall configuration photos..................................................48

Figure 42. Modified approach wall configuration dimensions............................................48

Figure 43. Alternative 2 Design velocity measurement locations.......................................50

Figure 44. Upstream velocity results for Alternative 2 Design configuration. .....................51

Figure 45. ADV velocity results for Alternative 2 Design testing..........................................53

Figure 46. ADV velocity results for Alternative 2 Design testing..........................................54

Figure 47. ADV velocity results for Alternative 2 Design testing. ...........................................55

Figure 48. Alternative 2 Design 5\% AEP event ADV-derived velocity vectors. .....................56

Figure 49. Alternative 2 Design 1\% AEP event ADV-derived velocity vectors. .......................56

Figure 50. Alternative 2 Design 0.2\% AEP event ADV-derived velocity vectors...................57

Figure 51. Alternative 2 Design maximum controlled releases ADV-derived

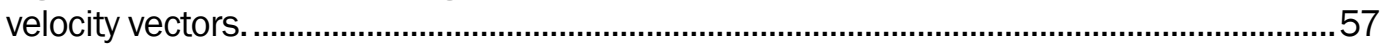

Figure 52. Alternative 2 Design 60,000 cfs releases ADV-derived velocity vectors............58

Figure 53. Alternative 2 Design PMF ADV-derived velocity vectors. .....................................58

Figure 54. Alternative 2 Design PMF resiliency ADV-derived velocity vectors. .....................59

Figure 55. Pre-test minus post-test LiDAR for Maximum Controlled Releases test. ..........60

Figure 56. Pre-test (left) and post-test (right) pictures for Maximum

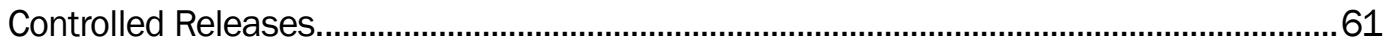

Figure 57. Alternative 3 Design (pre-test for PMF scenario). ............................................62

Figure 58. Alternative 3 Design velocity measurement locations........................................64

Figure 59. Upstream velocity results for Alternative 3 Design PMF Resiliency...................65

Figure 60. ADV velocity results for Alternative 3 Design PMF Resiliency testing. ................65

Figure 61. Alternative 3 Design PMF resiliency ADV-derived velocity vectors. ....................66

Figure 62. Pre-test minus post-test LiDAR for Test A PMF....................................................67

Figure 63. Pre-test (left) and post-test (right) pictures for Test A PMF...............................67

Figure 64. Pre-test minus post-test LiDAR for Test B PMF. ...............................................69

Figure 65. Pre-test (left) and post-test (right) pictures for Test B PMF. ..............................69 
Figure 66. Pre-test minus post-test LiDAR for Test C PMF resiliency (89,700 cfs)..............70

Figure 67. Pre-test (left) and post-test (right) pictures for Test C PMF resiliency $(89,700 \mathrm{cfs})$.

Figure 68. Pre-test minus post-test LiDAR for Test D PMF resiliency $(99,300$ cfs). ...........71

Figure 69. Pre (left) and post-test (right) pictures for Test D PMF

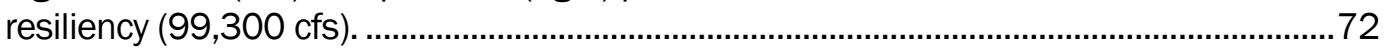

Figure 70. Pre minus post-test LiDAR for Test E PMF Resiliency (99,300 cfs). ...................72

Figure 71. Pre-test (left) and post-test (right) pictures for Test E PMF

resiliency $(99,300 \mathrm{cfs})$.

\section{Tables}

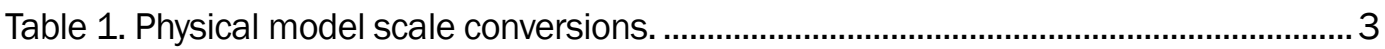

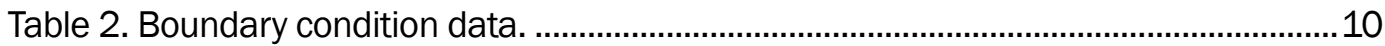

Table 3. WSE comparison of the initial model and final model domain AdH models. 19

Table 4. Model test results for the Base Design PMF condition.

Table 5. Model test results for the Base Design PMF sensitivity condition. ........................24

Table 6. Model results for the Base Design PMF and PMF sensitivity tests........................25

Table 7. Base Design PMF capacity testing velocity results (ft/s).....................................28

Table 8. Base Design maximum controlled releases velocity results.................................32

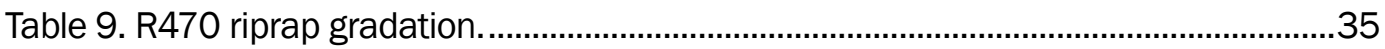

Table 10. Alternative 1 Design testing boundary condition data......................................37

Table 11. Alternative 2 Design testing boundary condition data........................................49

Table 12. Alternative 3 Design testing boundary condition data.......................................63 


\section{Preface}

This study was conducted for the U.S. Army Engineer District, St. Paul (MVP), under project identification "Fargo-Moorhead Metropolitan Area Flood Risk Management Project: Red River Structure Physical Model Study," MIPR W81G6591564227. Non-federal sponsors include City of Fargo, ND; City of Moorhead, MN; Cass County, ND; Clay County, MN; and the Cass County Joint Water Resources District. The technical monitor for the MVP was Mr. Kevin Denn, hydraulic engineer.

The work was performed by the River and Estuarine Engineering Branch of the Flood and Storm Protection Division, U.S. Army Engineer Research and Development Center, Coastal and Hydraulics Laboratory (ERDCCHL). At the time of publication, Mr. David P. May was acting Branch Chief; Dr. Cary A. Talbot was Division Chief; and Dr. Julie D. Rosati was the Technical Director for the Flood \& Coastal Risk Management Research and Development. The Deputy Director of ERDC-CHL was Mr. Jeffrey R. Eckstein, and the Director was Dr. Ty V. Wamsley.

The Commander of ERDC was COL Teresa A. Schlosser, and the Director was Dr. David W. Pittman. 


\section{Introduction}

This U.S. Army Engineer and Development Center (ERDC), Coastal and Hydraulics Laboratory (CHL), effort describes the process to construct, apply, and evaluate a general physical model of the proposed Red River Structure (RRS) to be located on the Red River of the North just south of Fargo, ND. The RRS is one of three gated structures along the proposed dam of the Fargo-Moorhead Metropolitan (FMM) Area Flood Risk Management Project. The dam, known as the Southern Embankment, since it is located south of the metropolitan area, will store water when the inflow exceeds 21,000 $\mathrm{cfs}^{*}$, which corresponds to a 1/20 annual exceedance probability (AEP) flood event based on current hydrology. In addition to the RRS, two other gated structures will be located along the Southern Embankment. These gated structures are the Wild Rice River Structure (WRRS) and the Diversion Inlet Structure (DIS). See Figure 1 for a project overview map. The WRRS and DIS have completed the design phases and have broken ground on construction. The RRS remains in the design phase. The RRS, WRRS, and the DIS are designed to collectively pass the Probable Maximum Flood (PMF) while maintaining a headwater elevation of no more than $923.5 \mathrm{ft}$. The RRS is the largest of the gated structures and is required to pass more flow than the WRRS and DIS combined during the PMF. Thus, the implementation of an undistorted free-surface 1:40 Froudescaled general physical model evaluates the capacity potential of the RRS and the efficiency of various design considerations. The physical model also evaluates the energy dissipation capability of the RRS design to understand erosive potential near the structure.

\footnotetext{
* For a full list of the spelled-out forms of the units of measure used in this document, please refer to US Government Publishing Office Style Manual, 31st ed. (Washington, DC: US Government Publishing Office 2016), 248-52, https://www.govinfo.gov/content/pkg/GPO-STYLEMANUAL-2016/pdf/GPOSTYLEMANUAL-2016.pdf.
} 
Figure 1. Fargo-Moorhead Metropolitan Area Flood Risk Management Project overview.

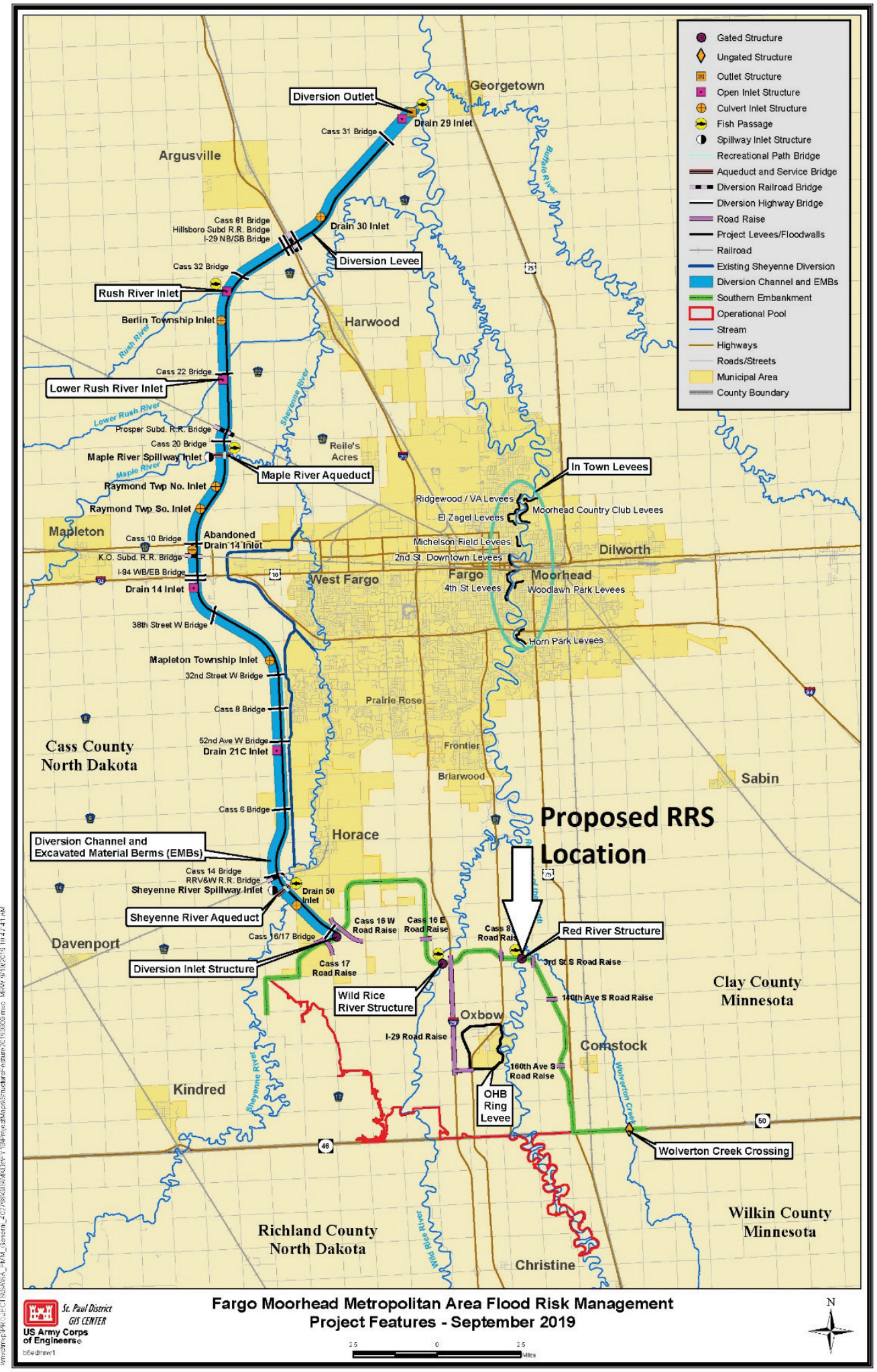


The initial effort of determining the proper scale of the model was done by analyzing various model scale relationships. For each potential model scale, the Reynolds number was checked at varying flows to verify that it was fully turbulent (greater than 5,000 cfs for the proposed RRS geometry). The average velocities and depths used for the analysis were provided from the St. Paul District one-dimensional Hydrologic Engineering Center River Analysis System model. The undistorted model with a geometric scale of Length ratio (Lr) 1:40 is fully turbulent for the selected range of flow conditions and surface tension is not an issue. The proposed conditions with the RRS were then simulated with the twodimensional (2D) Adaptive Hydraulics (AdH) code (ERDC 2017). One of the critical factors controlling the physical model scale was available modeling space. The largest available space that contained the proper pump capacity to pass the required flows was chosen for this model study. Multiple 2D AdH model simulations were conducted to determine the proper model footprint for the selected model scale and space. A table of $\mathrm{Lr}$ conversions relevant to the physical model is shown in Table 1.

Table 1. Physical model scale conversions.

\begin{tabular}{|l|l|}
\hline Variable & Froudian Similitude Scale \\
\hline Length & $\mathrm{L}_{r}$ \\
\hline Velocity & $\mathrm{L}_{r}{ }^{\wedge} 0.5$ \\
\hline Discharge & $\mathrm{L}^{\wedge} 2.5$ \\
\hline
\end{tabular}

\subsection{Background}

The Fargo-Moorhead metropolitan area has a history of high floodwaters. The years 1997, 2009, and 2011 are three examples of large flood events. The RRS, combined with the WRRS, DIS, and Southern Embankment, is intended to provide protection for over 230,000 people in the FargoMoorhead metropolitan area during periods of flooding. The RRS proposed location is approximately 10 miles south of the Fargo-Moorhead metropolitan area on the Red River, between Interstate 29 and U.S. Highway 75, to the west and east, respectively. The location of these structures can be seen in Figure 2 (the black line represents the Southern Embankment). The RRS will be subject to complex hydraulic conditions at higher flow rates such as the PMF that require a physical modeling effort to provide velocities and water surface elevation data near the RRS. These data will be used to optimize design features for the RRS, calibration of a 
three-dimensional (3D) OpenFOAM numerical model, and determination of riprap protection.

Figure 2. Gated structure locations.

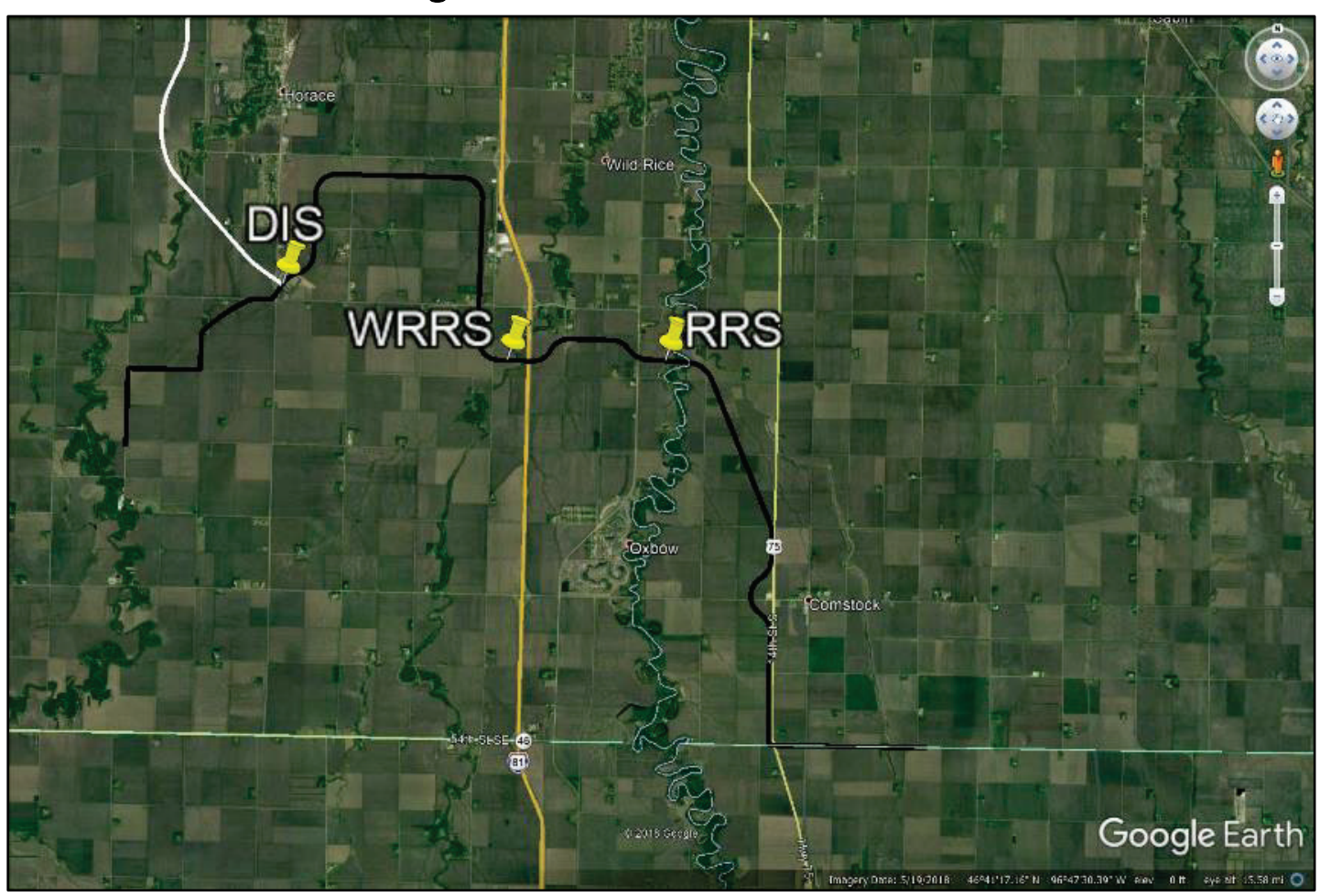

The RRS design concept is very similar to the WRRS in regards to gate width, pier length, stilling basin, etc. The WRRS was designed by the St. Paul District using information from numerical modeling efforts (USACE MVP 2019). The RRS has one more radial gate (three in total) than the WRRS and must pass larger flow rates upwards of approximately 105,000 cfs for the PMF. The design concept for the RRS is provided in Figure 3 and Figure 4. Note that flow direction is from south to north. 
Figure 3. Overview of proposed conditions.

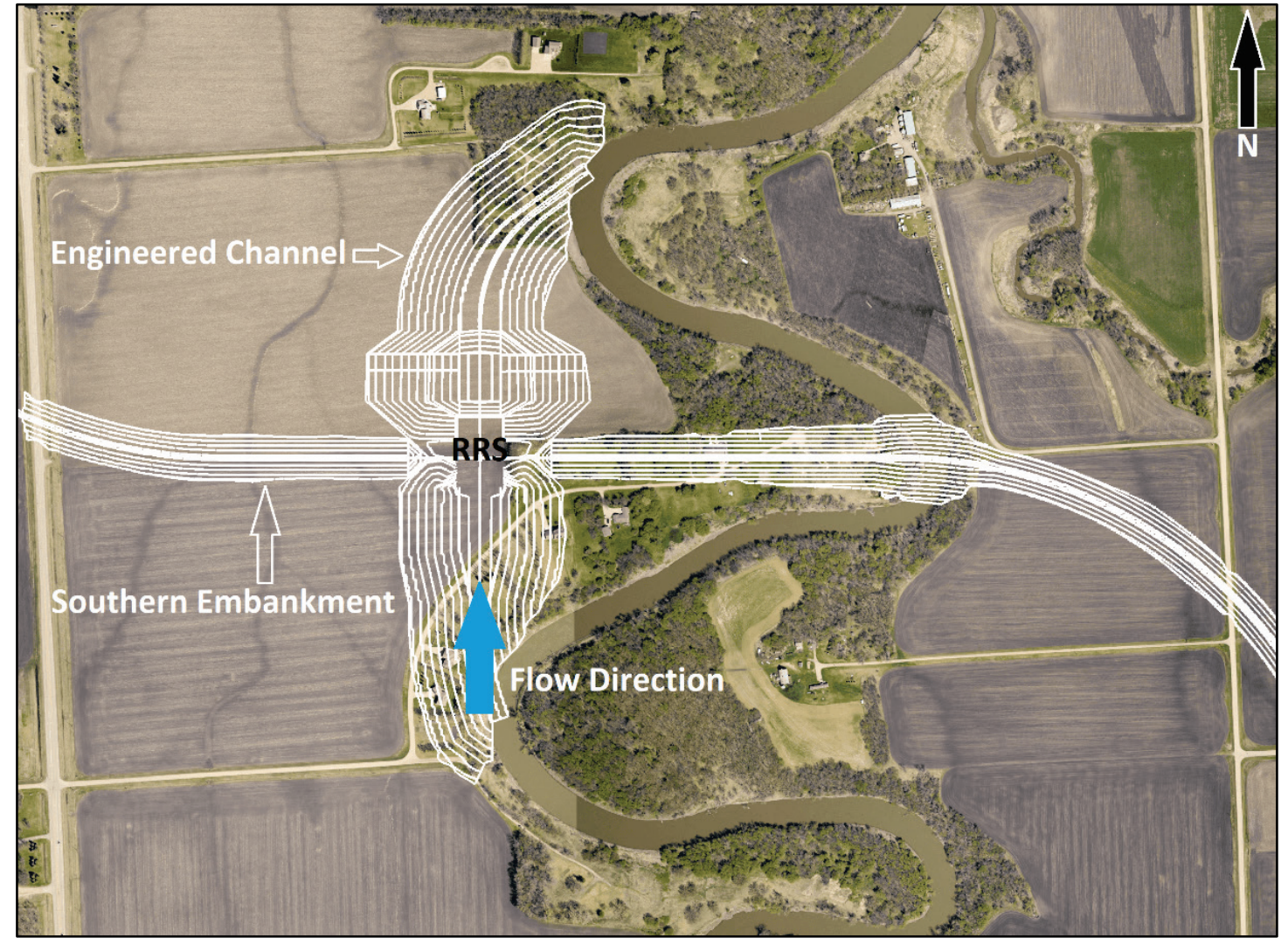

Figure 4. Design concept (left photo looking downstream; right photo looking upstream).
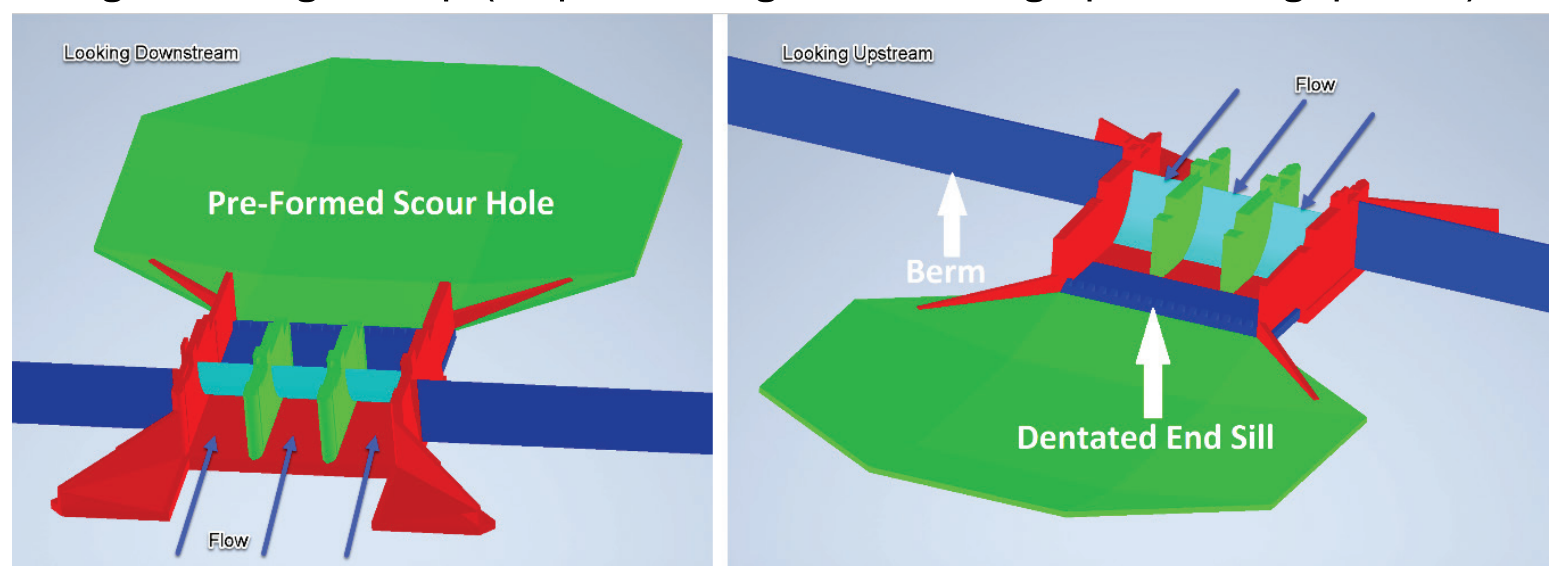


\subsection{Objective}

The objective of this effort is to provide the St. Paul District model data and analysis for the critical design aspects for the RRS as well as provide validation data for the computational fluid dynamics simulations. These aspects include the following:

- Structure efficiency for the PMF discharge

- Stilling basin length and configuration

- Usage and design of end sill

- Scour protection downstream of the stilling basin (optimization of geometry, including retaining walls, and riprap protection).

Data acquired from the general physical model will provide a qualitative and quantitative evaluation of the RRS ability to pass the PMF as well as inform the structure's design and erosion protection plans. These model data include water surface elevations (WSE), velocity measurements, and observations of movement/non-movement of various mobile materials in the model.

\subsection{Approach}

Prior to the design of the physical model, numerical modeling was used to determine the necessary footprint needed to appropriately capture the hydrodynamics of the proposed RRS in the physical model. The physical model was constructed to these limits, and the necessary instrumentation needed for water surface elevation measurements, velocity measurements, LiDAR measurements, and flow measurements were properly established on the physical model. The physical model was simulated with varying boundary conditions as well as design alternatives in order to optimize the structure's design. All physical model results presented here are in units of feet at the prototype scale. Note that CHL has provided the St. Paul District with the following data (separate from this report):

- Photographs (pre-test and post-test)

- Velocity measurements (upstream and downstream from the proposed structure)

- LiDAR data sets (pre-test and post-test)

- Videos of the physical model experiments (not all tests were filmed)

- Record of observed stage data from the physical model experiments. 


\section{Process and Setup}

\subsection{RRS structure designs}

One Base Design, along with three alternative designs, was tested to qualitatively and quantitatively evaluate performance; the Base Design was also investigated with $\mathrm{AdH}$. The Base Design consisted of sloped upstream approach walls flared at a 45-degree angle, three radial gates, $14 \mathrm{oft}$ long, $12 \mathrm{ft}$ wide bullet-nosed piers separating the gates, a dentated end sill (removable), a pre-formed scour hole, a flat stilling basin, and down-sloping stilling basin walls. Note that the horizontal datum is North American Datum 1983 State Plane North Dakota South FIPS 3302 (U.S. feet) and the vertical datum is North American Vertical Datum of 1988 (U.S. feet).

All the alternative designs incorporate a sloped stilling basin such that the end sill elevation is $7 \mathrm{ft}$ lower than the control structure elevation. They also have shortened $125 \mathrm{ft}$ long piers as well as modified down-sloping stilling basin walls due to the elevation drop. Additional modifications unique to each of the three alternative structure designs and/or surrounding bathymetry are discussed in Chapter 4, Physical Model Results. These modifications were implemented in an effort to optimize the structure design.

\subsection{Data collection/instrumentation}

To monitor and set the discharge rates into the physical model, the flow was measured directly through the supply lines by ultrasonic flowmeters from EESIFLO International. The flow meters accurately measure flow within $+/-2 \%$. Cross-linked polyethylene piping was routed under the graded deck to the 14 gage locations for monitoring WSE readings during testing (Figure 5). A stilling well station for monitoring the WSEs in the model was set up on the outer support wall of the upstream portion of the model (Figure 6). For WSE measurements, two methods were used: digital point gage measurements and Akamina capacitance gages. Both the Akamina gages and point gage have sub millimeter accuracies, which translates to accurate prototype-scale WSE measurements to within +/$0.1 \mathrm{ft}$. The instruments were referenced to a benchmark on the frame of the stilling well basin. Velocity measurements were taken using Nortek Vectrino acoustic Doppler velocimeters (ADVs). The velocimeters have an 
accuracy of $+/-0.5 \%$ of the measured value or $+/-1 \mathrm{~mm} / \mathrm{s}(0.1 \mathrm{ft} / \mathrm{s}$ at prototype scale), whichever is greater. The Akamina gages and the velocimeters are both controlled by National Instruments hardware. The data were collected through LabVIEW software.

Figure 5. Gage locations.

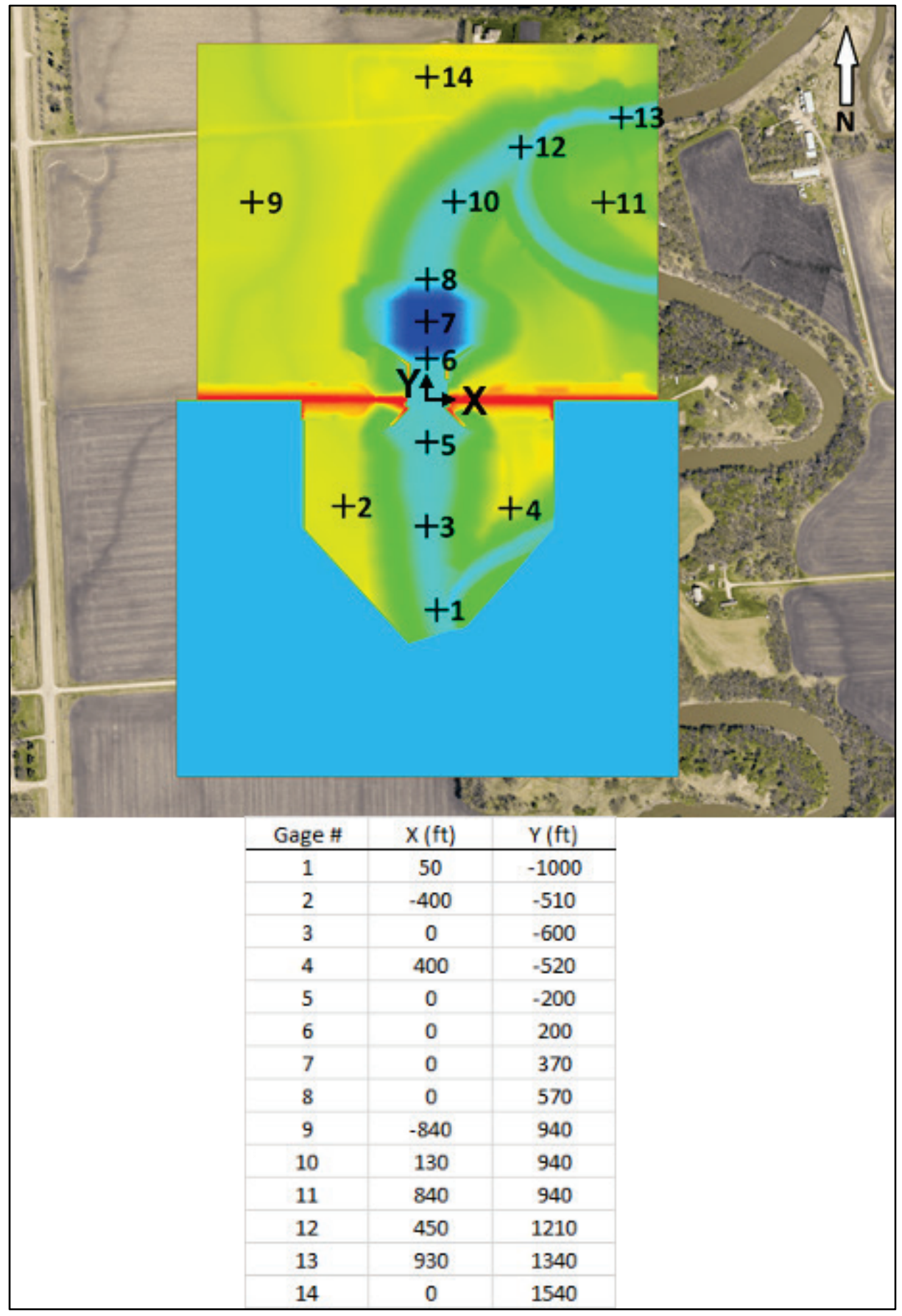


Figure 6. Stilling basin gage station.

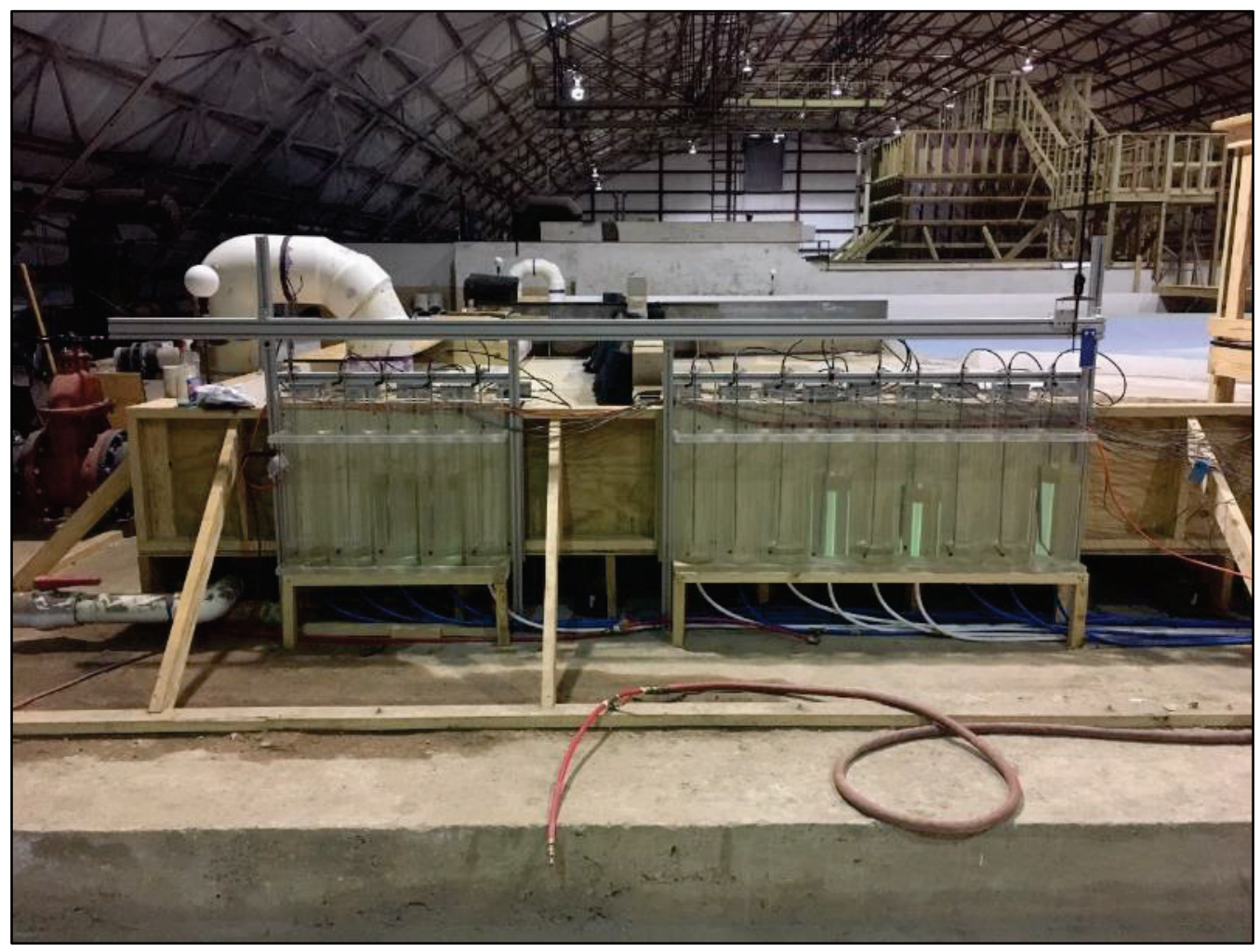

\subsection{Boundary conditions and model operation}

Nine potential boundary conditions outlined in Table 2 including five AEP events were tested in the physical model. For in-bank flow conditions, gage 13 was used as the tailwater control. For out-of-bank flow conditions, gages $9,11,13$, and 14 were used as the tailwater control. All three gates are completely open for the 5\% AEP and PMF (gates open) conditions; thus, the headwater elevation is uncontrolled. The PMF gates-open scenario was conducted to see how much water could get through the structure unencumbered by the gates. The headwater elevation is also uncontrolled for the PMF Resiliency condition, as the left (west) and center gate are completely open and the right (east) gate is completely closed. The remaining conditions (1\% AEP through PMF) consisted of adjusting the gate opening to achieve the desired headwater elevations listed in Table 2. 
Table 2. Boundary condition data.

\begin{tabular}{|c|c|c|c|}
\hline Event & $\begin{array}{c}\text { RRS Discharge } \\
\text { (cfs) }\end{array}$ & $\begin{array}{c}\text { Headwater } \\
\text { Elevation (ft) }\end{array}$ & $\begin{array}{c}\text { Tailwater } \\
\text { Elevation (ft) }\end{array}$ \\
\hline $5 \%$ AEP & 10,700 & $*$ & 910.1 \\
\hline $1 \%$ AEP & 14,000 & 921.0 & 911.3 \\
\hline $0.2 \%$ AEP & 18,000 & 922.4 & 913.0 \\
\hline $\begin{array}{c}\text { Max Controlled } \\
\text { Releases }\end{array}$ & 18,000 & 923.5 & 913.1 \\
\hline 60,000 cfs & 60,000 & 923.5 & 916.0 \\
\hline PMF & 104,300 & 923.5 & 917.5 \\
\hline $\begin{array}{c}\text { PMF (Gates } \\
\text { Open) }\end{array}$ & 104,300 & $*$ & 917.5 \\
\hline PMF Resiliency & 89,700 & $*$ & 917.0 \\
\hline PMF Resiliency & 99,300 & $*$ & 917.0 \\
\hline
\end{tabular}

* To be determined using the physical model.

The physical model was constructed as a 1:40 Froude-scaled model. The model was constructed in an approximately $70 \times 120 \mathrm{ft}$ space at the CHL. A deck was built above the concrete floor of the space and set to grade using stretcher plates due to the irregularities in the existing floor elevations. The proposed RRS was fabricated from acrylic and set to grade using three steel stretcher plates. Twelve-inch-diameter polyvinyl chloride piping was installed in two locations in the upstream headbay to control the inflow per the inflow specification determined using the numerical model results discussed in Chapter 3 (Figure 7). A baffle wall and aluminum flow splitter were put in place just downstream of the pipes (Figure 8). The baffle wall dissipated the turbulence of the water coming out of the pipes, and the flow splitter prevented mixing and was positioned per the results of the numerical modeling effort in Chapter 3. Adjustable flap gates (non-vertical) were installed on the descending left and right bank sides of the model terrain, and weirs were installed at the domain limits for nearly all of the model downstream of the structure to control the tailwater boundary condition (Figure 9). 
Figure 7. Inflow pipe locations.

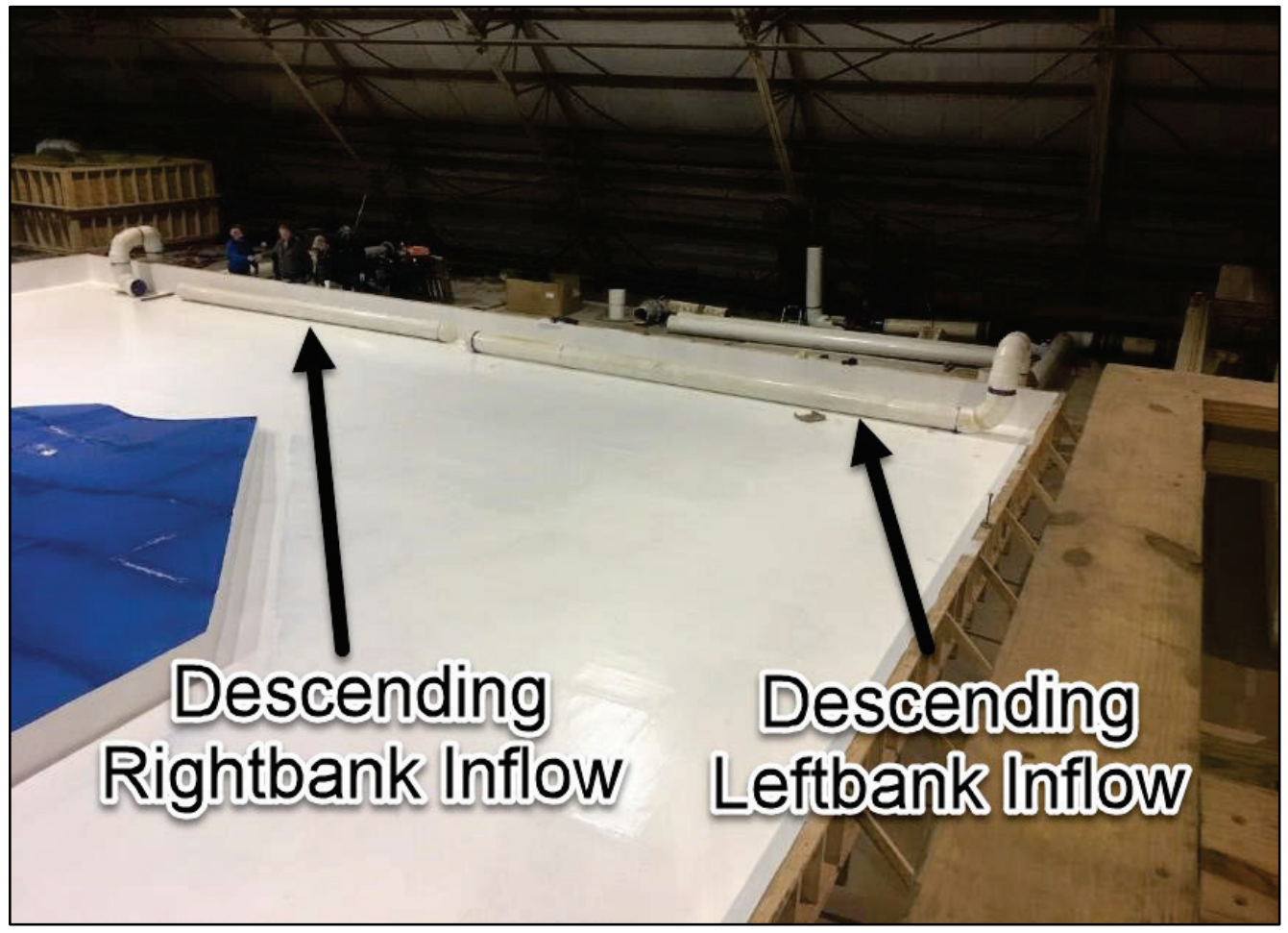

Figure 8. Baffle wall and flow splitter (looking upstream).

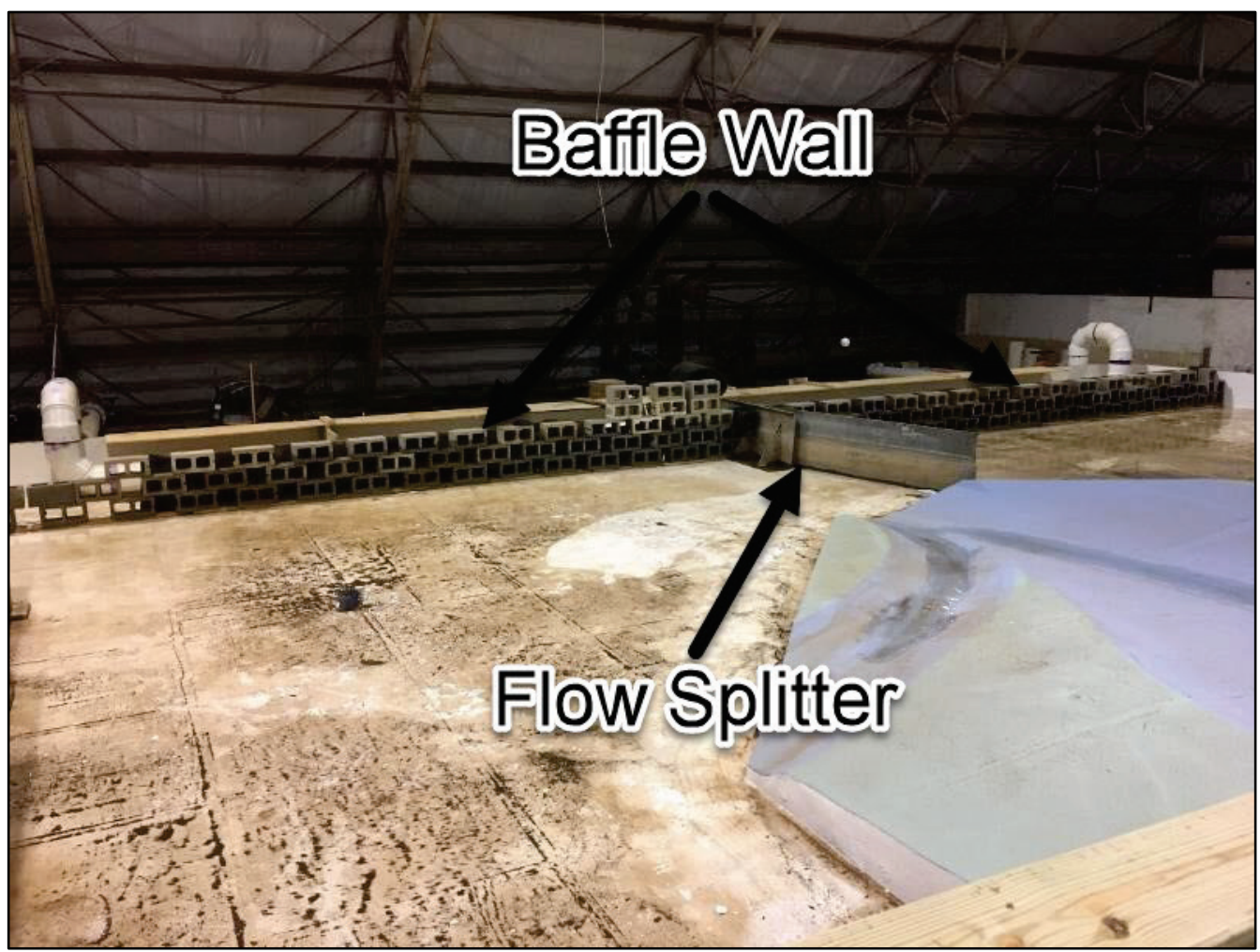


Figure 9. Descending right bank flap gate and one of the weirs.

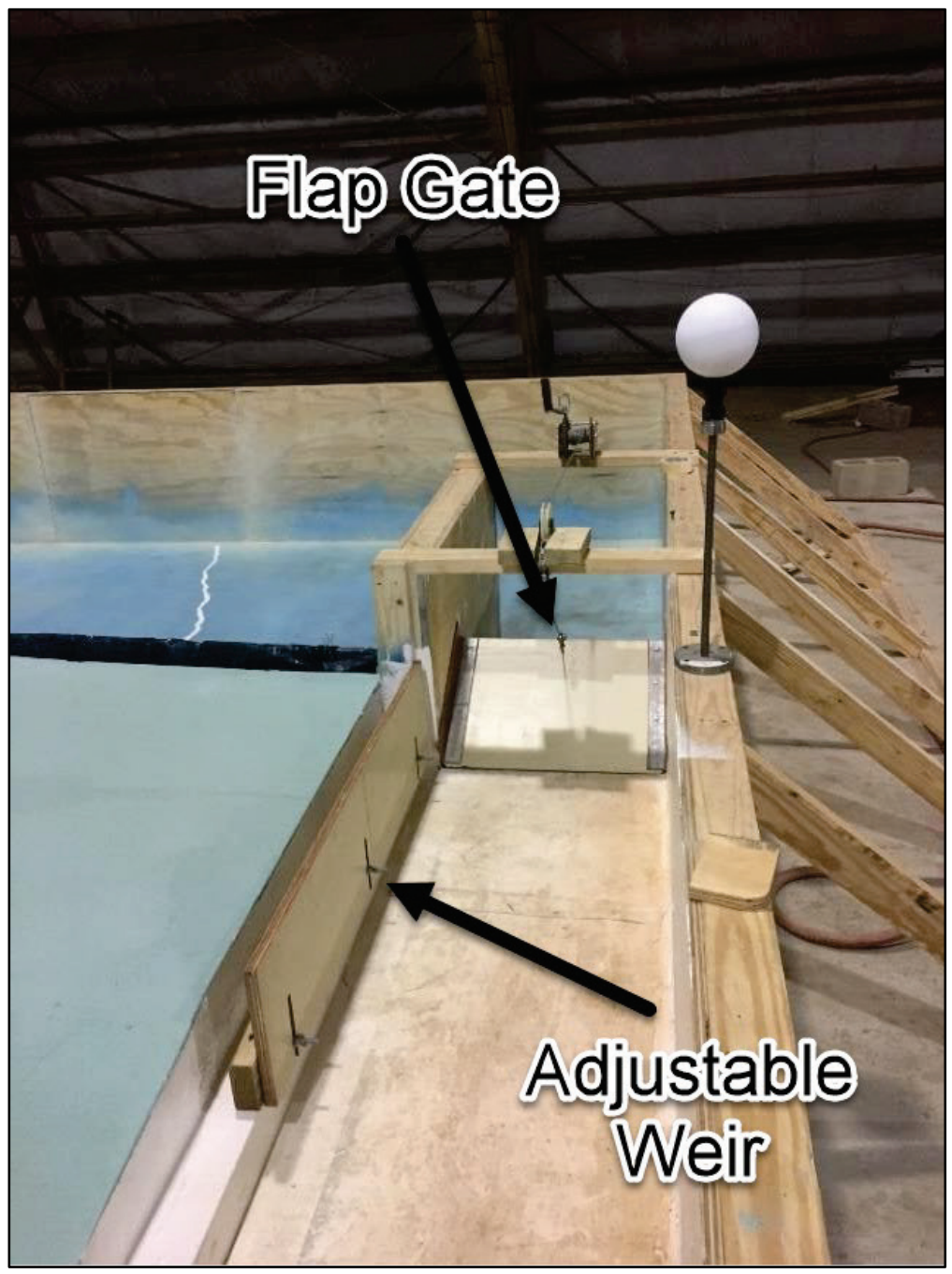




\section{Numerical Modeling}

\subsection{Purpose}

The goal of constructing, simulating, and analyzing a 2D AdH numerical model was to inform the selection of a final physical model domain. The initial AdH model was large enough such that the representative numerical modeling domain boundaries did not affect the hydraulic conditions at the proposed structure. The model extents were reduced until changes were noted in the velocity patterns and the water surface elevations in the vicinity of the proposed RRS. The smallest footprint for the physical model that does not affect the hydraulic conditions at the proposed structure was utilized as the topography/bathymetry that was deployed in the physical model.

\subsection{Model domain/layout}

To determine the appropriate domain for the physical model such that boundary hydraulic effects near the proposed structure were not present, a 2D AdH analysis was used. The initial AdH model extended from Highway 75 to Interstate 29 for the east and west boundaries, respectively, with downstream and upstream boundaries at 2.15 miles north and 5.5 miles south from the proposed RRS, respectively. The numerical model domain contained 330,305 mesh nodes and 659,105 elements. The initial AdH model domain is outlined in black in Figure 10. Note that there is a section on the east portion of the model domain where there is a triangle-shaped portion cut out. This cut out coincides with the natural high-ground elevations of the proposed Southern Embankment. 
Figure 10. Initial AdH model domain outlined in black.

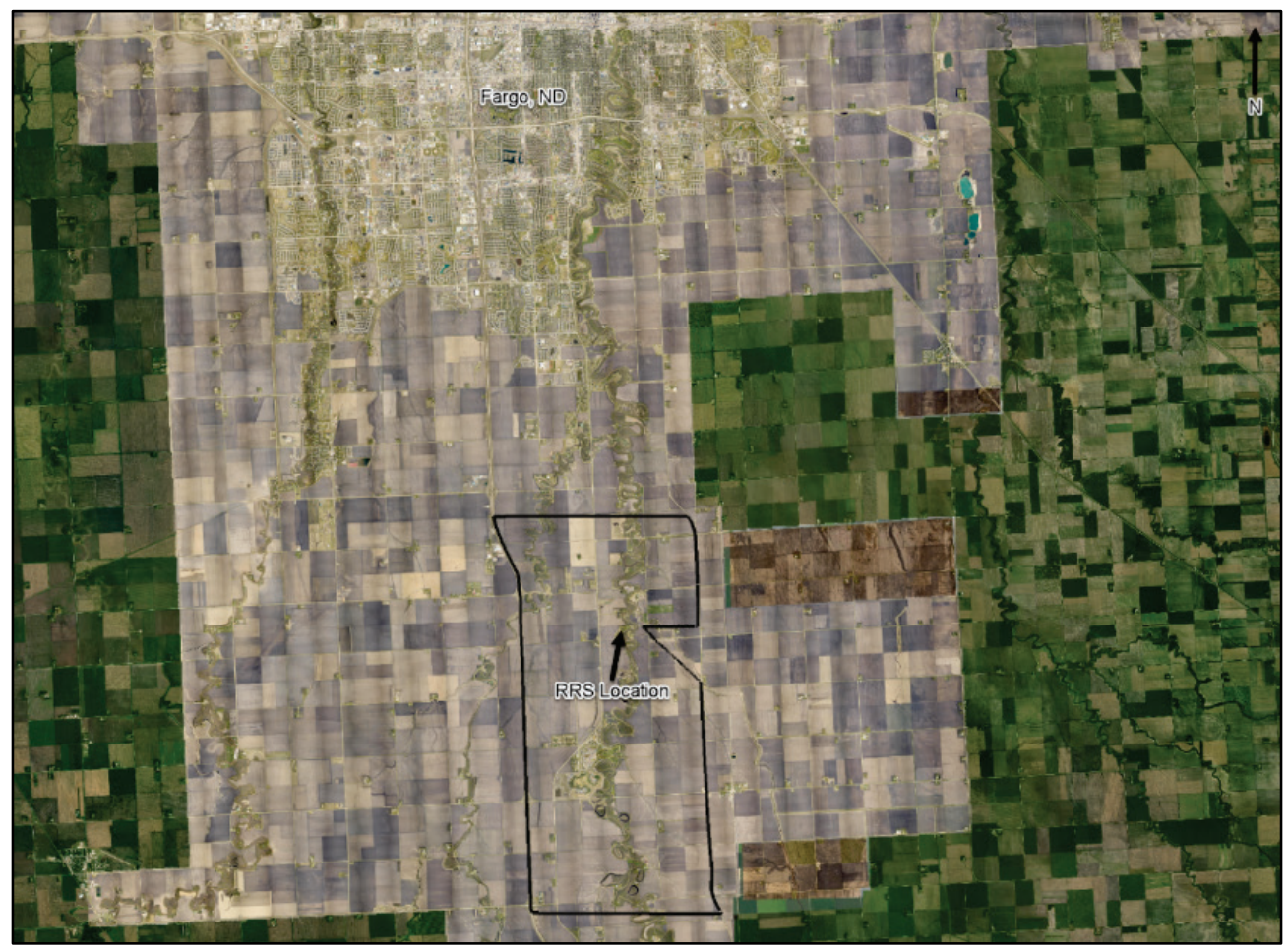

The domain extents of this initial numerical model were gradually reduced to optimize the construction of the physical model whereby the hydraulic conditions at the structure were accurately captured without creating hydraulic boundary effects at the structure. The final numerical model was compared to the initial model for reference by looking at differences in WSE, velocities, and flow patterns at and near the structure. The results were that the reduced size numerical model produced similar answers to the larger initial model. This final numerical model represents the physical model domain at prototype scale (from this point forward, this will be noted as the final model). In addition, the final model was used to determine the location and ratio of flow inputs in the physical model. A comparison of the initial AdH model and final model domain can be seen in Figure 11. The black line depicts the initial AdH model boundary, the blue line is the extents of the terrain included in the physical model, and the red line is the boundary of the space identified to house the physical model, including required model sump areas. Recall that flow is from south to north in the river. The final AdH model boundary is represented by the red line upstream of the proposed RRS and the blue line downstream of the structure. These boundaries were chosen to properly assign a tailwater boundary condition to the final AdH model that matched the physical model conditions. 
Figure 11. Initial (black line) and final (red line upstream and blue line downstream) AdH model extents. The blue line also designates the boundary of the modeled terrain in the physical model while the red line indicates the boundary of space identified to house the physical model.

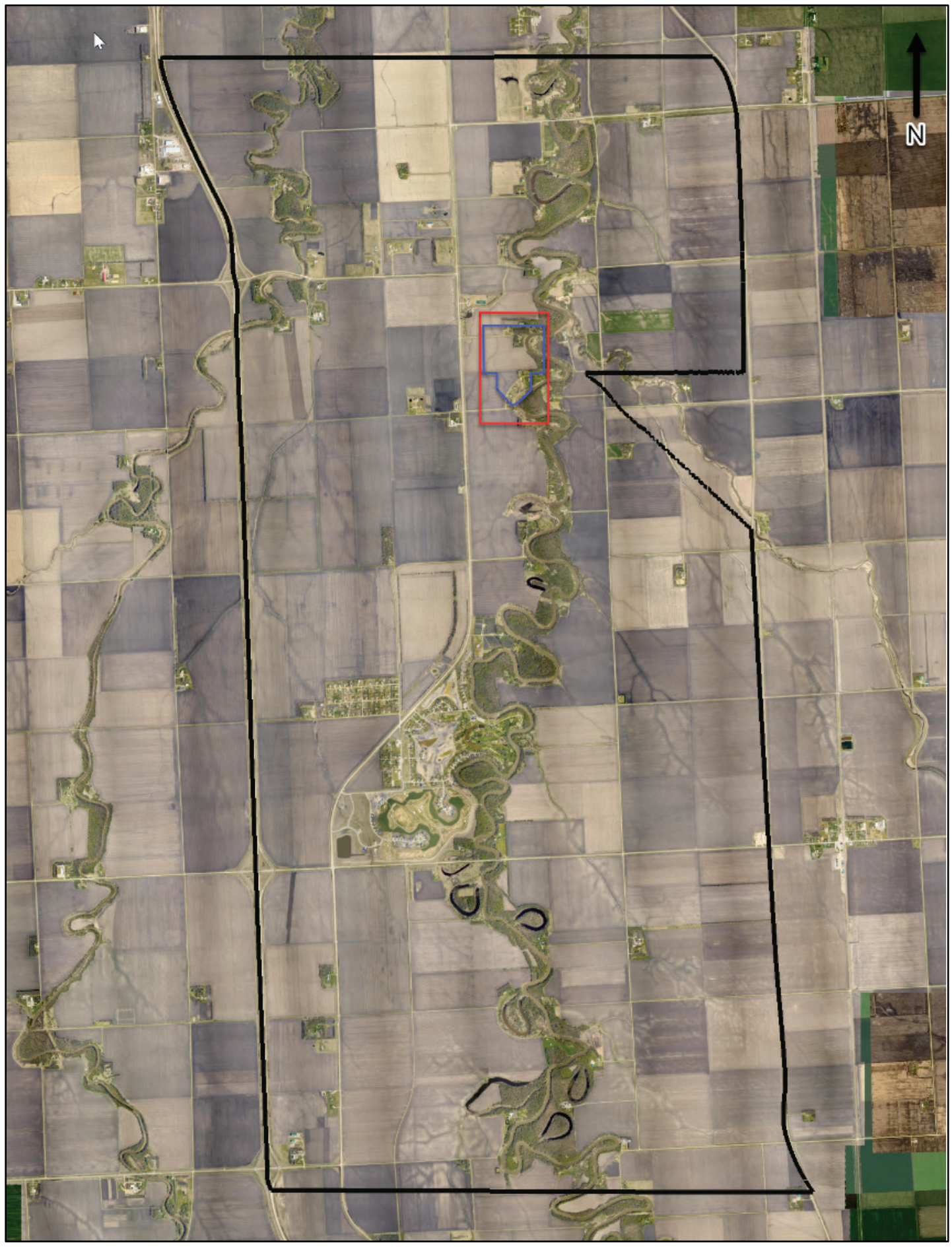


The initial model simulated the PMF condition with an inflow of $104,300 \mathrm{cfs}$ and a tailwater elevation of $917.5 \mathrm{ft}$. Velocity comparisons between the initial and final AdH model domain results for the PMF condition can be seen in Figure 12 (zoomed-in portion of the initial model on the left and final model on the right). A difference plot of the final minus initial AdH model velocities can be seen in Figure 13. Flow trace comparisons (initial model on top, final model on bottom) are presented in Figure 14. These figures show how the smaller domain does not have a significant impact on the velocity results (magnitude direction, and overall flow patterns). While there are some velocity differences, the differences approach zero near/through the proposed structure. Velocities vary at other locations in the model, but generally fall within $+/-1 \mathrm{ft} / \mathrm{s}$. Note that the area outside of the terrain upstream from the structure in the final model domain is the flat deck headbay portion of the physical model (removed in both of the final model figures presented below).

Figure 12. AdH velocity results from a zoomed-in portion of the initial model domain (left) and final model domain (right).

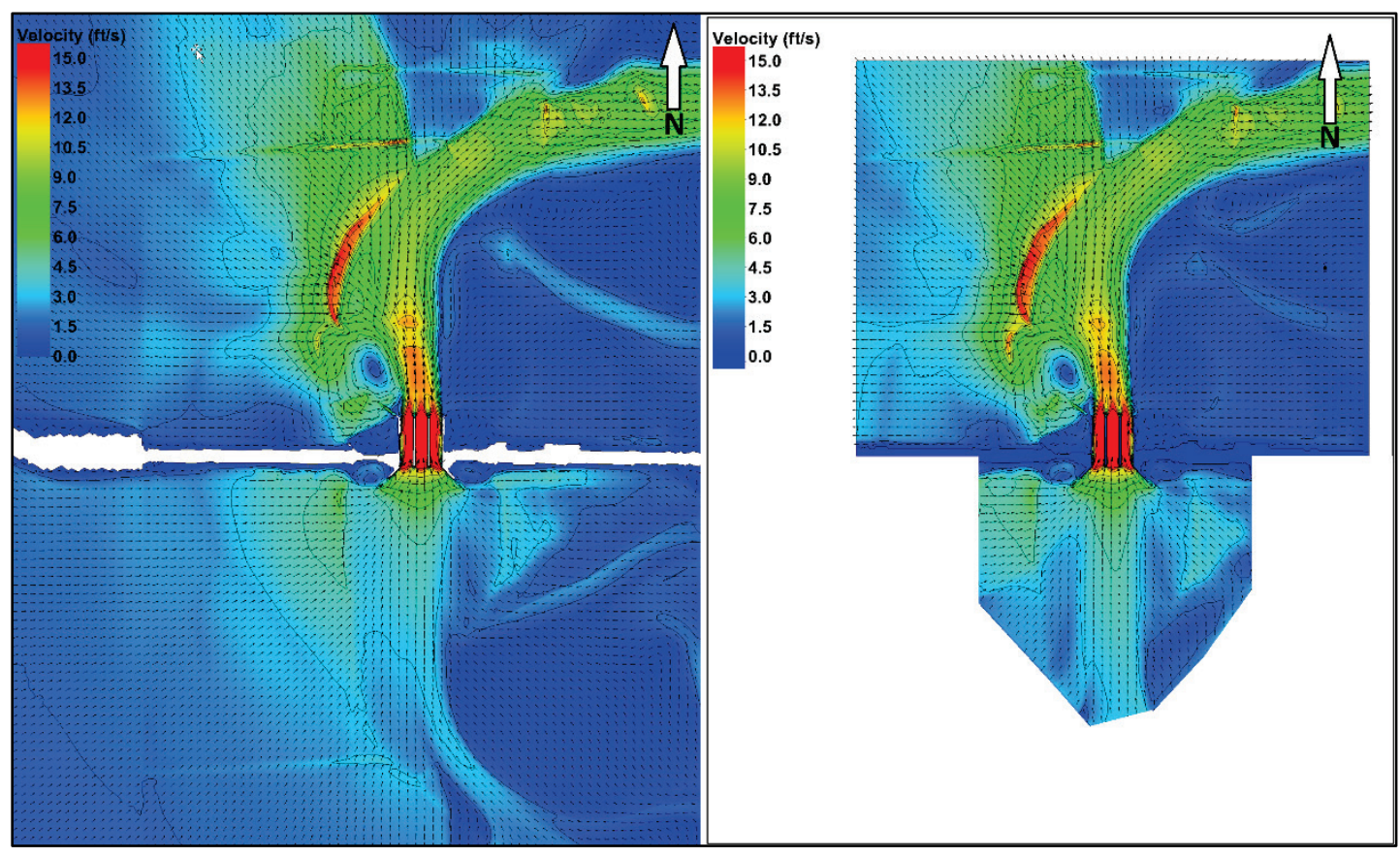


Figure 13. Difference plot of the final model minus initial model velocities.

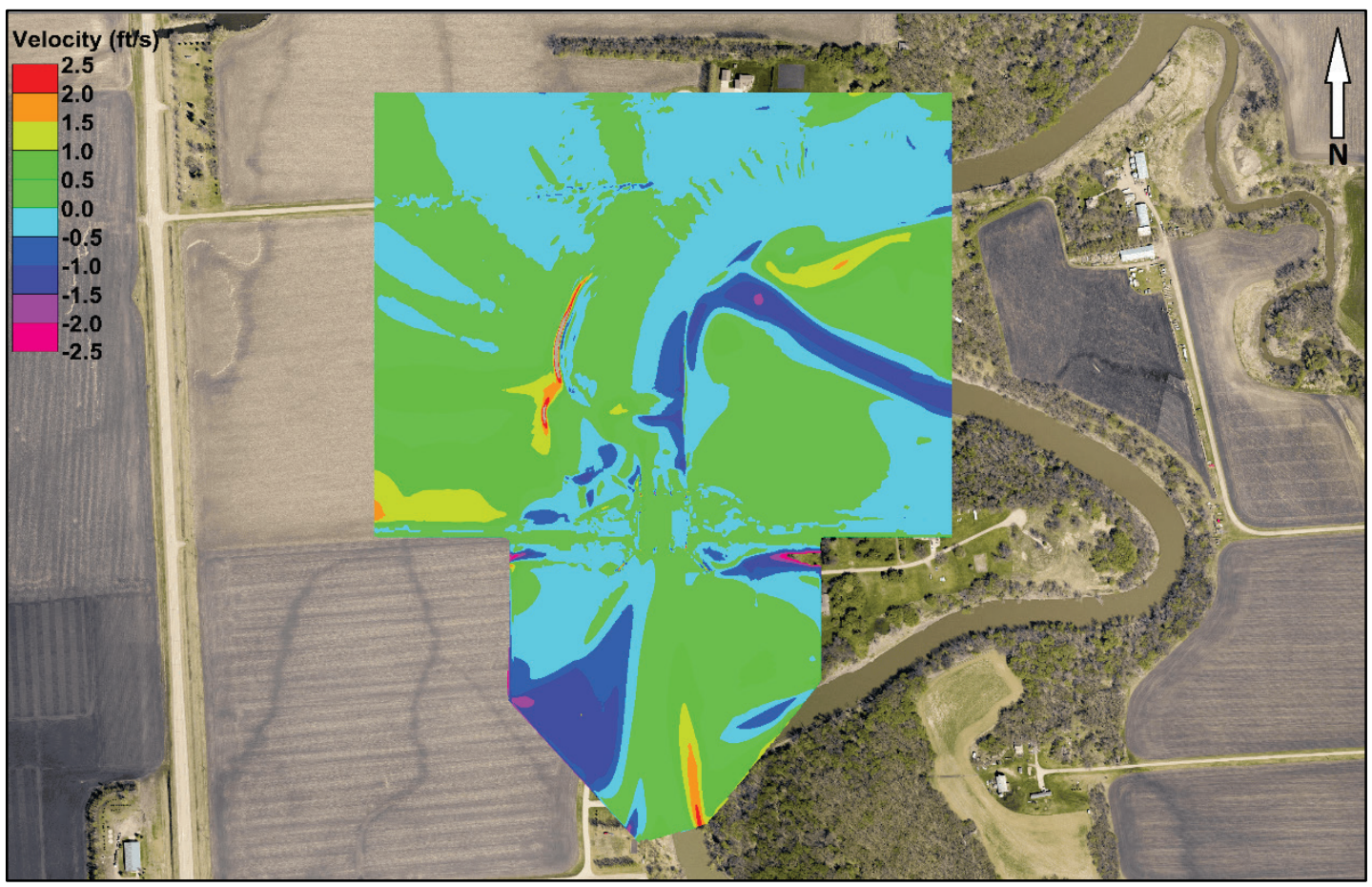

Figure 14. AdH flow trace comparison.

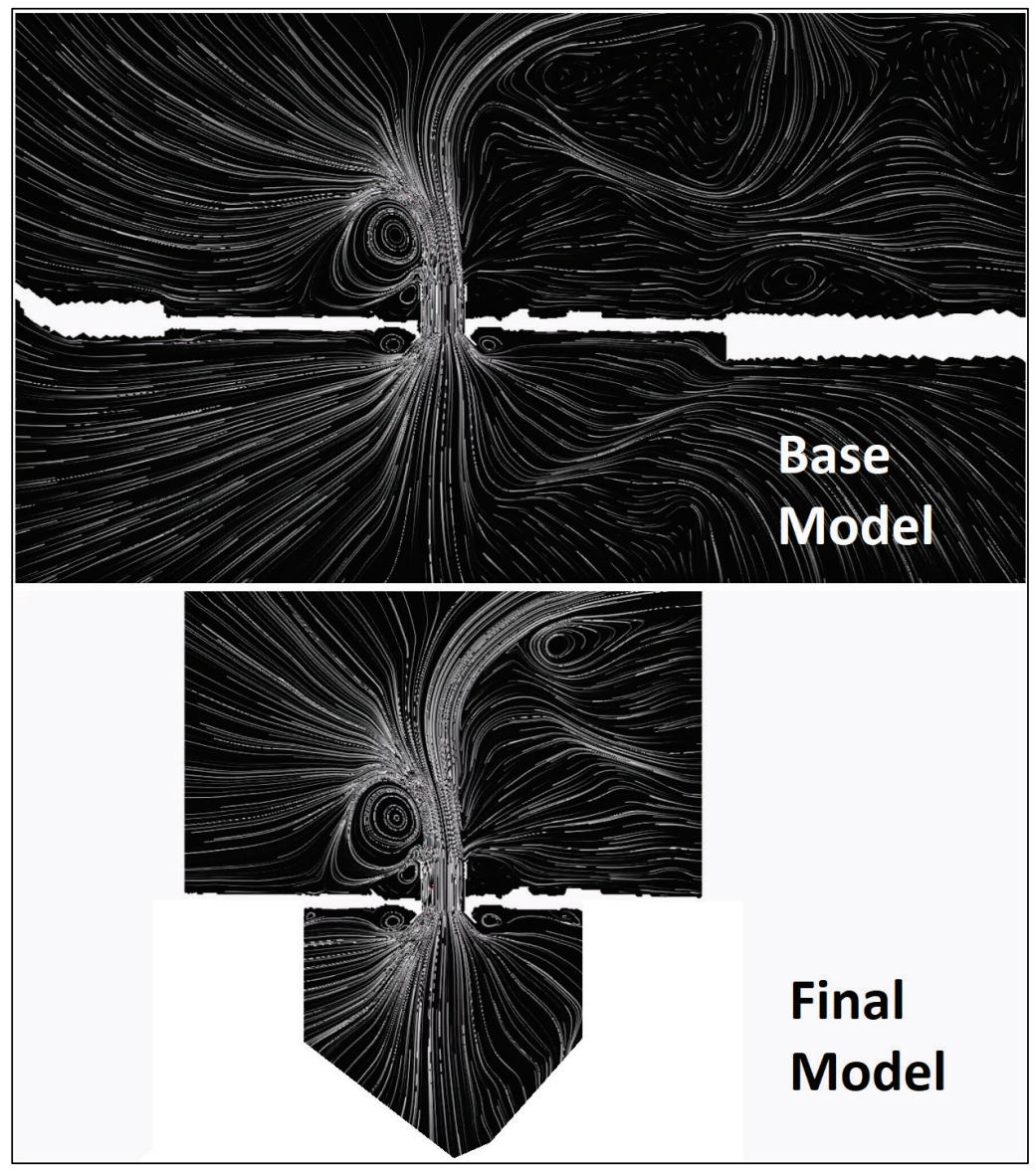


The WSEs were compared at 14 gage locations. Figure 15 displays the locations, and Table 3 contains the results. A WSE profile was generated for the two models, starting upstream of the proposed RRS, through the middle gate, and terminating at the downstream boundary. The WSE profile can be viewed in Figure 16. The profile begins at distance $\mathrm{x}=\mathrm{oft}$ at the upstream limits of the final model domain and ends at approximately $\mathrm{x}$ $=3,500 \mathrm{ft}$. Figure 17 displays difference plots of the WSE from the final model minus the initial model. The differences of WSE are generally $+/-$ $0.5 \mathrm{ft}$ or less and generally fall approximately $+/-0.15 \mathrm{ft}$. These results (velocity and WSE) are within the accuracy limits of the models; therefore, the final model domain is considered to accurately represent the hydraulics of the proposed conditions and is the proposed domain for the physical model.

Figure 15. Model gage locations.

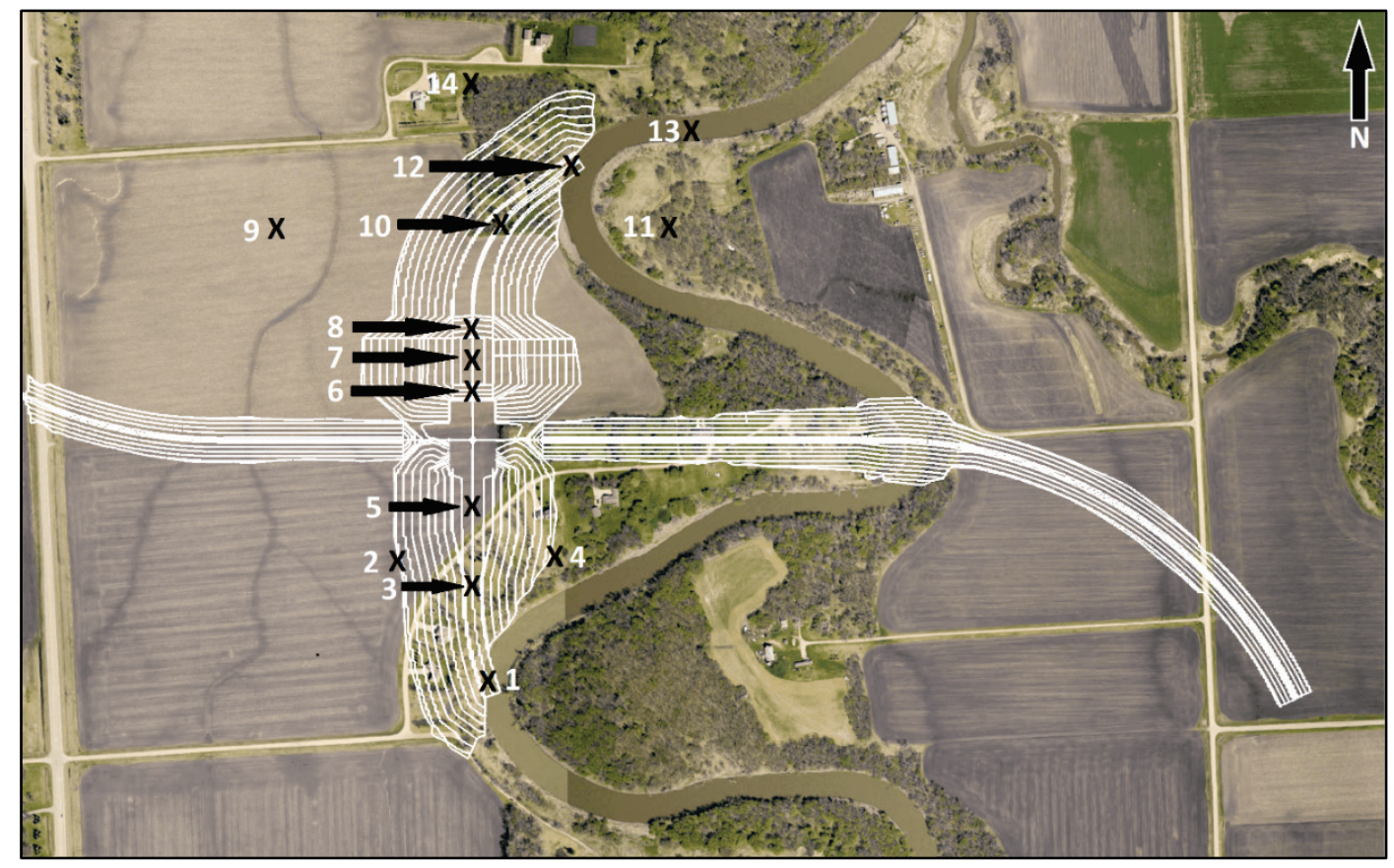


Table 3. WSE comparison of the initial model and final model domain AdH models.

\begin{tabular}{|c|c|c|}
\hline Gage Number & $\begin{array}{c}\text { Final Model Domain } \\
\text { AdH WSE, feet }\end{array}$ & $\begin{array}{c}\text { Initial Model } \\
\text { Domain, AdH WSE, } \\
\text { feet }\end{array}$ \\
\hline 1 & 922.0 & 922.0 \\
\hline 2 & 921.8 & 921.8 \\
\hline 3 & 921.8 & 921.9 \\
\hline 4 & 921.8 & 921.9 \\
\hline 5 & 921.4 & 921.5 \\
\hline 6 & 916.4 & 916.5 \\
\hline 7 & 917.2 & 917.2 \\
\hline 8 & 917.2 & 917.2 \\
\hline 9 & 917.5 & 917.7 \\
\hline 10 & 917.4 & 917.6 \\
\hline 11 & 917.4 & 917.5 \\
\hline 12 & 917.4 & 917.5 \\
\hline 13 & 917.5 & 917.5 \\
\hline 14 & 917.5 & 917.6 \\
\hline
\end{tabular}

Figure 16. WSE profile comparison between the initial model and final domain AdH models.

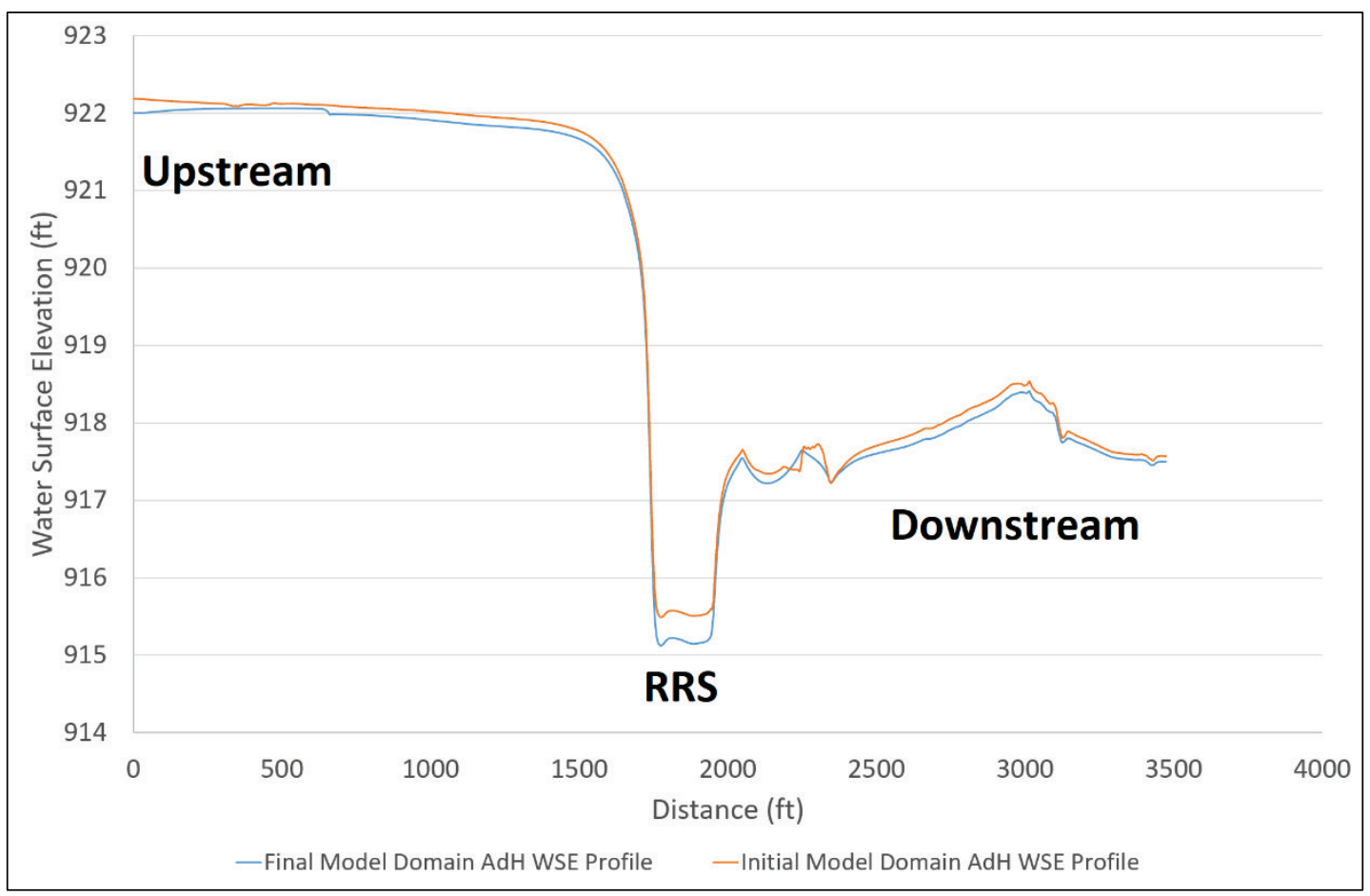


Figure 17. Difference plot of the final model minus the initial model WSEs.

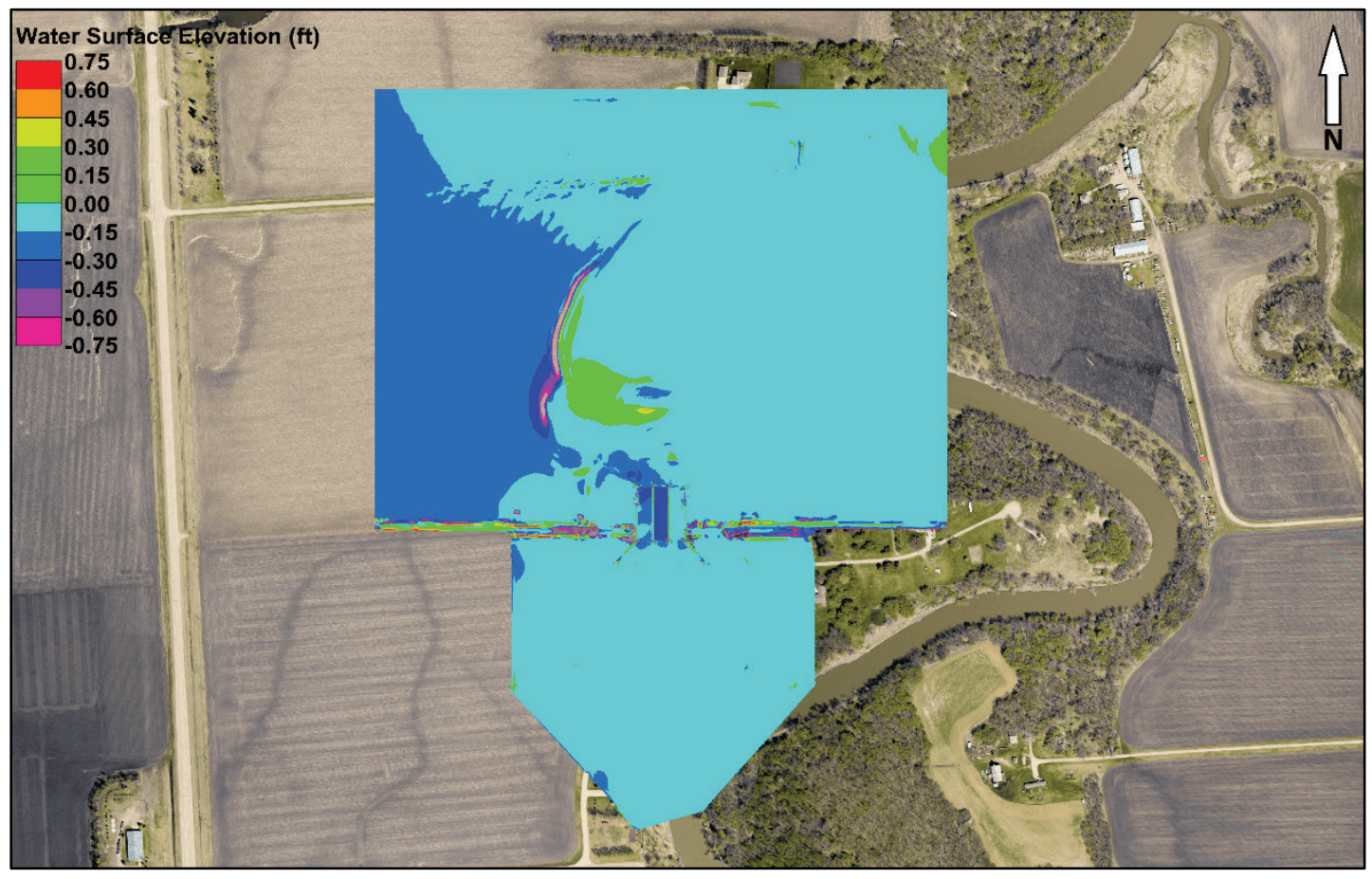




\section{Physical Model Results}

\subsection{Base Structure Design}

The proposed RRS physical model was evaluated for the PMF flow scenario to determine the ability of the structure to pass the flow. The Base Design of the structure can be seen in Figure 18 and includes the following:

- A fixed bed model with an engineered channel upstream of the structure

- Sloped upstream approach walls flared at 45-degree angles

- Three radial gates, each having a width of $50 \mathrm{ft}$ and a height of $52 \mathrm{ft}$

- A sill elevation of $873 \mathrm{ft}$ throughout the structure

- A $174 \mathrm{ft}$ wide, $140 \mathrm{ft}$ long control structure, with $12 \mathrm{ft}$ wide bullet-nosed piers separating each gate bay

- A flat $174 \mathrm{ft}$ wide stilling basin extending $70 \mathrm{ft}$ downstream from the control structure

- A dentated end sill

- A pre-formed scour hole with a bottom elevation of $853 \mathrm{ft}$

- Downsloping stilling basin walls (note that these walls were lowered in elevation after the capacity testing at the St. Paul District's request; Figure 18 includes this minor modification). 
Figure 18. Base Design details (looking downstream).

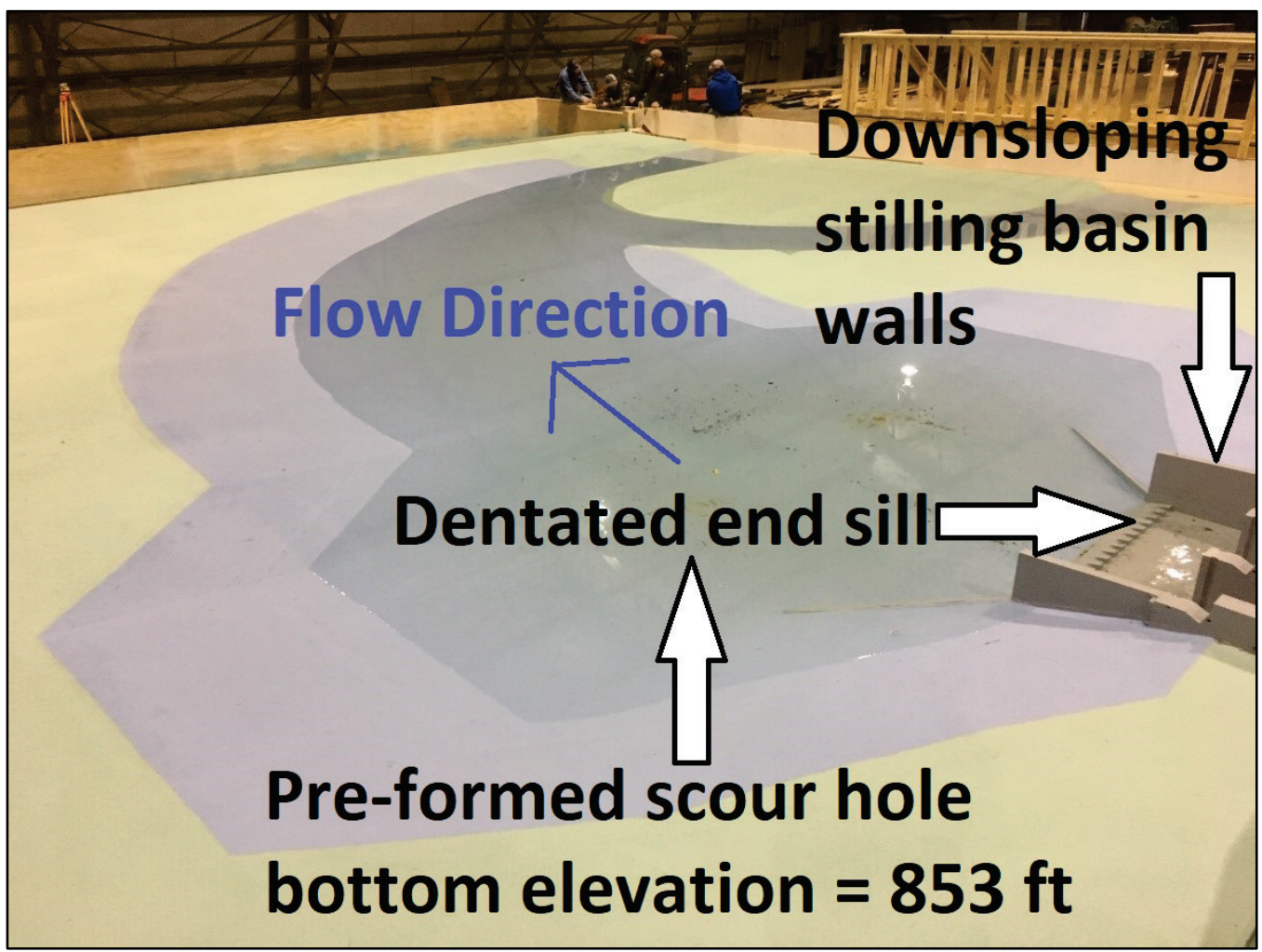

\subsubsection{PMF capacity testing}

Full details of the capacity testing can be found in the Appendix. The WSE results of the PMF tests are shown in Figure 19 and Table 4. The gates are completely open for these PMF tests. For the downstream tailwater boundary, gages $9,11,13$, and 14 were the control locations. Two tests were performed for the PMF conditions to ensure repeatability. The PMF sensitivity test considered an approximately $1 \mathrm{ft}$ higher tailwater boundary condition (Figure 20 and Table 5). The model was considered successful in passing the PMF flow in both scenarios due to headwater elevations at or below $923.5 \mathrm{ft}$ at gage locations 2 and 4. Gage 5 was not used as a verification location for headwater evaluation due to the drawdown effect in the vicinity of the gage. For the sensitivity tests, gage 14 was approximately $1.5 \mathrm{ft}$ high compared to the target increase of $1 \mathrm{ft}$. The weir controlling the tailwater near that gage was set slightly high in the physical model resulting in a marginally high WSE in that area. This was considered acceptable since the conditions being tested were a sensitivity test and thus a higher tailwater would yield more conservative results. 
Figure 19. PMF Base Design results (ft).

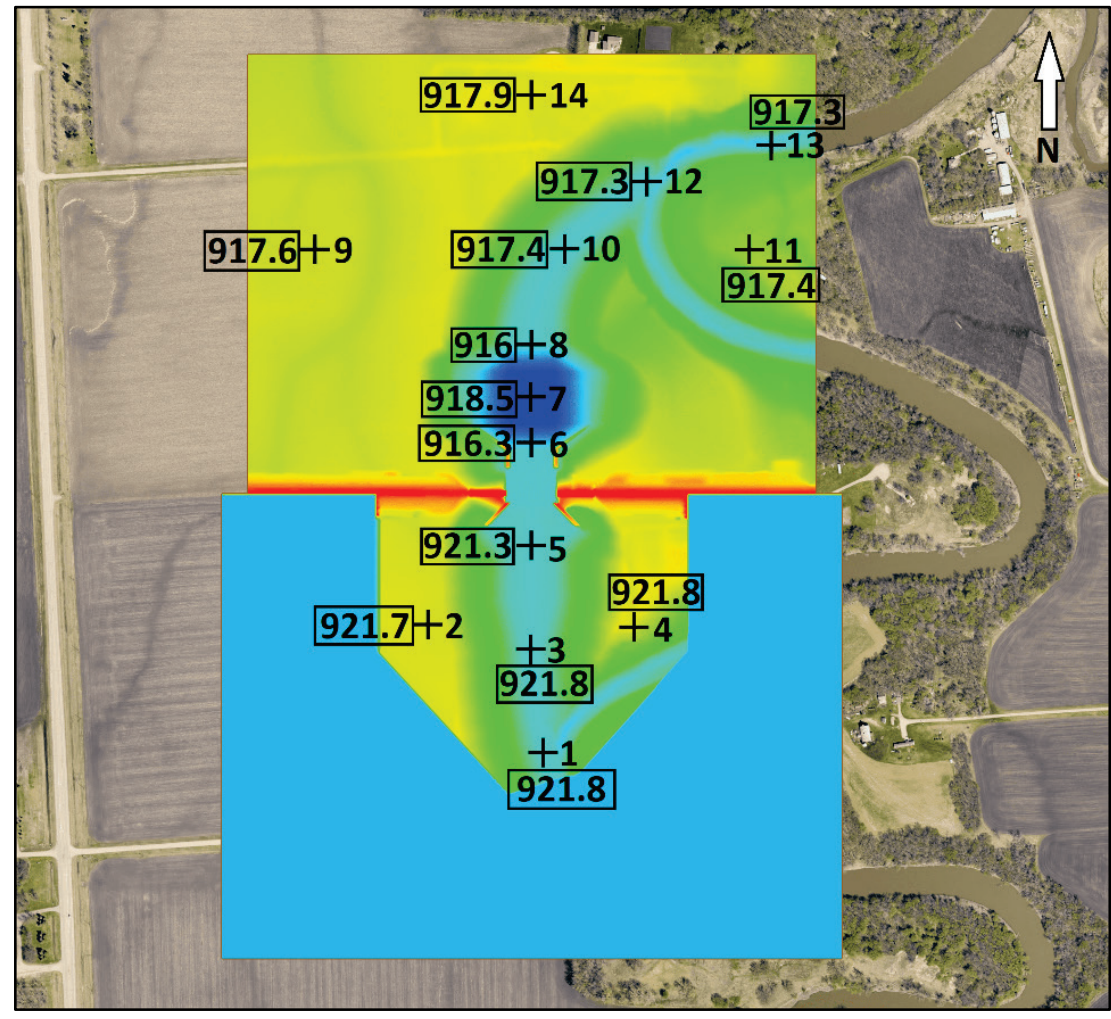

Table 4. Model test results for the Base Design PMF condition.

\begin{tabular}{|c|c|c|c|}
\hline Gage Number & Test 1 WSE, ft & Test 2 WSE, $\mathrm{ft}$ & Average, $\mathrm{ft}$ \\
\hline 1 & 921.8 & 921.9 & 921.8 \\
\hline 2 & 921.6 & 921.8 & 921.7 \\
\hline 3 & 921.7 & 921.9 & 921.8 \\
\hline 4 & 921.7 & 921.8 & 921.8 \\
\hline 5 & 921.2 & 921.3 & 921.3 \\
\hline 6 & 916.2 & 916.3 & 916.3 \\
\hline 7 & 918.6 & 918.5 & 918.5 \\
\hline 8 & 916.2 & 915.8 & 916.0 \\
\hline 9 & 917.6 & 917.6 & 917.6 \\
\hline 10 & 917.3 & 917.4 & 917.4 \\
\hline 11 & 917.3 & 917.4 & 917.4 \\
\hline 12 & 917.3 & 917.3 & 917.3 \\
\hline 13 & 917.3 & 917.4 & 917.3 \\
\hline 14 & 918.1 & 917.7 & 917.9 \\
\hline Flow (cfs) & 103,800 & 104,200 & 104,000 \\
\hline
\end{tabular}


Figure 20. PMF sensitivity Base Design results (ft).

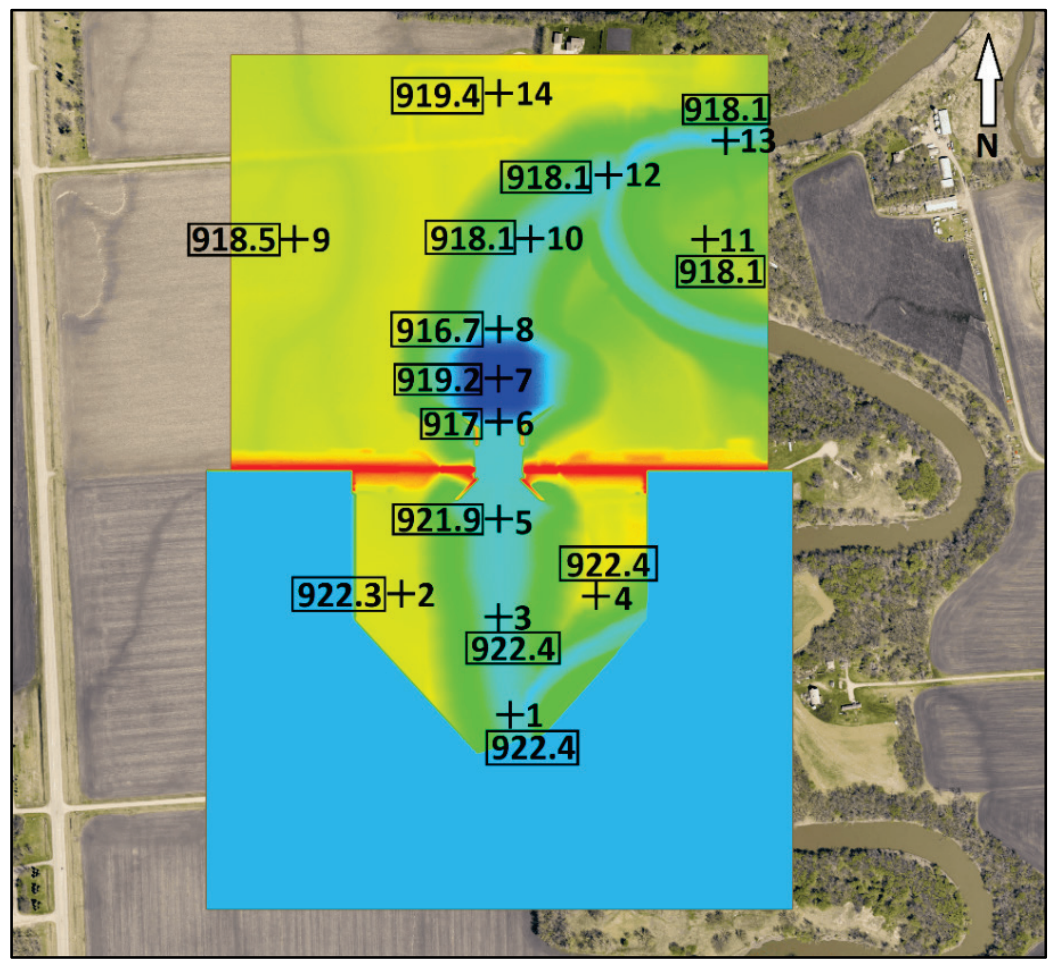

Table 5. Model test results for the Base Design PMF sensitivity condition.

\begin{tabular}{|c|c|c|c|}
\hline Gage Number & Test 1 WSE, $\mathrm{ft}$ & Test 2 WSE, $\mathrm{ft}$ & Average, $\mathrm{ft}$ \\
\hline 1 & 922.4 & 922.4 & 922.4 \\
\hline 2 & 922.3 & 922.3 & 922.3 \\
\hline 3 & 922.4 & 922.4 & 922.4 \\
\hline 4 & 922.4 & 922.4 & 922.4 \\
\hline 5 & 921.9 & 921.8 & 921.9 \\
\hline 6 & 916.9 & 917.1 & 917.0 \\
\hline 7 & $*$ & 919.2 & 919.2 \\
\hline 8 & 916.8 & 916.5 & 916.7 \\
\hline 9 & 918.5 & 918.5 & 918.5 \\
\hline 10 & 918.1 & 918.1 & 918.1 \\
\hline 11 & 918.0 & 918.1 & 918.1 \\
\hline 12 & $*$ & 918.1 & 918.1 \\
\hline 13 & 918.0 & 918.1 & 918.1 \\
\hline 14 & 919.7 & 919.0 & 919.4 \\
\hline Flow (cfs) & 105,000 & 103,700 & 104,400 \\
\hline
\end{tabular}

* Gage reading discarded due to erroneous measurement. 
WSE readings from gages 2 and 4 are considered representative of the pool elevations. The FMM Project's maximum pool elevation is $923.5 \mathrm{ft}$ during the PMF event. Therefore, readings equal to or less than $923.5 \mathrm{ft}$ at gages 2 and 4 during the tests indicate the RRS has sufficient capacity to pass the PMF event. Table 6 summarizes the measurements for gages 2 and 4 for each test. As shown in the table, all measurements for both tests and for both downstream boundary condition scenarios have WSEs less than $923.5 \mathrm{ft}$. Therefore, the RRS has sufficient capacity to pass the PMF event when all gates are lifted out of the water based on the physical modeling effort and boundary condition information provided by the St. Paul District.

Table 6. Model results for the Base Design PMF and PMF sensitivity tests.

\begin{tabular}{|c|c|c|c|c|c|}
\hline \multirow{2}{*}{$\begin{array}{c}\text { Gage } \\
\text { Number }\end{array}$} & \multirow{2}{*}{$\begin{array}{c}\text { Maximum } \\
\text { Allowable } \\
\text { WSE, ft }\end{array}$} & \multicolumn{4}{|c|}{ Test Summary } \\
\cline { 3 - 6 } & & Test 1 WSE, ft & Test 2 WSE, ft & $\begin{array}{c}\text { Test 3 Sensitivity } \\
\text { WSE, ft }\end{array}$ & $\begin{array}{c}\text { Test 4 Sensitivity } \\
\text { WSE, ft }\end{array}$ \\
\hline 2 & 923.5 & 921.6 & 921.8 & 922.3 & 922.3 \\
\hline 4 & 923.5 & 921.7 & 921.9 & 922.4 & 922.4 \\
\hline Flow (cfs) & - & 103,800 & 104,200 & 105,000 & 103,700 \\
\hline
\end{tabular}

Velocities were taken at several locations shown in Figure 21 and Figure 22, and the results from the PMF condition can be seen in Table 7. The data were broken up into $\mathrm{x}-, \mathrm{y}-$, and $\mathrm{z}$-components. High turbulence in the area of ADVs 4, 5, and 6 produced noisy data, and thus those measurements were discarded. The upstream ADVs $(1-3)$ were positioned in the model at locations representing approximately $123 \mathrm{ft}$ from the face of the piers upstream from the center of each gate opening. The upstream ADVs were positioned in the model at depths representing $30 \mathrm{ft}$ above the channel bed and $20 \mathrm{ft}$ below the water surface during the PMF test conditions. A roaming $A D V$ was placed at varying locations and elevations along the longitudinal centerline of the pre-formed scour hole defined in Figure 23. The velocities in Figure 23 are the $x$-components of the velocity measurement (in the general direction of flow). For upstream ADVs $(1-3)$, the velocities recorded are considered sufficiently accurate for each test due to Signal to Noise Ratio (SNR) values that were 20 or higher as well as correlation data metrics higher than $70 \%$ for the measured data. Measurements with SNR values below 20 indicate that the water does not have enough particles to make accurate readings (i.e., it is too clear). This was alleviated by releasing hollow engineered glass microspheres into the model well upstream of the measurement location. The correlation was 
calculated using Doppler processing in which the ADV measures the change in phase of the return signal from two successive acoustic pulses (Martin et al. 2004). The average approach velocities for the gates are approximately 7.2, 8.2, and $7.6 \mathrm{ft} / \mathrm{s}$ in the general direction of flow from left to right descending bank, respectively. Measured velocities downstream of the stilling basin are highest at the top of the pre-formed scour hole where the elevation transitions to the channel bed. The N/A notation in Figure 23 indicates that good measurements were not obtained due to noisy data from the ADV measurements. Note that $\mathrm{X}=\mathrm{O}$ and $\mathrm{Y}=\mathrm{O}$ are as shown in Figure 5.

Figure 21. Upstream ADV locations (looking downstream).

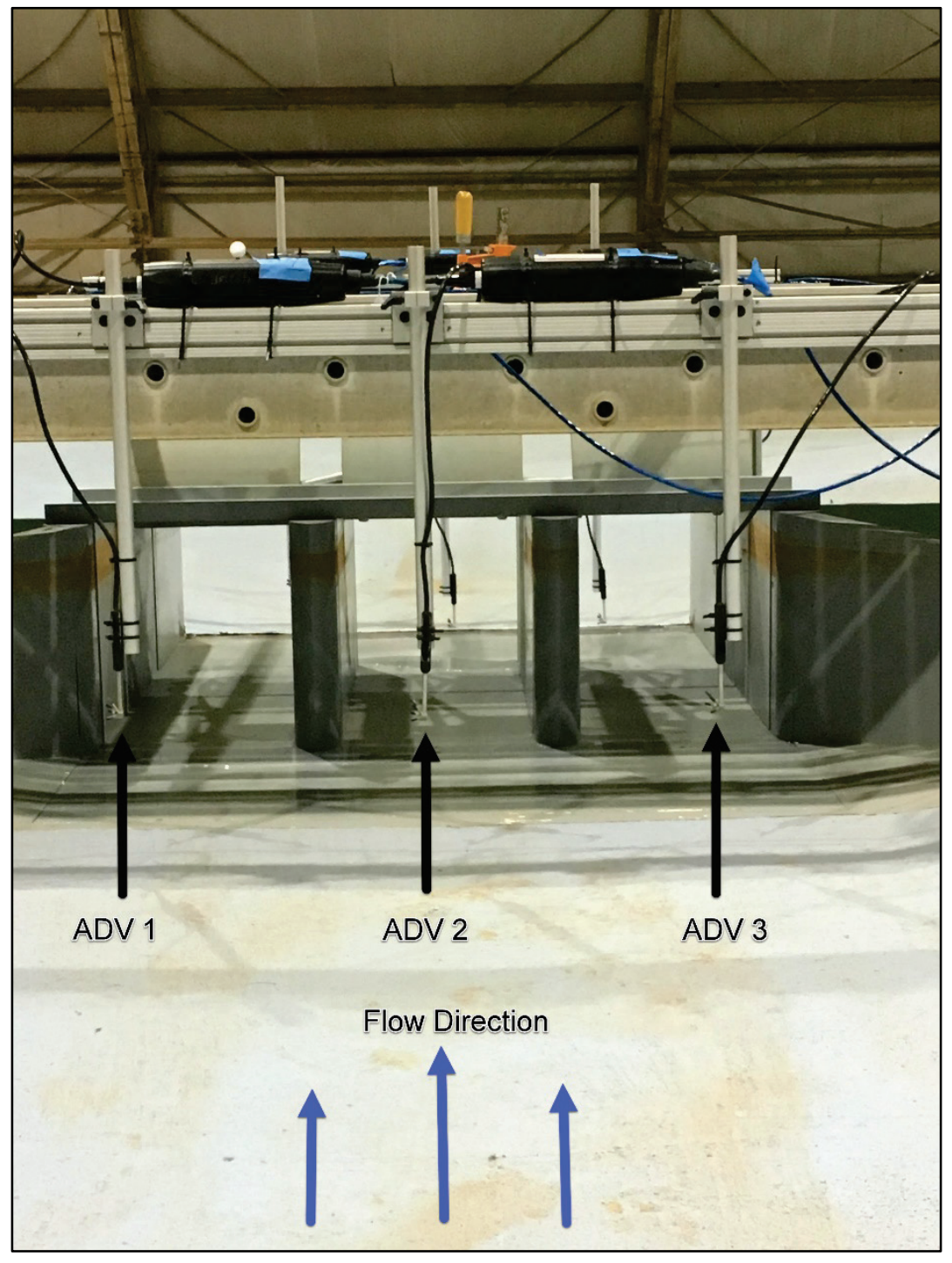


Figure 22. Downstream ADVs (looking upstream).

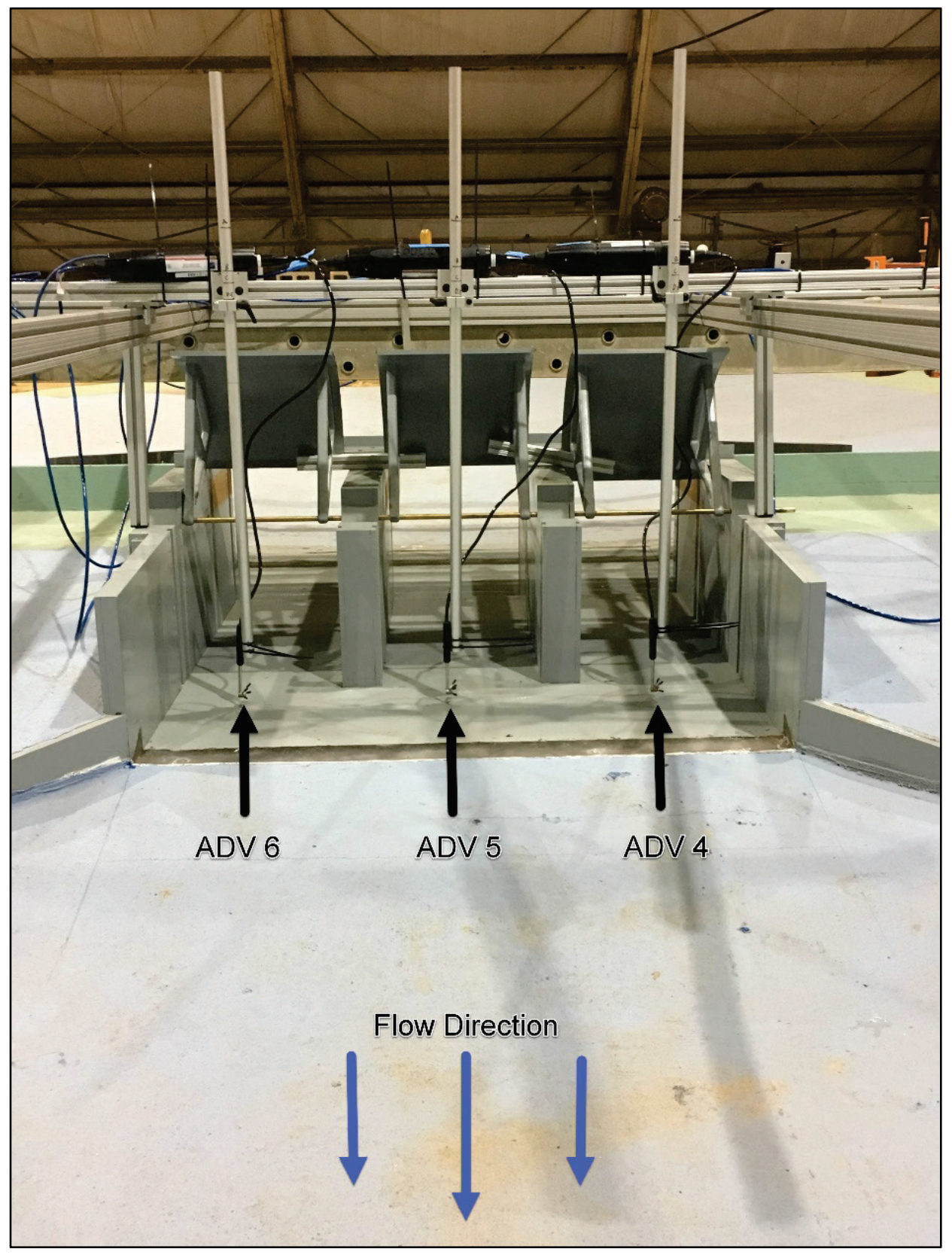


Figure 23. Roaming ADV velocity measurements along the centerline of the pre-formed scour hole for Base Design PMF capacity testing.

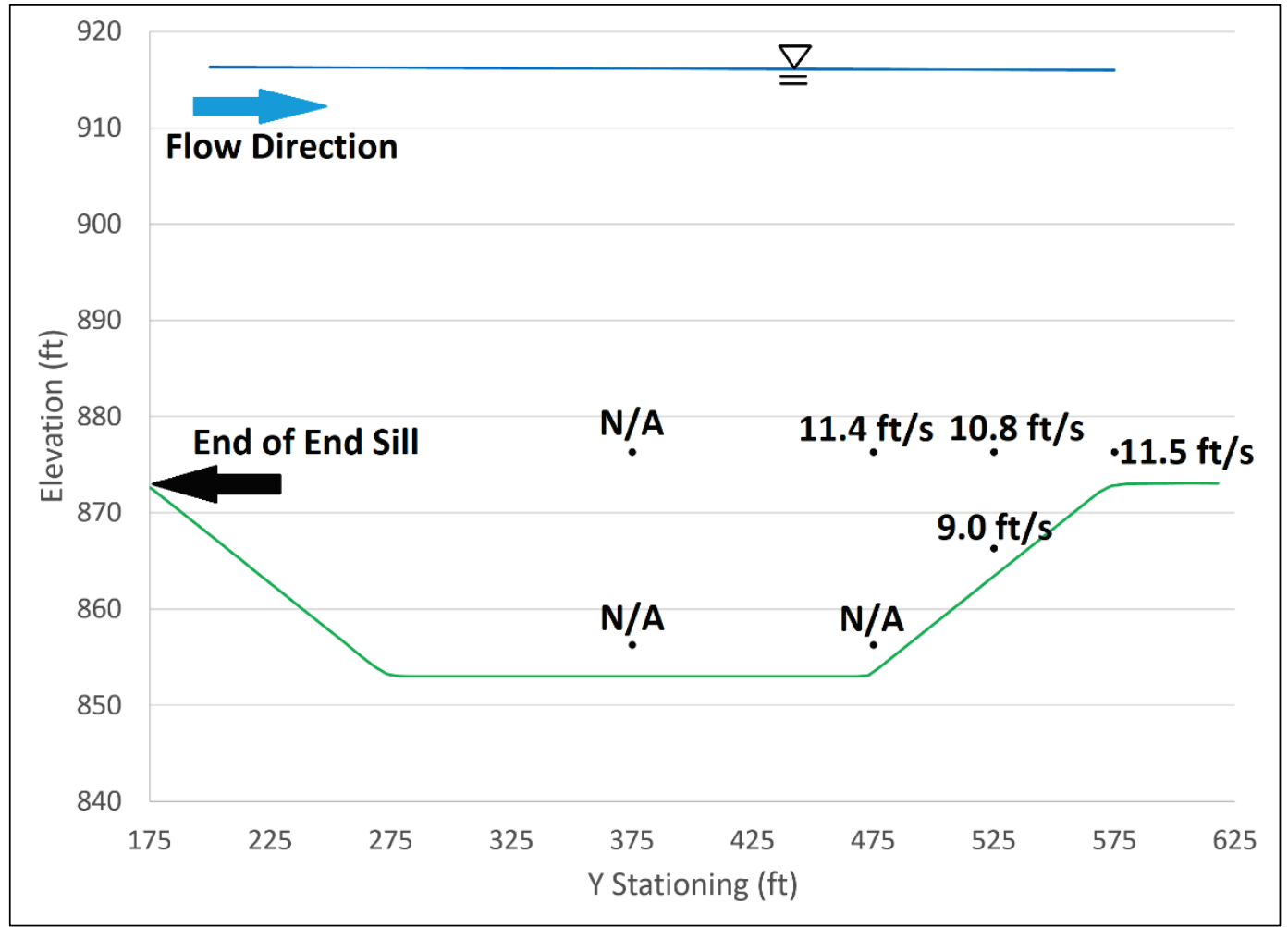

Table 7. Base Design PMF capacity testing velocity results (ft/s).

\begin{tabular}{|c|c|c|c|c|c|c|c|c|}
\hline \multirow{2}{*}{ ID } & \multirow{2}{*}{$\begin{array}{c}\text { Depth } \\
\text { above } \\
\text { Bed (ft) }\end{array}$} & \multicolumn{3}{|c|}{ Location } & \multicolumn{4}{c|}{ PMF } \\
\cline { 2 - 9 } & & $\mathrm{Y}(\mathrm{ft})$ & $\mathrm{Z}(\mathrm{ft})$ & $\mathrm{u}(\mathrm{ft} / \mathrm{s})$ & $\mathrm{v}(\mathrm{ft} / \mathrm{s})$ & $\mathrm{w}(\mathrm{ft} / \mathrm{s})$ & $\begin{array}{c}\text { Total } \\
(\mathrm{ft} / \mathrm{s})\end{array}$ \\
\hline ADV 1 & 30 & -60 & -165 & 904.3 & 7.2 & -1.3 & -0.9 & 7.4 \\
\hline ADV 2 & 30 & 0 & -165 & 903.1 & 8.2 & -0.7 & -0.2 & 8.2 \\
\hline ADV 3 & 30 & 60 & -165 & 904.0 & 7.6 & 2.4 & -2.0 & 8.2 \\
\hline & 3.3 & 0 & 575 & 876 & 11.5 & 0.8 & 0.7 & 11.5 \\
\cline { 2 - 10 } & 13.3 & 0 & 530 & 874.3 & 10.8 & 0.9 & 0.8 & 10.9 \\
\cline { 2 - 10 } & 3.3 & 0 & 530 & 864.3 & 9.0 & 0.2 & 1.3 & 9.1 \\
\cline { 2 - 10 } & 23.3 & 0 & 485 & 877.3 & 11.4 & 1.1 & -0.1 & 11.5 \\
\cline { 2 - 10 } & 3.3 & 0 & 485 & 857.3 & - & - & - & - \\
\cline { 2 - 10 } & 23.3 & 0 & 375 & 876.3 & - & - & - & - \\
\cline { 2 - 10 } & 3.3 & 0 & 375 & 856.3 & - & - & - & - \\
\hline
\end{tabular}

\subsubsection{Reduced pre-formed scour hole testing}

As part of the Base Design testing phase, the maximum controlled releases flow scenario was conducted with a reduced scour hole size. This was accomplished by adding pea gravel in the scour hole and then dusting the rock with brick mortar to armor the material and protect the pea gravel from moving during testing (Figure 24 and Figure 25). The objective of 
reducing the pre-formed scour hole was to qualitatively assess the resulting hydraulics in the near field of the structure as a result of the bathymetric change in the scour hole. Velocity changes in the near field of the structure were observed but not measured. These tests gave insight and valuable information in regards to future modifications discussed later in this report.

Figure 24. Reduced size scour hole viewed from the east.

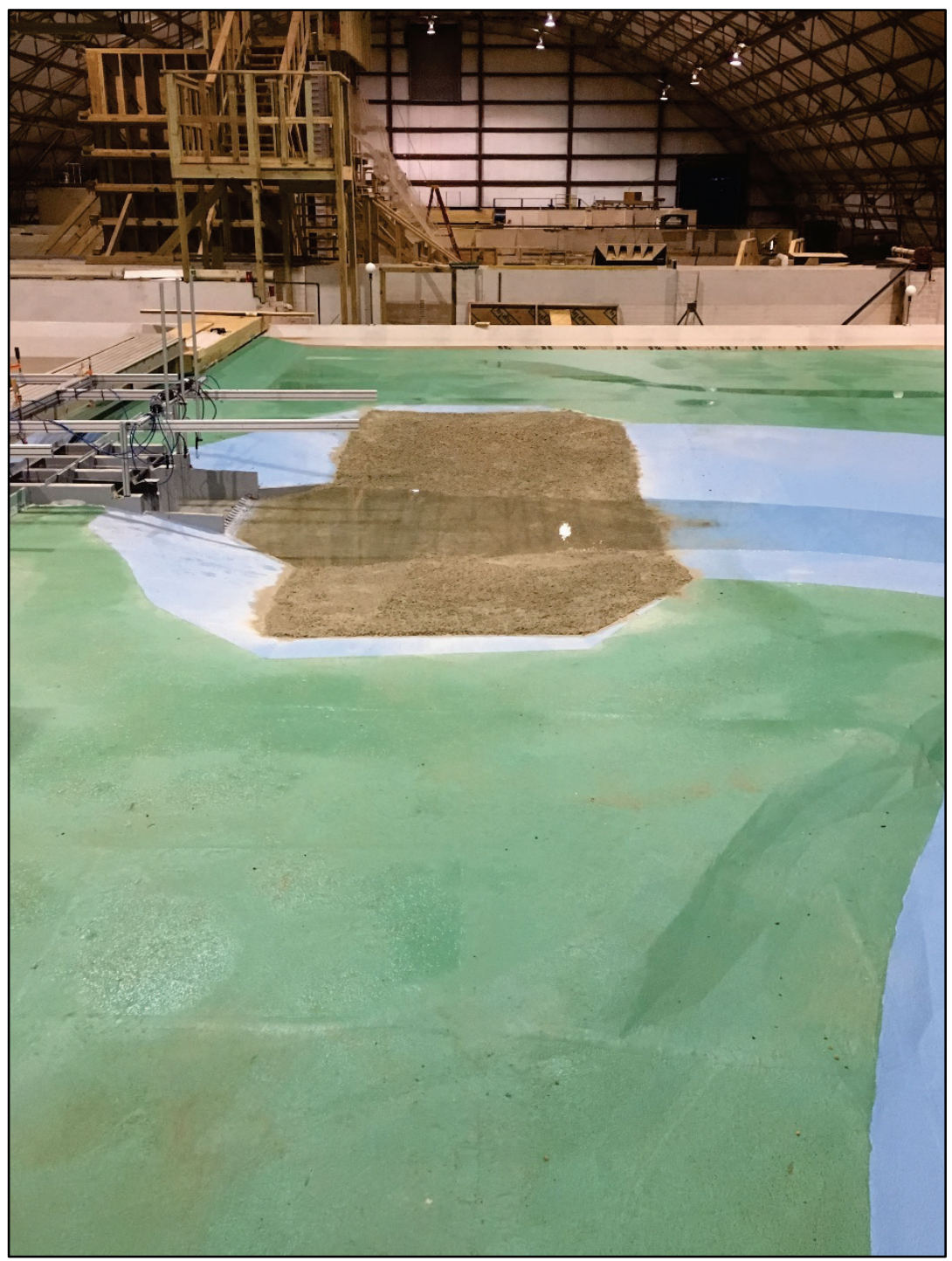


Figure 25. Reduced size scour hole viewed from the northwest.

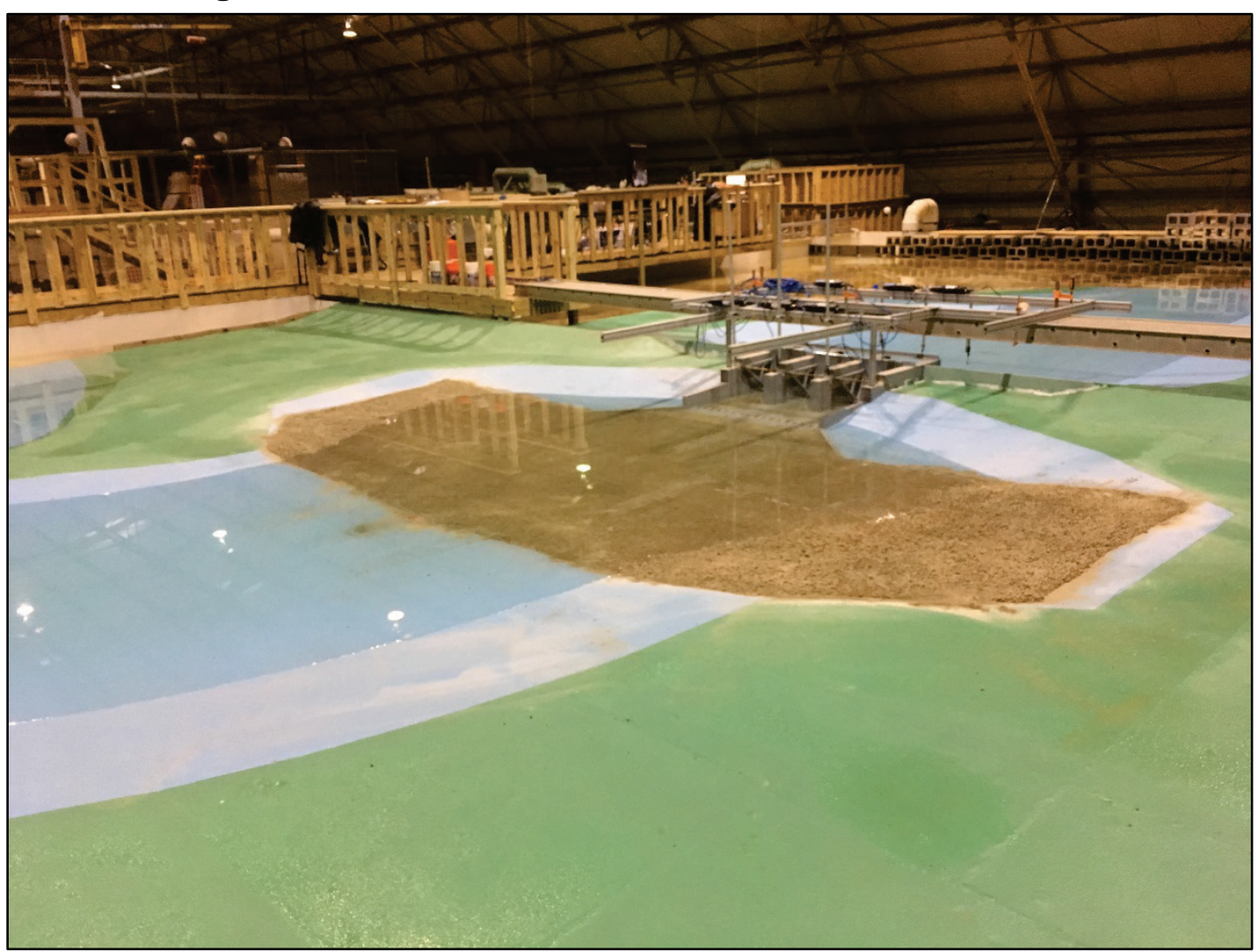

\subsubsection{Maximum controlled releases testing}

The maximum controlled releases flow and tailwater conditions are provided in Table 2. The WSE data can be seen in Figure 26. Gages 9 and 14 do not have data because the flow is in-bank and these gage locations are out-of-bank. The headwater at gage locations 2 and 4 was approximately $924.4 \mathrm{ft}$ during the testing, almost $1 \mathrm{ft}$ higher than the target value of $923.5 \mathrm{ft}$. 
Figure 26. Maximum controlled releases WSE results (ft).

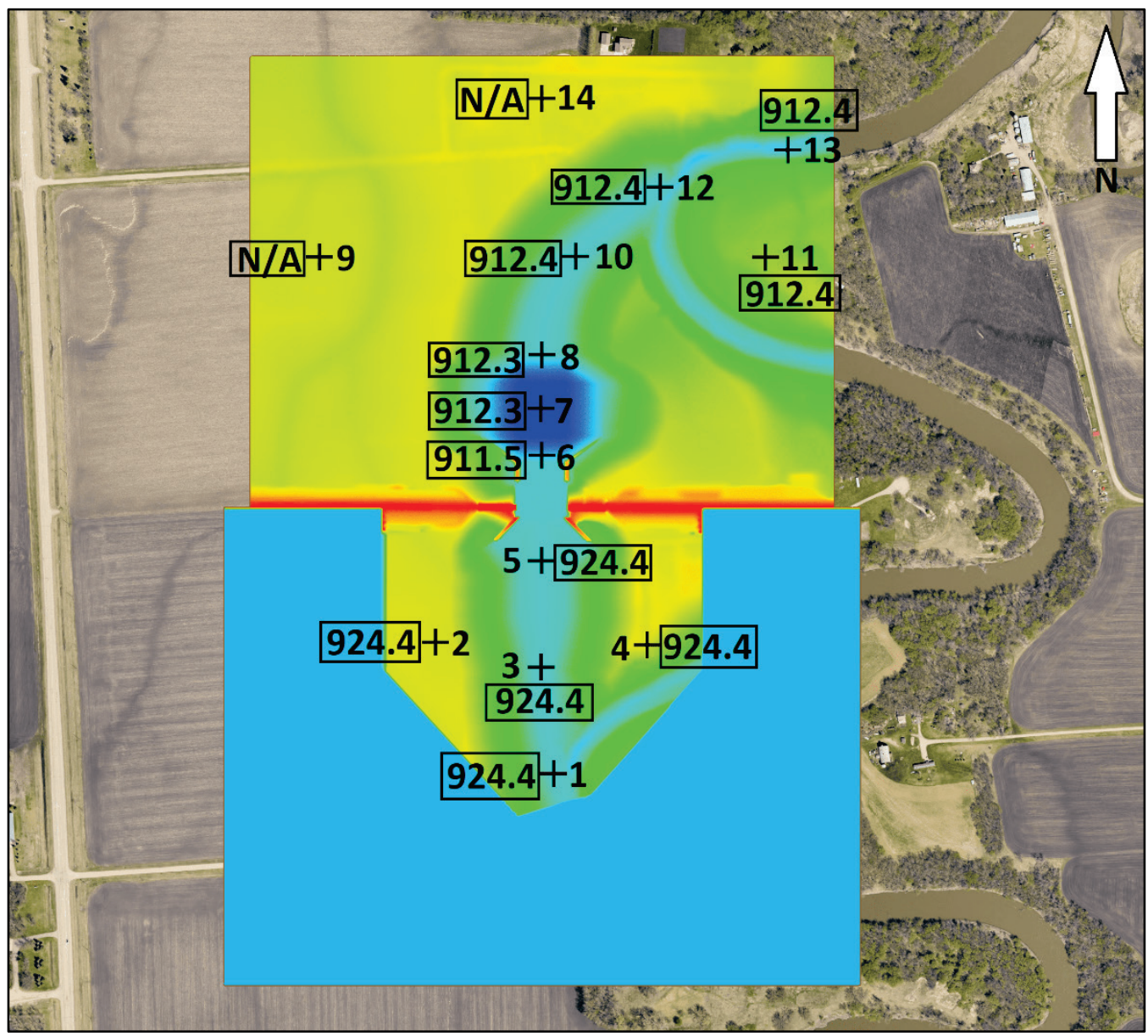

As with the PMF tests, the upstream ADVs $1-3$ were positioned in the model at locations representing approximately $123 \mathrm{ft}$ from the face of the piers upstream of the center of each gate opening. The ADVs were positioned in the model at depths representing $30 \mathrm{ft}$ above the channel bed and approximately $20 \mathrm{ft}$ below the water surface. The approach velocities (x-component) for the gages from left to right descending bank are approximately $1.1,1.3$, and $1.3 \mathrm{ft} / \mathrm{s}$, respectively. The roaming ADV was placed at varying locations and elevations along the longitudinal centerline of the pre-formed scour hole defined in Figure 27. The velocities are highest in measurement 7 , which is approximately $23.3 \mathrm{ft}$ above the channel bed in the center of the pre-formed scour hole. Table 8 displays the velocity results. 
Figure 27. Roaming ADV location and values for Base Design maximum controlled releases testing.

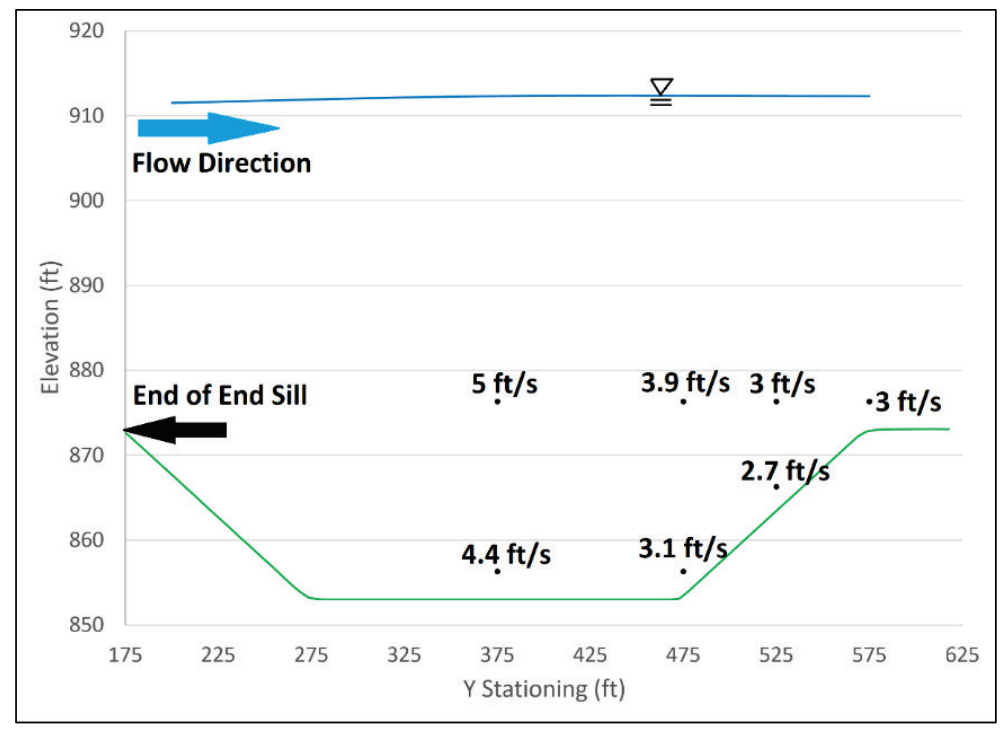

Table 8. Base Design maximum controlled releases velocity results.

\begin{tabular}{|c|c|c|c|c|c|c|c|c|}
\hline \multirow[b]{2}{*}{ ID } & \multirow{2}{*}{$\begin{array}{c}\text { Depth } \\
\text { above } \\
\text { Bed ( } \mathrm{ft} \text { ) }\end{array}$} & \multicolumn{3}{|c|}{ Location } & \multicolumn{4}{|c|}{ Maximum Controlled Releases } \\
\hline & & $X(f t)$ & $Y(f t)$ & $\mathrm{Z}(\mathrm{ft})$ & $\mathrm{u}(\mathrm{ft} / \mathrm{s})$ & $v(\mathrm{ft} / \mathrm{s})$ & $w(f t / s)$ & $\begin{array}{l}\text { Total } \\
(\mathrm{ft} / \mathrm{s})\end{array}$ \\
\hline ADV 1 & 30.0 & -60 & -165 & 904.3 & 1.1 & -0.1 & -0.1 & 1.1 \\
\hline ADV 2 & 30.0 & 0 & -165 & 903.1 & 1.3 & 0.0 & 0.0 & 1.3 \\
\hline ADV 3 & 30.0 & 60 & -165 & 904.0 & 1.3 & 0.4 & -0.3 & 1.4 \\
\hline ADV 4 & 3.3 & -60 & 190 & 872.8 & 1.4 & 0.0 & 0.2 & 1.4 \\
\hline ADV 5 & 3.3 & 0 & 190 & 873.0 & 0.0 & -0.5 & -0.2 & 0.5 \\
\hline ADV 6 & 3.3 & 60 & 190 & 872.8 & -0.4 & -0.2 & -0.3 & 0.5 \\
\hline ADV 4 & 5.0 & -60 & 190 & 874.5 & 0.3 & 0.0 & -0.3 & 0.4 \\
\hline ADV 5 & 5.0 & 0 & 190 & 874.7 & 0.4 & -0.2 & -1.2 & 1.3 \\
\hline ADV 6 & 5.0 & 60 & 190 & 874.5 & 0.2 & -0.1 & -0.6 & 0.6 \\
\hline ADV 4 & 1.7 & -60 & 190 & 871.2 & 2.3 & 0.8 & 0.8 & 2.5 \\
\hline ADV 5 & 1.7 & 0 & 190 & 871.4 & 3.8 & -0.5 & -2.3 & 4.5 \\
\hline ADV 6 & 1.7 & 60 & 190 & 871.2 & -0.8 & -0.6 & 1.8 & 2.0 \\
\hline ADV 4 & 3.3 & -60 & 250 & 859.4 & -1.1 & 0.1 & -2.5 & 2.7 \\
\hline ADV 5 & 3.3 & 0 & 250 & 859.7 & 0.0 & -0.1 & -1.0 & 1.0 \\
\hline ADV 6 & 3.3 & 60 & 250 & 860.3 & 0.9 & -0.9 & -1.5 & 1.9 \\
\hline ADV 4 & 5.0 & -60 & 250 & 861.1 & -0.6 & -0.7 & -0.9 & 1.4 \\
\hline ADV 5 & 5.0 & 0 & 250 & 861.4 & 0.0 & 0.0 & -1.7 & 1.7 \\
\hline ADV 6 & 5.0 & 60 & 250 & 862.0 & 0.3 & -0.7 & -0.7 & 1.0 \\
\hline ADV 4 & 1.7 & -60 & 250 & 857.8 & -1.6 & 0.3 & 0.0 & 1.6 \\
\hline ADV 5 & 1.7 & 0 & 250 & 858.1 & 0.2 & -0.5 & -2.4 & 2.4 \\
\hline ADV 6 & 1.7 & 60 & 250 & 858.7 & -0.3 & -0.6 & -1.5 & 1.7 \\
\hline ADV 4 & 3.3 & -60 & 290 & 856.3 & 1.0 & 0.1 & -2.6 & 2.7 \\
\hline ADV 5 & 3.3 & 0 & 290 & 856.3 & 0.9 & 0.1 & -1.7 & 1.9 \\
\hline ADV 6 & 3.3 & 60 & 290 & 856.3 & -1.1 & 0.1 & 0.4 & 1.1 \\
\hline ADV 4 & 5.0 & -60 & 290 & 858.0 & -0.2 & 0.1 & -0.9 & 0.9 \\
\hline ADV 5 & 5.0 & 0 & 290 & 858.0 & 0.9 & 0.2 & -1.5 & 1.8 \\
\hline ADV 6 & 5.0 & 60 & 290 & 858.0 & -1.1 & 0.1 & -0.9 & 1.4 \\
\hline ADV 4 & 1.7 & -60 & 290 & 854.7 & 2.1 & -0.3 & -1.4 & 2.6 \\
\hline ADV 5 & 1.7 & 0 & 290 & 854.7 & 1.6 & 0.1 & -1.8 & 2.4 \\
\hline ADV 6 & 1.7 & 60 & 290 & 854.7 & 0.7 & 0.3 & -0.5 & 0.9 \\
\hline \multirow{7}{*}{ Roaming ADV } & 3.3 & 0 & 575 & 876.0 & 3.0 & 0.4 & 0.2 & 3.0 \\
\hline & 13.3 & 0 & 530 & 874.3 & 3.0 & 0.7 & 0.3 & 3.0 \\
\hline & 3.3 & 0 & 530 & 864.3 & 2.7 & 0.6 & 0.4 & 2.8 \\
\hline & 23.3 & 0 & 485 & 877.3 & 3.9 & 1.3 & 0.0 & 4.1 \\
\hline & 3.3 & 0 & 485 & 857.3 & 3.1 & 1.2 & 0.2 & 3.3 \\
\hline & 23.3 & 0 & 375 & 876.3 & 5.0 & 0.7 & -0.4 & 5.1 \\
\hline & 3.3 & 0 & 375 & 856.3 & 4.4 & 1.0 & 0.0 & 4.5 \\
\hline
\end{tabular}




\subsection{Alternative 1}

\subsubsection{Alternative 1 Design modifications}

The St. Paul District designed several structure modifications to be evaluated in the physical model for alternative design testing. These modifications included (Figure 28) the following:

- Shortening of the piers to a length of $125 \mathrm{ft}$.

- Stilling basin length remains $70 \mathrm{ft}$, but was moved upstream to account for the shortened pier length.

- A sloping stilling basin with a $7 \mathrm{ft}$ elevation change that decreases from $873 \mathrm{ft}$ at the end of the downstream face of the piers to a flat landing area at elevation $866 \mathrm{ft}$. The dentated end sill was placed on this flat area, with the top of the blocks being at an elevation of $873 \mathrm{ft}$.

- The retaining walls are down sloping from the end of the stilling basin walls until they reach the channel bottom and are approximately $120 \mathrm{ft}$ long.

- The reduced pre-formed scour hole testing discussed in Section 4.1.2 suggested a layer of R470 riprap at the $866 \mathrm{ft}$ elevation from the downstream end of the dentated end sill $(7 \mathrm{ft}$ lower than the Base Design) to the downstream end of the retaining walls would be sufficient and that a pre-formed scour hole (a lowering of the bed to an elevation lower than what the structure requires) would not be necessary. Downstream of the retaining walls, the R470 riprap was placed to transition from the $866 \mathrm{ft}$ bed elevation back up to the $873 \mathrm{ft}$ bed elevation of the engineered channel at a $1 \mathrm{~V}: 3 \mathrm{H}$ slope. Uniformly graded sand $\left(\mathrm{d}_{50}=0.25 \mathrm{~mm}\right)$ was used to fill in the remainder of the Base Design pre-formed scour hole such that the engineered channel bed elevation of $873 \mathrm{ft}$ was achieved. The critical velocity for this material was approximately $6 \mathrm{ft} / \mathrm{s}$. Material placement, and grading was specified by the St. Paul District.

- The top elevation of the stilling basin walls was modified by constructing pieces that could be attached to the Base Design stilling basin walls. 
Figure 28. Alternative 1 Design (pre-test for Maximum Controlled Releases scenario), looking at the structure from the east.

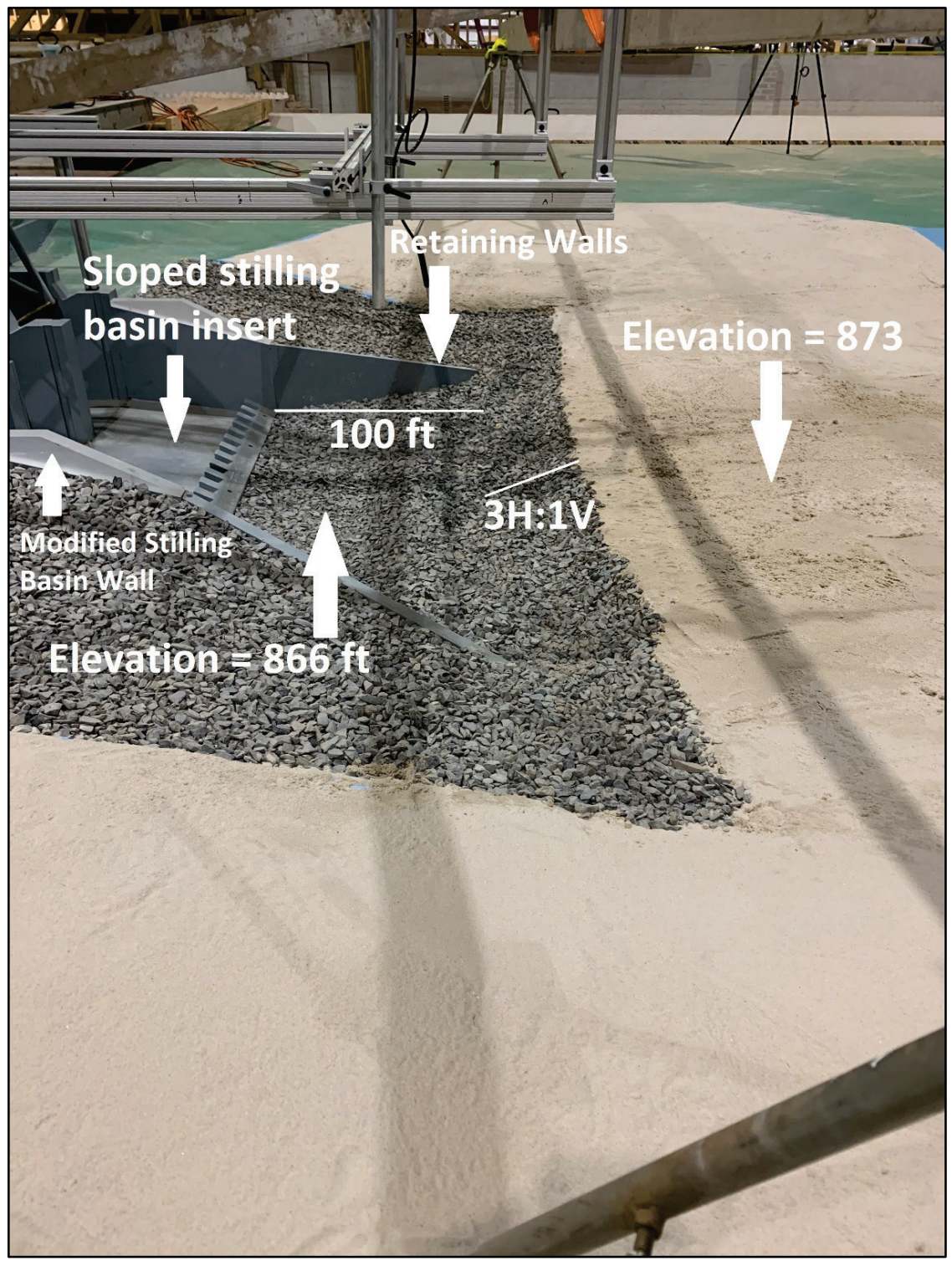

The $\mathrm{R} 470$ riprap prototype gradation is provided in Table 9. Four sieve sizes were used to produce 1:40 scale R470 riprap for the physical model: $3 / 4,5 / 8,1 / 2$, and $3 / 8$ in. Materials retained on the $5 / 8,1 / 2$, and $3 / 8$ in. sieves were kept. The ERDC Sedimentation Laboratory performed a gradation analysis on the retained material used in the physical model. The results are shown in Figure 29 (prototype scale). The retained materials were scaled to the prototype scale and plotted on the figure to show that the stone used in the physical model falls within the acceptable range of stone for the R470 gradation. 
Table 9. R470 riprap gradation.

\begin{tabular}{|c|c|c|c|c|}
\hline \multirow{4}{*}{$\%$ Finer } & \multicolumn{4}{|c|}{ R470 } \\
\hline & \multicolumn{2}{|c|}{ Maximum } & \multicolumn{2}{|c|}{ Minimum } \\
\hline & Weight & Diameter & Weight & Diameter \\
\hline & (lb) & $(\mathrm{ft})$ & (lb) & $(\mathrm{ft})$ \\
\hline 100 & 2300 & 2.99 & 950 & 2.22 \\
\hline 50 & 990 & 2.25 & 470 & 1.76 \\
\hline 15 & 490 & 1.78 & 145 & 1.19 \\
\hline 5 & 400 & 1.67 & 80 & 0.97 \\
\hline
\end{tabular}

Figure 29. Scaled R470 riprap gradation results.

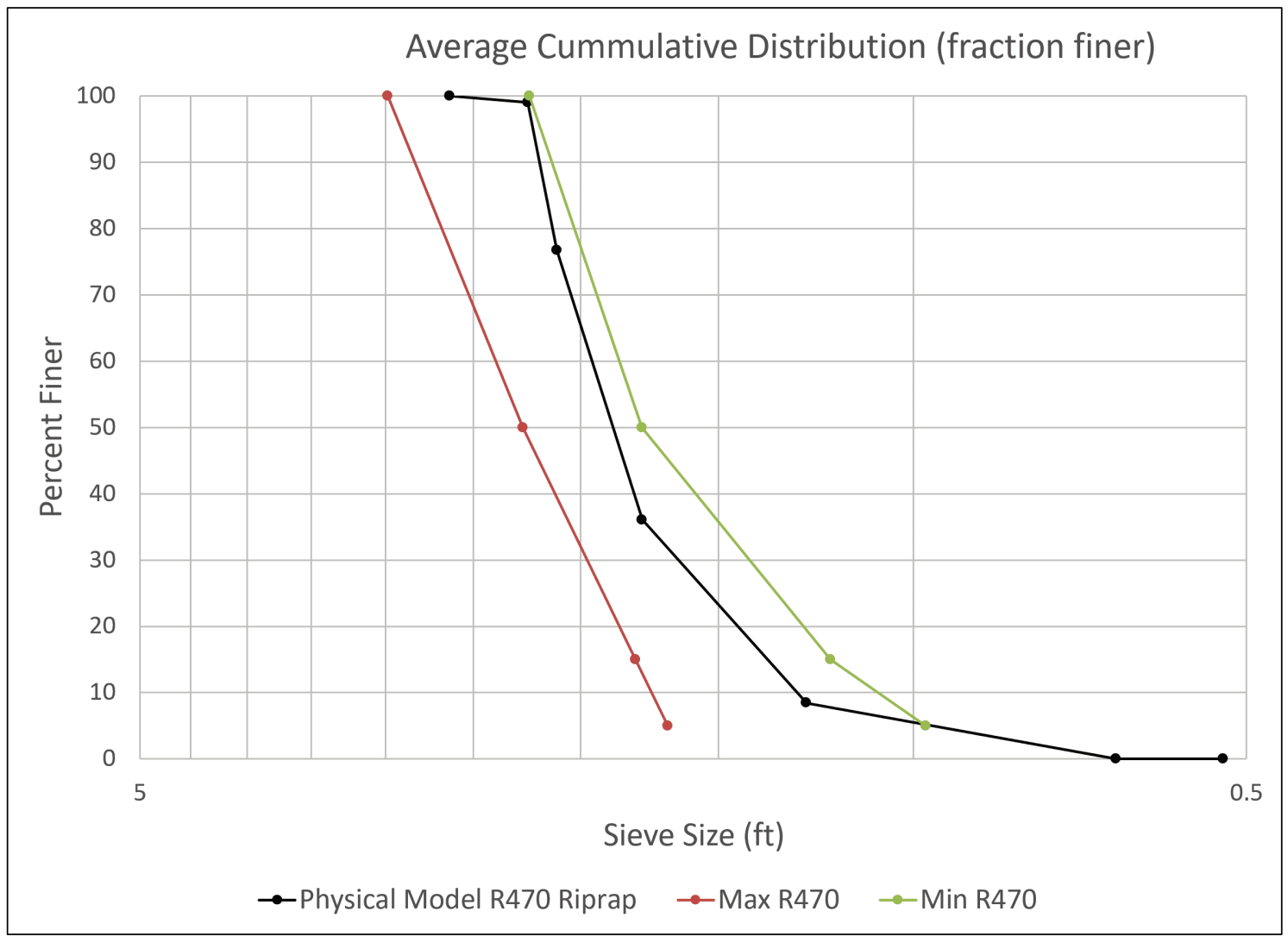




\subsubsection{Alternative 1 Design testing}

The Alternative 1 Design configuration was tested under the following flow/boundary conditions in Table 10. There are several things to note:

1. Downstream velocity data were taken with the ADVs similar to the Base Design testing simulations. Velocity data upstream of the gates were taken with a Valeport model 801 electromagnetic flow meter (accuracy of $\pm 0.5 \%$ of measurement plus $\sim 0.7 \mathrm{ft} / \mathrm{s}$ prototype). The less turbulent approach flow conditions allow for the use of the Valeport instrument instead of the ADVs, which allowed for more velocity measurements to be taken in less time and required much less data processing.

2. Gate openings were measured from the floor of the structure (flat surface at elevation $=873 \mathrm{ft}$ ) vertically to the bottom of the radial gate. "Open" in Table 10 indicates the gates are completely out of the water, and the flow is uncontrolled.

3. LiDAR data were collected for each Alternative Design test. However, velocity measurement activities caused the movement of bed material for the 60,000 cfs releases, PMF, and PMF resiliency events. Only LiDAR data relevant to design decisions and not affected by velocity measurement activities are being documented in this report. 
Table 10. Alternative 1 Design testing boundary condition data.

\begin{tabular}{|c|c|c|c|c|c|c|}
\hline Scenario & $\begin{array}{c}\text { Target } \\
\text { Headwater } \\
\text { Elevation } \\
\text { (ft) }\end{array}$ & $\begin{array}{c}\text { Target } \\
\text { Tailwater } \\
\text { Elevation } \\
\text { (ft) }\end{array}$ & $\begin{array}{c}\text { Target } \\
\text { Discharge } \\
\text { (cfs) }\end{array}$ & $\begin{array}{c}\text { Model Headwater } \\
\text { Elevation' } \text { (ft) }\end{array}$ & $\begin{array}{c}\text { Model } \\
\text { Tailwater } \\
\text { Elevation }{ }^{2} \\
\text { (ft) }\end{array}$ & $\begin{array}{c}\text { Model Discharge } \\
\text { (cfs) }\end{array}$ \\
\hline $5 \%$ AEP Event & - & 910.1 & 10,700 & $910.2^{4}$ & 910.1 & 10,800 \\
\hline $\begin{array}{c}\text { Maximum Controlled } \\
\text { Releases }\end{array}$ & 923.5 & 912.9 & 18,000 & 923.3 & 912.9 & 18,200 \\
\hline $\begin{array}{c}\text { 60,000 cfs Releases } \\
\text { Height (ft) }\end{array}$ & 923.5 & 915.6 & 60,000 & 923.3 & 915.7 & 60,000 \\
\hline $\begin{array}{c}\text { PMF } \\
\text { PMF Resiliency } \\
\text { (Descending Right } \\
\text { Bank Gate Completely } \\
\text { Closed) }\end{array}$ & 923.5 & 917.5 & 104,300 & 923.3 & 917.7 & 104,200 \\
\hline
\end{tabular}

1. Reported headwater elevations were the average of gages 2 and 4 over the course of the test. These gages were chosen to avoid the potential impact of drawdown effects located closer to the structure.

2. Reported tailwater elevations are from the average of measurements taken at gage 13 .

3. Flow measurements were averaged over the course of the experiment.

4. Reported headwater elevation is from the average of measurements taken at gage 5 (gages 2 and 4 were out of bank and flow was only in channel during this simulation/event). 
Velocity measurements were taken with an ADV downstream of the gates and a Valeport electromagnetic meter upstream of the gates. The turbulence that occurs just downstream of the gates in the stilling basin area is too chaotic to record velocity measurements with the Valeport instrument (Figure 30).

Figure 30. Turbulence downstream of gate openings during a PMF resiliency test.

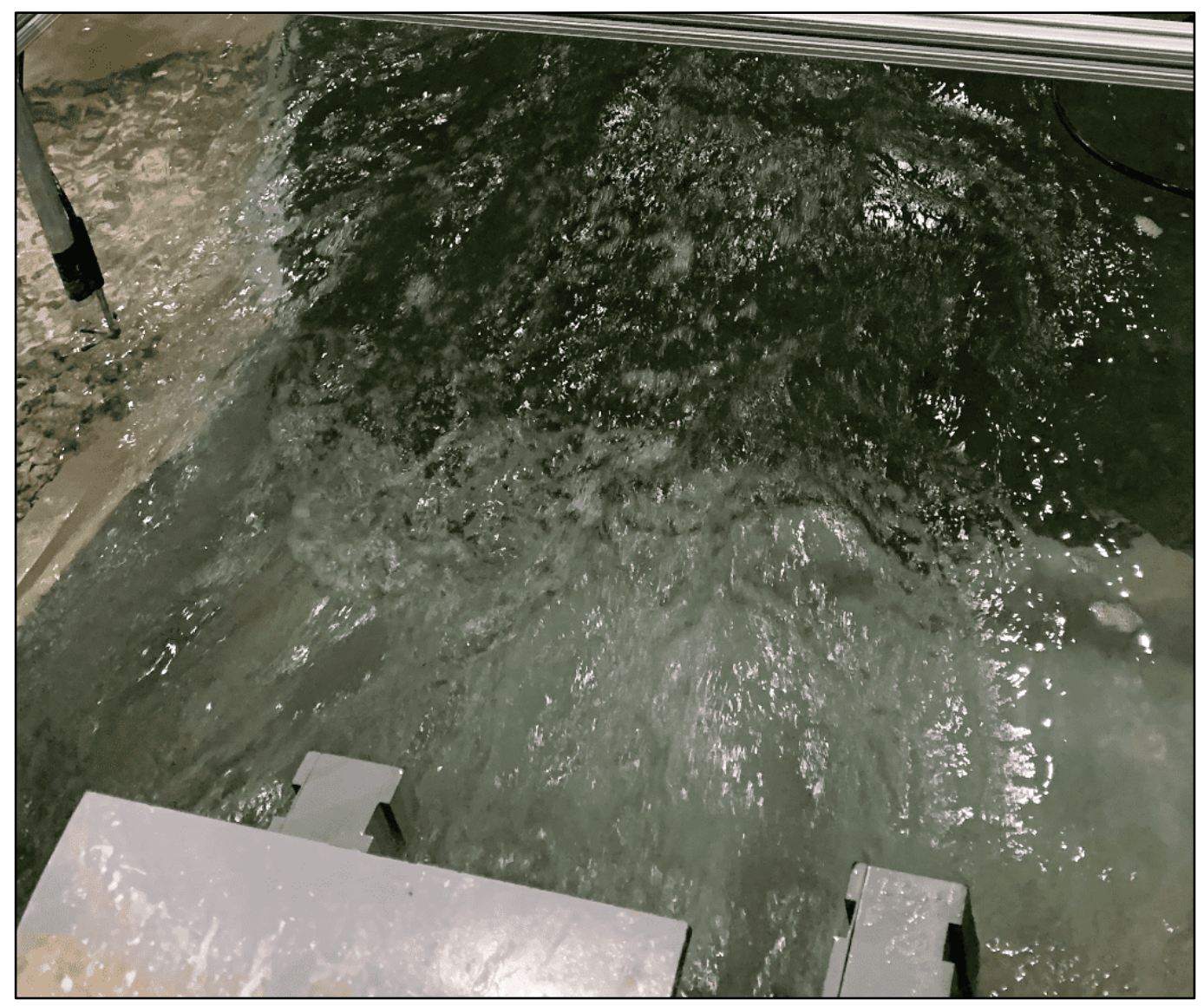

Exact locations where velocity measurements were taken for the Alternative 1 Design configuration can be seen in Figure 31. The "U" locations are for upstream Valeport measurements, and the " $\mathrm{D}$ " locations are for downstream ADV measurements. Figure 32 tabulates the measurements for the upstream velocities. Note that the Valeport measurements only record the magnitude of the velocities. 
Figure 31. Alternative 1 Design velocity measurement locations.

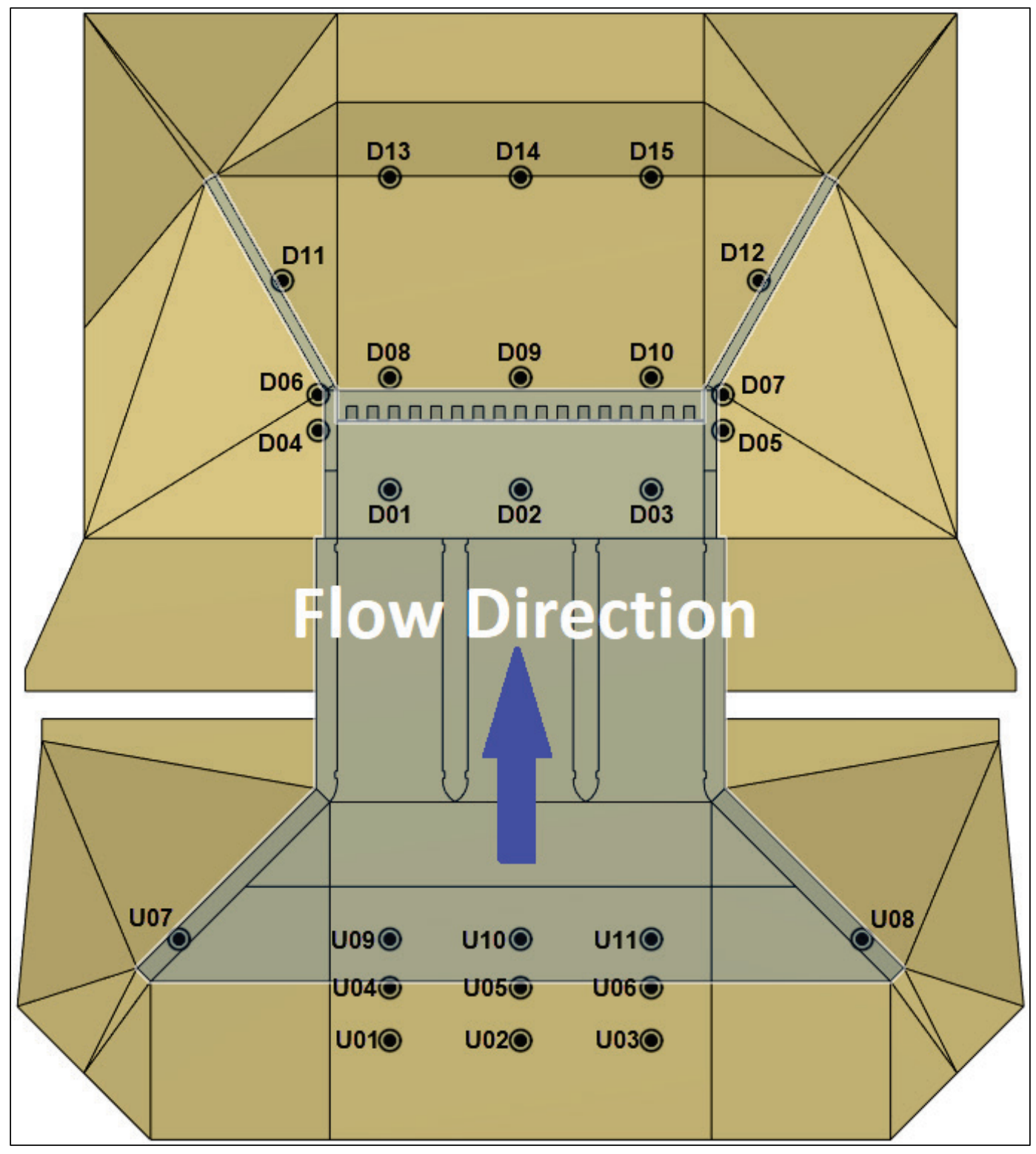


Figure 32. Upstream velocity results for Alternative 1 Design configuration.

\begin{tabular}{|c|c|c|c|c|c|c|c|c|c|}
\hline \multirow{2}{*}{ ID } & \multirow{2}{*}{$\begin{array}{l}\text { Depth } \\
\text { above } \\
\text { Bed (ft) }\end{array}$} & \multicolumn{3}{|c|}{ Location } & \multirow{2}{*}{\begin{tabular}{|c|}
$5 \%$ AEP \\
Velocity $(\mathrm{ft} / \mathrm{s})$ \\
\end{tabular}} & \multirow{2}{*}{\begin{tabular}{|l} 
Max. Ctr. Rel. \\
Velocity $(\mathrm{ft} / \mathrm{s})$ \\
\end{tabular}} & \multirow{2}{*}{$\begin{array}{c}60 \mathrm{kcfs} \\
\text { Releases } \\
\text { Velocity }(\mathrm{ft} / \mathrm{s})\end{array}$} & \multirow{2}{*}{\begin{tabular}{|l|} 
PMF Gates In \\
Velocity $(\mathrm{ft} / \mathrm{s})$ \\
\end{tabular}} & \multirow{2}{*}{\begin{tabular}{|c} 
PMF \\
Resiliency \\
Velocity (ft/s
\end{tabular}} \\
\hline & & $X(\mathrm{ft})$ & $Y(\mathrm{ft})$ & $\mathrm{Z}(\mathrm{ft})$ & & & & & \\
\hline \multirow{2}{*}{ U01 } & 3.3 & \multirow{2}{*}{-62} & \multirow{2}{*}{-154} & 876.3 & - & \begin{tabular}{|l|}
1.1 \\
\end{tabular} & 3.3 & 5.9 & 7.0 \\
\hline & 20 & & & 893.0 & - & 1.2 & - & - & - \\
\hline \multirow{2}{*}{ U02 } & 3.3 & \multirow{2}{*}{0} & \multirow{2}{*}{-154} & 876.3 & - & 1.1 & 3.5 & 7.6 & 7.0 \\
\hline & 20 & & & 893.0 & - & 1.1 & - & - & - \\
\hline \multirow{2}{*}{ U03 } & 3.3 & \multirow{2}{*}{62} & \multirow{2}{*}{-154} & 876.3 & - & 1.1 & 3.2 & 7.0 & 5.5 \\
\hline & 20 & & & 893.0 & - & 1.1 & - & - & - \\
\hline \multirow{2}{*}{ U04 } & 3.3 & \multirow{2}{*}{-62} & \multirow{2}{*}{-129} & 876.3 & 1.6 & 1.3 & 3.6 & 7.1 & 7.8 \\
\hline & 20 & & & 893.0 & - & 1.4 & - & - & - \\
\hline \multirow{2}{*}{ U05 } & 3.3 & \multirow{2}{*}{0} & \multirow{2}{*}{-129} & 876.3 & 1.5 & 1.7 & 4.1 & 8.9 & 7.7 \\
\hline & 20 & & & 893.0 & - & 1.8 & - & - & - \\
\hline \multirow{2}{*}{ U06 } & 3.3 & \multirow{2}{*}{62} & \multirow{2}{*}{-129} & 876.3 & 0.9 & 1.4 & 4.4 & 7.6 & 5.2 \\
\hline & 20 & & & 893.0 & - & 1.6 & - & - & - \\
\hline \multirow{2}{*}{ U07 } & 3.3 & \multirow{2}{*}{-162} & \multirow{2}{*}{-106} & 895.7 & - & 0.7 & - & 4.0 & - \\
\hline & 20 & & & 912.3 & - & - & - & - & - \\
\hline \multirow{2}{*}{ U08 } & 3.3 & \multirow{2}{*}{162} & \multirow{2}{*}{-106} & 895.7 & - & 0.4 & - & 4.1 & 2.0 \\
\hline & 20 & & & 912.3 & - & - & - & - & - \\
\hline & 3.3 & & & 876.3 & 1.7 & 1.5 & 4.9 & 8.2 & 9.6 \\
\hline 009 & 20 & -62 & -106 & 893.0 & 2.1 & 1.3 & 4.2 & 7.8 & 8.7 \\
\hline 1110 & 3.3 & 0 & -106 & 876.3 & 1.5 & 1.6 & 4.9 & 9.5 & 10.6 \\
\hline 010 & 20 & 0 & -106 & 893.0 & 1.5 & 1.8 & 5.2 & 9.6 & 9.7 \\
\hline & 3.3 & & & 876.3 & 1.1 & 1.5 & 4.3 & 8.3 & 5.4 \\
\hline U11 & 20 & 62 & -106 & 893.0 & 1.3 & 1.6 & 4.3 & 8.3 & 5.3 \\
\hline
\end{tabular}

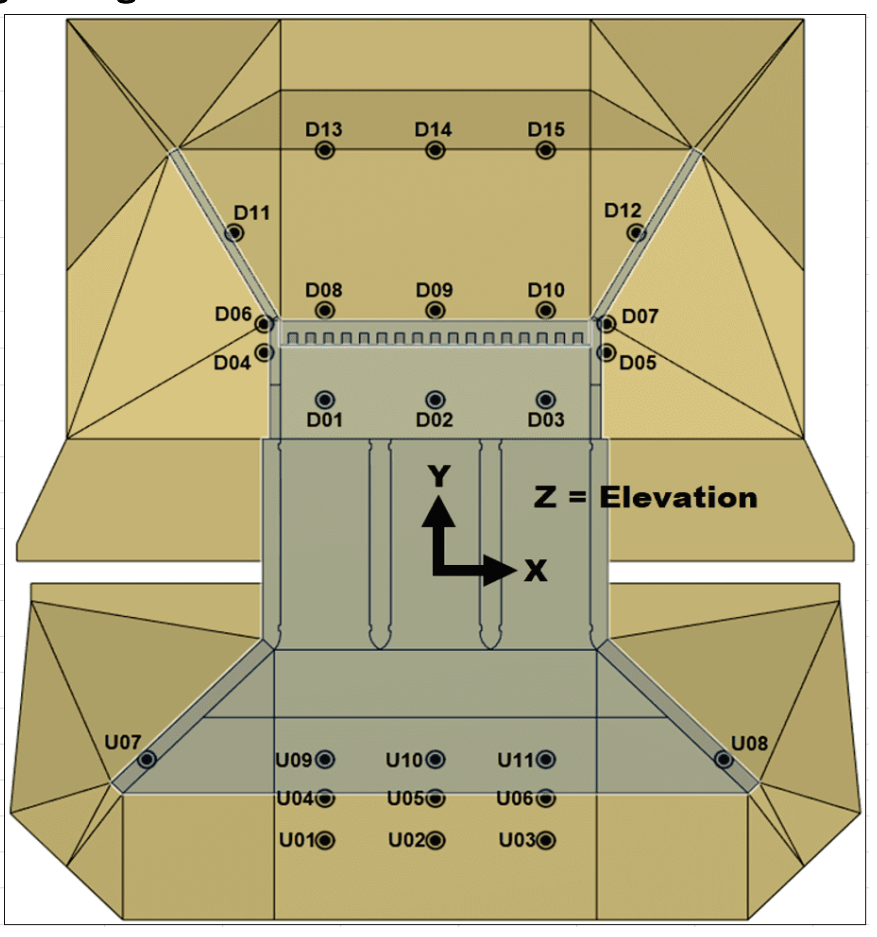


In Figure 33 through Figure 39, the velocity data collected using the ADV for the Alternative 1 Design testing are presented. These figures depict the velocity measurements at a prototype depth of $3.3 \mathrm{ft}$ above the channel bed. The designations $U, v$, and $w$ stand for the $\mathrm{x}-, \mathrm{y}-$, and $\mathrm{z}$-components of the velocity vectors, respectively. The vectors represent the $\mathrm{x}$ - and $y$-component of the velocity and are scaled to allow for better visualization. Each figure has a reference vector arrow. In each plot, the z-component of the velocity is denoted by $w$ and has a magnitude as shown on the figures (positive $\mathrm{w}$ is upwards from the bed). The $\mathrm{x}$-axis is from south to north (positive north), and the y-axis is east to west (positive west). In the maximum controlled releases test, the jet is moving at approximately $16 \mathrm{ft} / \mathrm{s}$ in the $\mathrm{x}$-direction of flow and slightly down in the z-direction. Immediately following the dentated end sill, the z-components of the velocities are positive indicating that the jet was propelled vertically into the water column. The same is true for the 60,000 cfs releases, PMF (gates out), and PMF events. Also note that for the PMF resiliency scenario, the descending right bank gate is completely closed such that no flow comes through the gate. 
Figure 33. Downstream velocity results for Alternative 1 Design testing.

\begin{tabular}{|c|c|c|c|c|c|c|c|c|c|c|c|c|c|c|c|c|c|c|c|c|c|}
\hline \multirow[b]{2}{*}{ ID } & \multirow{2}{*}{$\begin{array}{l}\text { Depth } \\
\text { above } \\
\text { Bed (ft) }\end{array}$} & \multicolumn{3}{|c|}{ Location } & \multicolumn{4}{|c|}{$5 \%$ AEP Velocity } & \multicolumn{4}{|c|}{ Max. Ctrl. Rel. Velocity } & \multicolumn{4}{|c|}{60 kcfs Releases Velocity } & & \multirow[b]{4}{*}{ D13 } & \multirow{4}{*}{ D14 } & \multirow[b]{4}{*}{ D15 } & \\
\hline & & \multirow{3}{*}{$\begin{array}{c}X(f t) \\
-62\end{array}$} & $Y(f t)$ & $z(\mathrm{ft})$ & $u(f t / s)$ & $v(f t / s)$ & $\mathrm{w}(\mathrm{ft} / \mathrm{s})$ & $\begin{array}{l}\text { Total } \\
(\mathrm{ft} / \mathrm{s})\end{array}$ & $u(f t / s)$ & $\mathrm{v}(\mathrm{ft} / \mathrm{s})$ & $w(\mathrm{ft} / \mathrm{s})$ & $\begin{array}{l}\text { Total } \\
(\mathrm{ft} / \mathrm{s})\end{array}$ & $\mathrm{u}(\mathrm{ft} / \mathrm{s})$ & $v(f t / s)$ & $w(f t / s)$ & $\begin{array}{l}\text { Total } \\
\text { (ft/sts }\end{array}$ & & & & & \\
\hline & 3.3 & & & 873.4 & 2.0 & -0.2 & -0.2 & & 16.1 & -0.6 & -1.2 & 16.1 & 22.3 & 1.6 & 0.8 & 22.4 & & & & & \\
\hline D01 & 20 & & 107 & 890.1 & & & & & & & - & & & & & & & & & & \\
\hline & 3.3 & & & 873.4 & 1.8 & 0.0 & -0.1 & 1.8 & 15.3 & -1.6 & -1.4 & 15.4 & 23.5 & 1.8 & -0.9 & 23.6 & & & & & \\
\hline D02 & 20 & 0 & 107 & 890.1 & & & - & & & & $-a_{0}$ & & & & & & & & & & \\
\hline D03 & 3.3 & & & 873.4 & 1.6 & 0.5 & -0.1 & 1.7 & 15.4 & -1.9 & -1.2 & 15.6 & 23.1 & 2.0 & 0.1 & 23.2 & & & & & \\
\hline D03 & 20 & 62 & 107 & 890.1 & - & - & - & - & - & - & - & - & - & - & - & & & & & & \\
\hline 004 & 3.3 & -96 & 135 & 905.6 & - & - & - & - & - & - & - & - & 1.7 & -2.7 & -0.1 & 3.2 & & & & & \\
\hline D04 & 20 & -96 & 135 & 922.2 & - & - & - & - & - & - & - & - & - & - & - & - & & 0 & Dog & D10 & \\
\hline D05 & 3.3 & 96 & 135 & 905.6 & - & - & - & - & 1.4 & 2.6 & 0.3 & 3.0 & -3.0 & 1.2 & -4.1 & 5.2 & & & & плпппип & \\
\hline 005 & 20 & 96 & 135 & 922.2 & - & - & - & - & & & & & & & & & & & & & \\
\hline 006 & 3.3 & -96 & 152 & 900.8 & - & - & - & - & 0.3 & -2.3 & -0.1 & 2.4 & 1.8 & -2.7 & -0.1 & 3.3 & & & & & \\
\hline 006 & 20 & -96 & 152 & 917.5 & - & - & - & - & - & - & - & - & - & - & - & - & & DO & D02 & D03 & \\
\hline 007 & 3.3 & 96 & 152 & 900.8 & - & - & - & - & 0.5 & 2.1 & 0.3 & 2.2 & 0.6 & 2.2 & -0.8 & 2.5 & & & & & \\
\hline tor & 20 & 96 & 152 & 917.5 & - & & - & - & & & & & & & & & & & $\mathbf{Y}$ & & \\
\hline & 3.3 & & & 869.3 & 0.8 & -0.3 & -0.3 & 0.9 & 1.2 & -0.7 & 0.9 & 1.7 & -1.3 & -0.4 & 0.1 & 1.3 & & & & $\mathbf{Z}=$ & $=$ Elevation \\
\hline D08 & 20 & -62 & 160 & 886.0 & & & - & & & & & & & & & & & & & & \\
\hline & 3.3 & 0 & & 869.3 & 0.6 & -0.1 & -0.1 & 0.6 & -2.0 & 0.1 & 0.1 & 2.0 & -0.6 & 0.1 & -0.2 & 0.7 & & & & & \\
\hline D09 & 20 & 0 & 160 & 886.0 & 2.0 & -0.3 & -0.1 & 2.0 & 6.4 & 1.4 & 4.7 & 8.0 & 16.5 & 4.7 & 2.9 & 17.4 & & & & $\mathbf{x}$ & \\
\hline$D 10$ & 3.3 & & 169 & 869.3 & 0.5 & 0.0 & 0.0 & 0.5 & -2.9 & 2.7 & 0.2 & 4.0 & -0.4 & 1.3 & -0.1 & 1.4 & & & & & \\
\hline D10 & 20 & 62 & 160 & 886.0 & - & - & - & - & - & - & - & - & - & - & - & - & & & \} & 3 & \\
\hline & 3.3 & -113 & 206 & 870.8 & - & - & - & - & -1.5 & 0.7 & 0.4 & 1.7 & -1.9 & 0.6 & 0.7 & 2.1 & & & & & \\
\hline D11 & 20 & -113 & 206 & 887.5 & - & - & - & - & & & & & & & & & & & & & \\
\hline D12 & 3.3 & & 206 & 870.8 & - & - & - & - & -2.5 & 2.5 & -0.9 & 3.7 & -1.3 & 0.2 & 0.2 & 1.3 & & & & & \\
\hline $\mathrm{D}_{12}$ & 20 & 113 & 206 & 887.5 & - & - & - & - & & & & & & & & & & & & (1498 > & \\
\hline & 3.3 & & & 869.3 & - & - & - & - & 1.7 & 0.3 & -0.2 & 1.7 & 6.0 & 2.0 & 0.9 & 6.4 & & 0090 & U100 & 0110 & \\
\hline D13 & 20 & -62 & 255 & 886.0 & - & - & - & - & - & & & & & & & & & v040 & 0050 & v060 & \\
\hline D14 & 3.3 & 0 & 255 & 869.3 & - & - & - & - & 0.8 & 0.3 & 0.0 & 0.8 & 6.2 & 1.3 & 0.7 & 6.4 & & v010 & u020 & บ030 & \\
\hline & 20 & 0 & & 886.0 & - & - & - & - & 1.6 & 0.8 & 0.4 & 1.8 & 7.5 & 2.4 & 0.5 & 7.9 & & & & & \\
\hline & 3.3 & & & 869.3 & - & - & - & - & \begin{tabular}{|c|}
-1.1 \\
\end{tabular} & 1.1 & -0.3 & 1.6 & 4.9 & 3.0 & 0.1 & 5.7 & & & & & \\
\hline D15 & 20 & 62 & 255 & 886.0 & - & . & - & - & & & - & & & & & & & & & & \\
\hline
\end{tabular}


Figure 34. Downstream velocity results for Alternative 1 Design testing.

\begin{tabular}{|c|c|c|c|c|c|c|c|c|c|c|c|c|}
\hline \multirow[b]{2}{*}{ ID } & \multirow{2}{*}{$\begin{array}{l}\text { Depth } \\
\text { above } \\
\text { Bed (ft) }\end{array}$} & \multicolumn{3}{|c|}{ Location } & \multicolumn{4}{|c|}{ PMF Gates In Velocity } & \multicolumn{4}{|c|}{ PMF Resiliency Velocity } \\
\hline & & $X(\mathrm{ft})$ & $Y(\mathrm{ft})$ & $Z(\mathrm{ft})$ & $u(f t / s)$ & $v(\mathrm{ft} / \mathrm{s})$ & $w(f t / s)$ & $\begin{array}{l}\text { Total } \\
(\mathrm{ft} / \mathrm{s})\end{array}$ & $u(f t / s)$ & $v(\mathrm{ft} / \mathrm{s})$ & $w(f t / s)$ & $\begin{array}{l}\text { Total } \\
(\mathrm{ft} / \mathrm{s})\end{array}$ \\
\hline \multirow{2}{*}{ D01 } & 3.3 & \multirow{2}{*}{-62} & \multirow{2}{*}{107} & 873.4 & 19.6 & -2.6 & -1.2 & 19.8 & 24.6 & -1.6 & -2.5 & 24.8 \\
\hline & 20 & & & 890.1 & - & - & - & - & - & - & - & - \\
\hline \multirow{2}{*}{ D02 } & 3.3 & \multirow{2}{*}{0} & \multirow{2}{*}{107} & 873.4 & 19.8 & -2.1 & -0.9 & 20.0 & 24.0 & 4.2 & -2.4 & 24.5 \\
\hline & 20 & & & 890.1 & - & - & - & - & - & - & - & - \\
\hline \multirow{2}{*}{ D03 } & 3.3 & \multirow{2}{*}{62} & \multirow{2}{*}{107} & 873.4 & 19.8 & -0.5 & -1.1 & 19.9 & -1.5 & 0.3 & -0.2 & 1.5 \\
\hline & 20 & & & 890.1 & - & - & - & - & - & - & - & - \\
\hline \multirow{2}{*}{ D04 } & 3.3 & \multirow{2}{*}{-96} & \multirow{2}{*}{135} & 905.6 & 0.9 & -1.2 & 0.2 & 1.5 & 0.8 & -1.1 & 0.4 & 1.4 \\
\hline & 20 & & & 922.2 & - & - & - & - & - & - & - & - \\
\hline \multirow{2}{*}{ D05 } & 3.3 & \multirow{2}{*}{96} & \multirow{2}{*}{135} & 905.6 & 0.0 & 0.0 & 0.0 & 0.0 & -0.6 & 0.2 & 0.2 & 0.7 \\
\hline & 20 & & & 922.2 & - & - & - & - & - & - & - & - \\
\hline \multirow{2}{*}{ D06 } & 3.3 & \multirow{2}{*}{-96} & \multirow{2}{*}{152} & 900.8 & 2.4 & -2.1 & -0.2 & 3.2 & 2.1 & -2.4 & -0.3 & 3.2 \\
\hline & 20 & & & 917.5 & - & - & - & - & - & - & - & - \\
\hline \multirow{2}{*}{ D07 } & 3.3 & \multirow{2}{*}{96} & \multirow{2}{*}{152} & 900.8 & 0.2 & 1.2 & -0.8 & 1.5 & -0.4 & 1.2 & 0.0 & 1.2 \\
\hline & 20 & & & 917.5 & - & - & - & - & - & - & - & - \\
\hline \multirow{2}{*}{ D08 } & 3.3 & & & 869.3 & 1.8 & -0.4 & 0.8 & 2.1 & 2.1 & -0.8 & 1.8 & 2.9 \\
\hline & 20 & -62 & 160 & 886.0 & - & - & - & - & - & - & - & - \\
\hline & 3.3 & & & 869.3 & 1.7 & -0.4 & -0.6 & 1.9 & 6.9 & 2.1 & 1.8 & 7.5 \\
\hline D09 & 20 & 0 & 160 & 886.0 & 19.5 & -0.2 & 1.3 & 19.6 & 24.8 & 1.2 & 1.1 & 24.8 \\
\hline & 3.3 & & & 869.3 & 5.1 & 0.0 & -1.5 & 5.4 & -1.5 & 0.5 & 0.1 & 1.5 \\
\hline D10 & 20 & 62 & 160 & 886.0 & - & - & - & - & - & - & - & - \\
\hline & 3.3 & -13 & 200 & 870.8 & 2.1 & 3.9 & -4.4 & 6.3 & 7.1 & 1.8 & -0.1 & 7.3 \\
\hline D11 & 20 & -113 & 200 & 887.5 & - & - & - & - & - & - & - & - \\
\hline & 3.3 & & & 870.8 & 2.4 & -1.0 & -0.3 & 2.6 & -1.5 & 0.8 & -0.3 & 1.7 \\
\hline D12 & 20 & 113 & 206 & 887.5 & - & - & - & - & - & - & - & - \\
\hline & 3.3 & & & 869.3 & 11.7 & -2.8 & 1.3 & 12.1 & 15.8 & 2.7 & -1.0 & 16.1 \\
\hline D13 & 20 & -62 & 255 & 886.0 & - & - & - & - & - & - & - & - \\
\hline & 3.3 & & & 869.3 & 10.1 & -3.8 & 1.5 & 11.0 & $\begin{array}{ll}14.7 \\
\end{array}$ & 3.6 & -1.3 & 15.2 \\
\hline D14 & 20 & 0 & 255 & 886.0 & 15.5 & -2.5 & 1.3 & 15.8 & 21.1 & 3.5 & -0.5 & 21.4 \\
\hline & 3.3 & & & 869.3 & 12.5 & -4.5 & -0.3 & 13.3 & -1.5 & 0.4 & -0.2 & 1.5 \\
\hline D15 & 20 & 62 & 255 & 886.0 & - & - & - & - & - & - & - & - \\
\hline
\end{tabular}

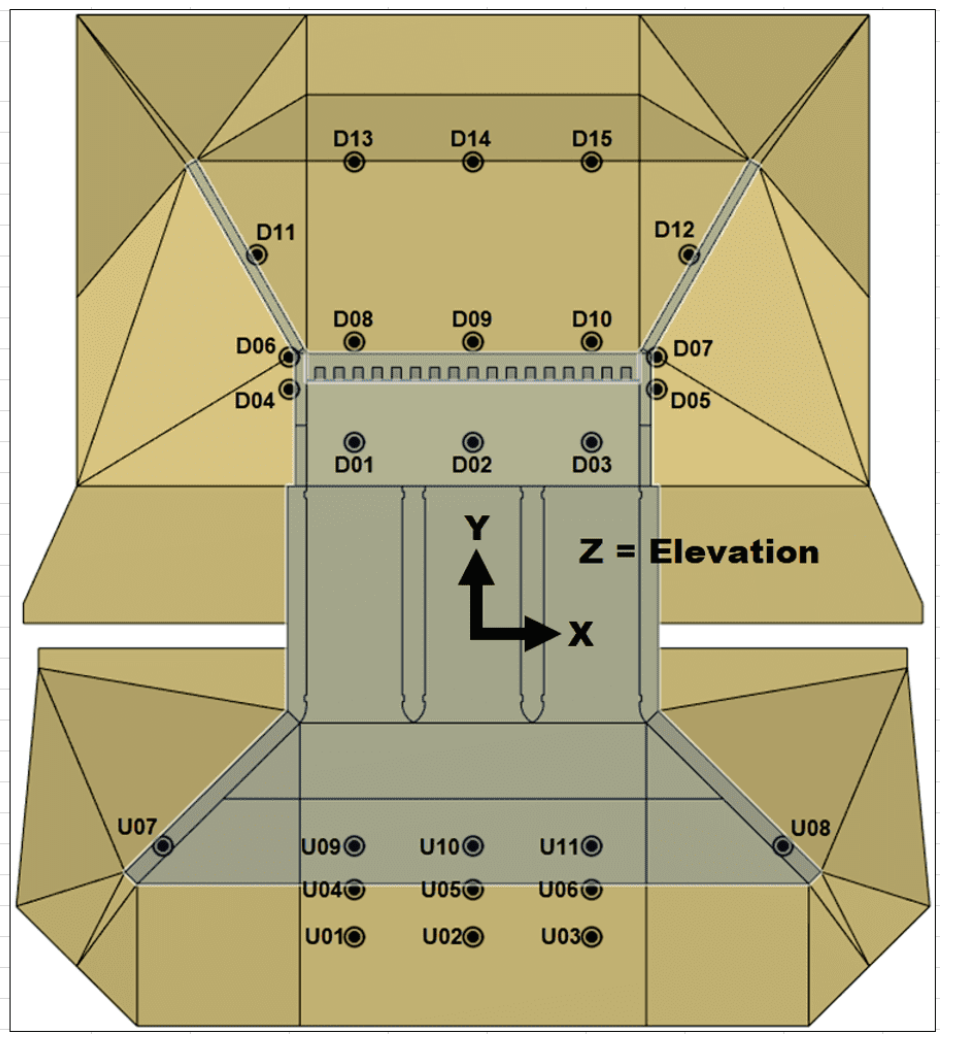


Figure 35. Alternative 1 Design 5\% AEP event ADV-derived velocity vectors.

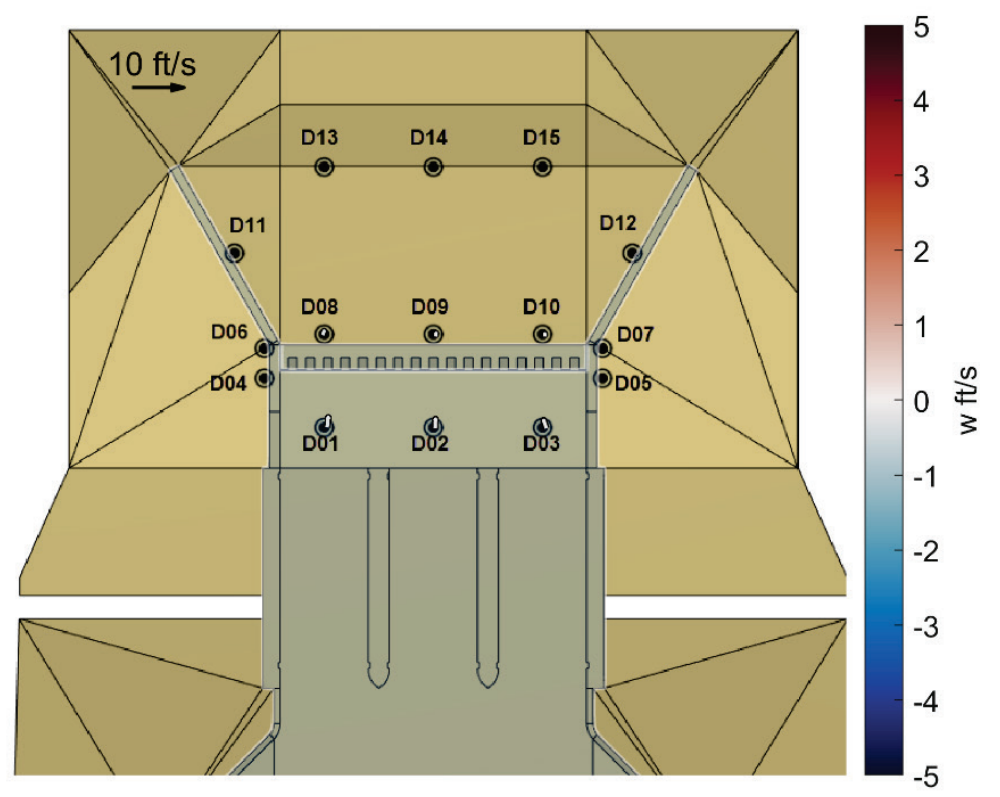

Figure 36. Alternative 1 Design Maximum Controlled Releases ADV-derived velocity vectors.

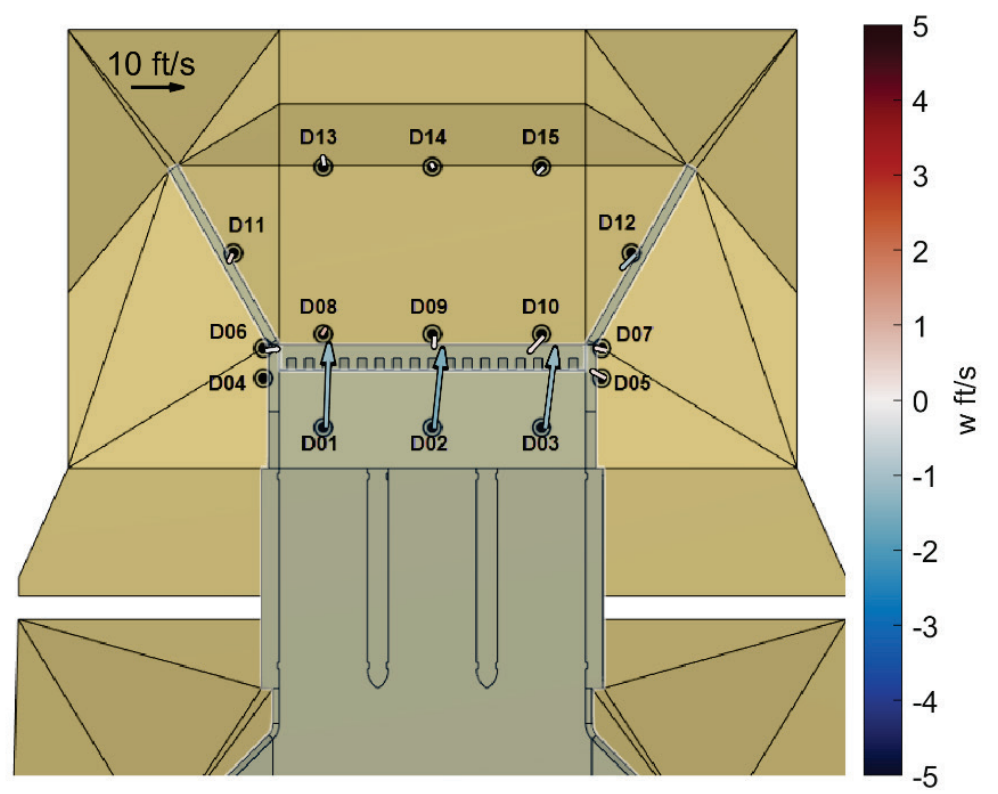


Figure 37. Alternative 1 Design 60,000 cfs releases ADV-derived velocity vectors.

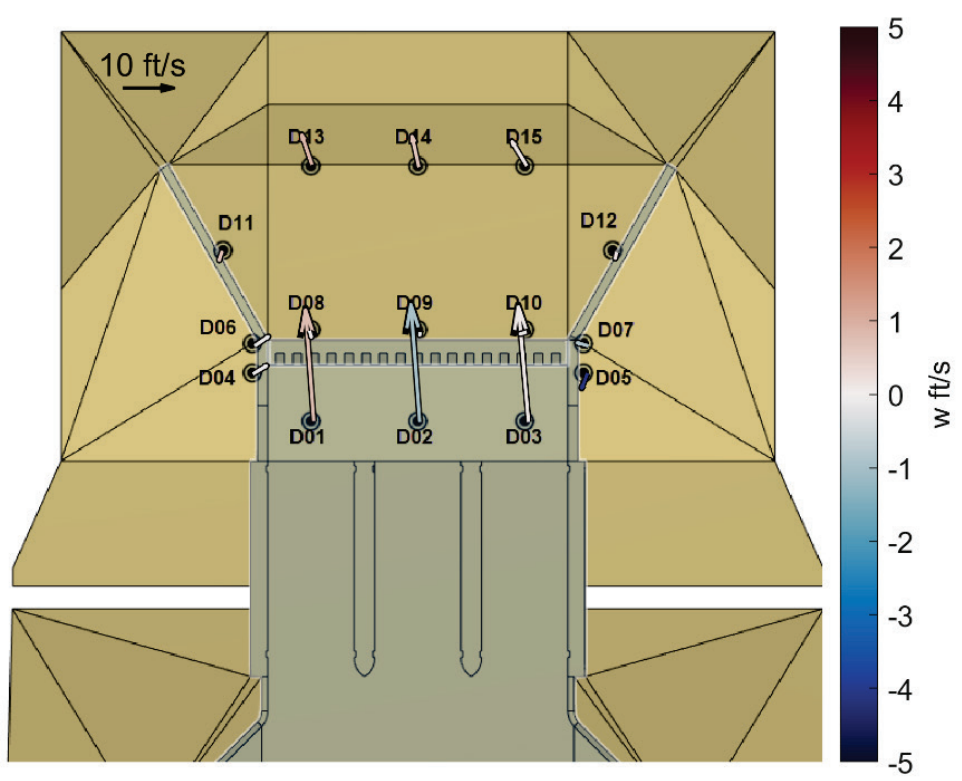

Figure 38. Alternative 1 Design PMF ADV-derived velocity vectors.

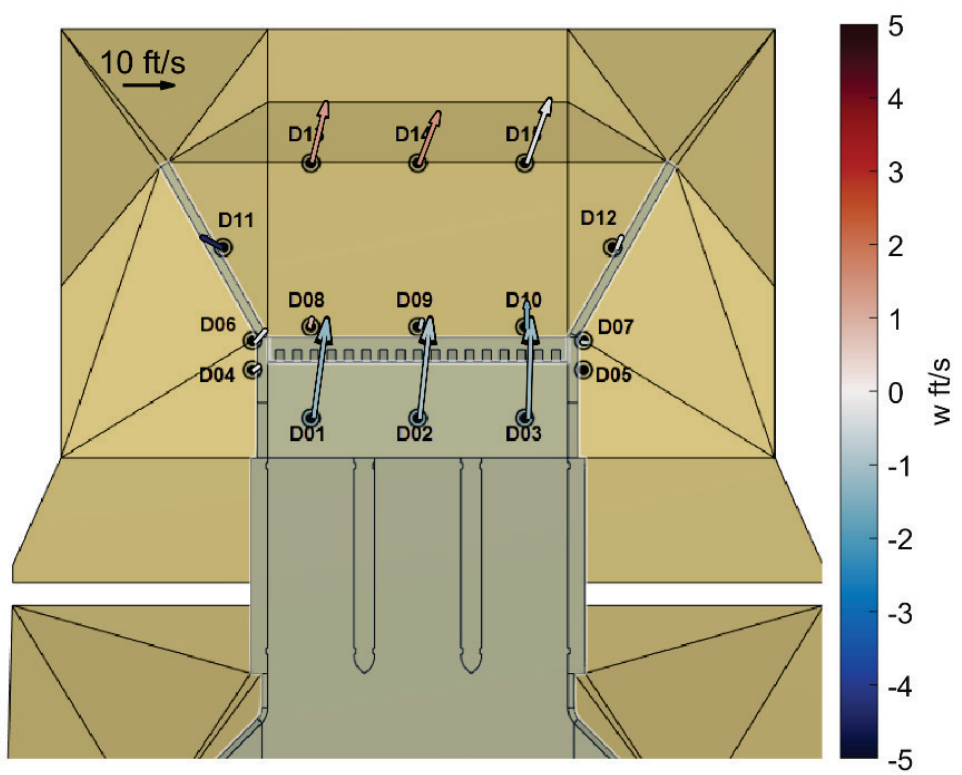


Figure 39. Alternative 1 Design PMF resiliency ADV-derived velocity vectors.

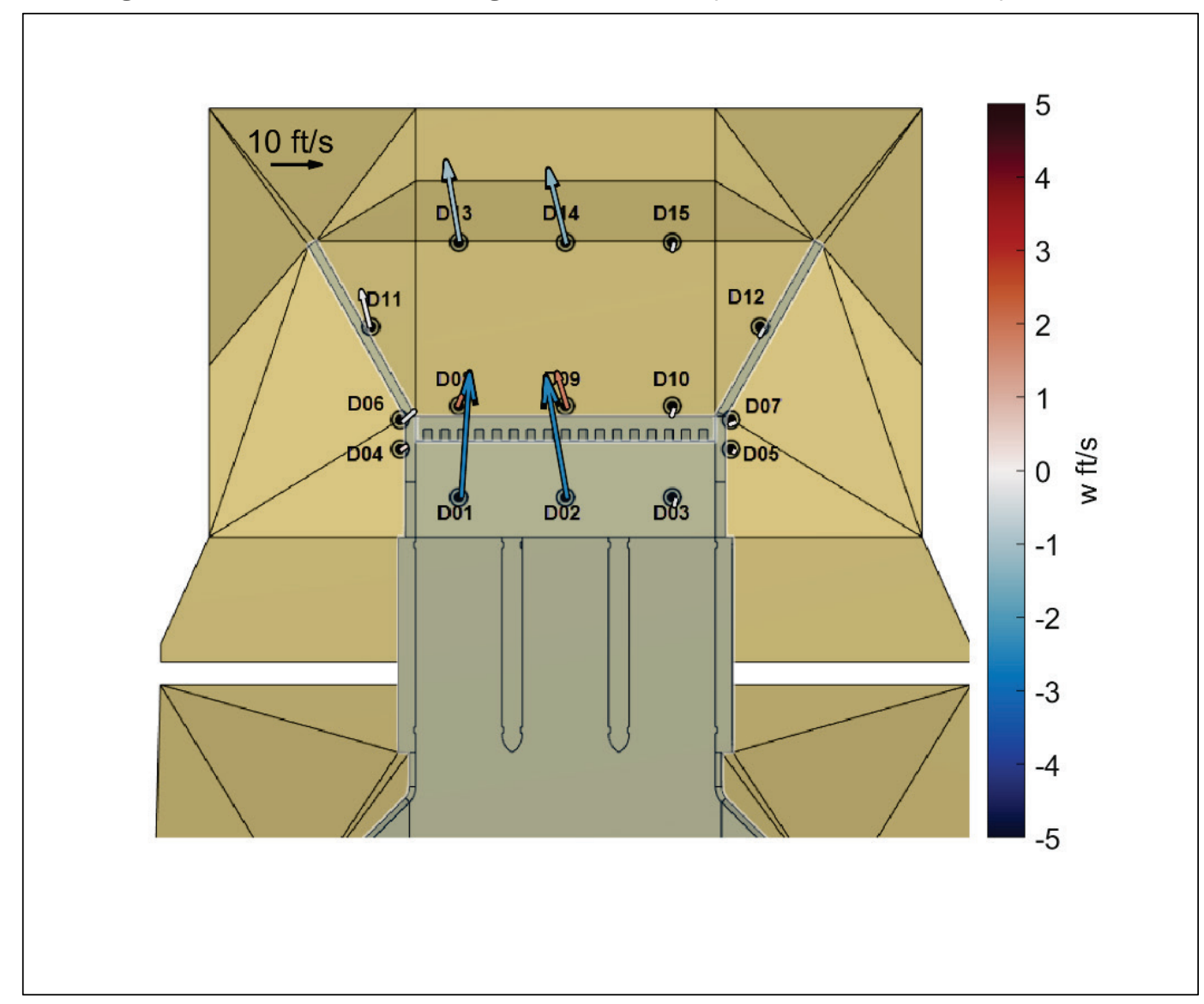

\subsubsection{Alternative 1 Design summary}

At the conclusion of the Alternative 1 Design testing, it was confirmed that the structure possessed the capability to pass the PMF with the modified geometry (similar to the test performed on the Base Design in Section 4.1.1). This was confirmed by staying at or below the maximum allowable headwater elevation of $923.5 \mathrm{ft}$ during the PMF (gates open) testing and by the need to have the gates in the water during the PMF test to produce a pool of $923.5 \mathrm{ft}$. It was also confirmed that the sloped stilling basin insert and dentated end sill performed correctly since the velocity results demonstrate the flow jet is directed upward into the water column. The modified stilling basin walls were also effective in that the scaled R470 riprap did not move in the near vicinity of the walls (visual inspection after tests). 


\subsection{Alternative 2}

\subsubsection{Alternative 2 Design modifications}

Alternative 2 incorporates the same design specifications as Alternative 1, except for the addition of a new approach wall configuration and revised riprap geometry. The original approach walls were left in place since their position outside the new approach walls did not affect flow conditions approaching and through the structure. The upslope of the riprap area was also changed from $3 \mathrm{H}: 1 \mathrm{~V}$ to $5 \mathrm{H}: 1 \mathrm{~V}$, but the toe of the slope remained at $100 \mathrm{ft}$ downstream of the end sill. The flat area just downstream of the dentated end sill and in between the retaining walls remained at an elevation of $866 \mathrm{ft}$. All of these details can be seen in Figure 40 through Figure 42.

Figure 40. Alternative 2 Design modifications.

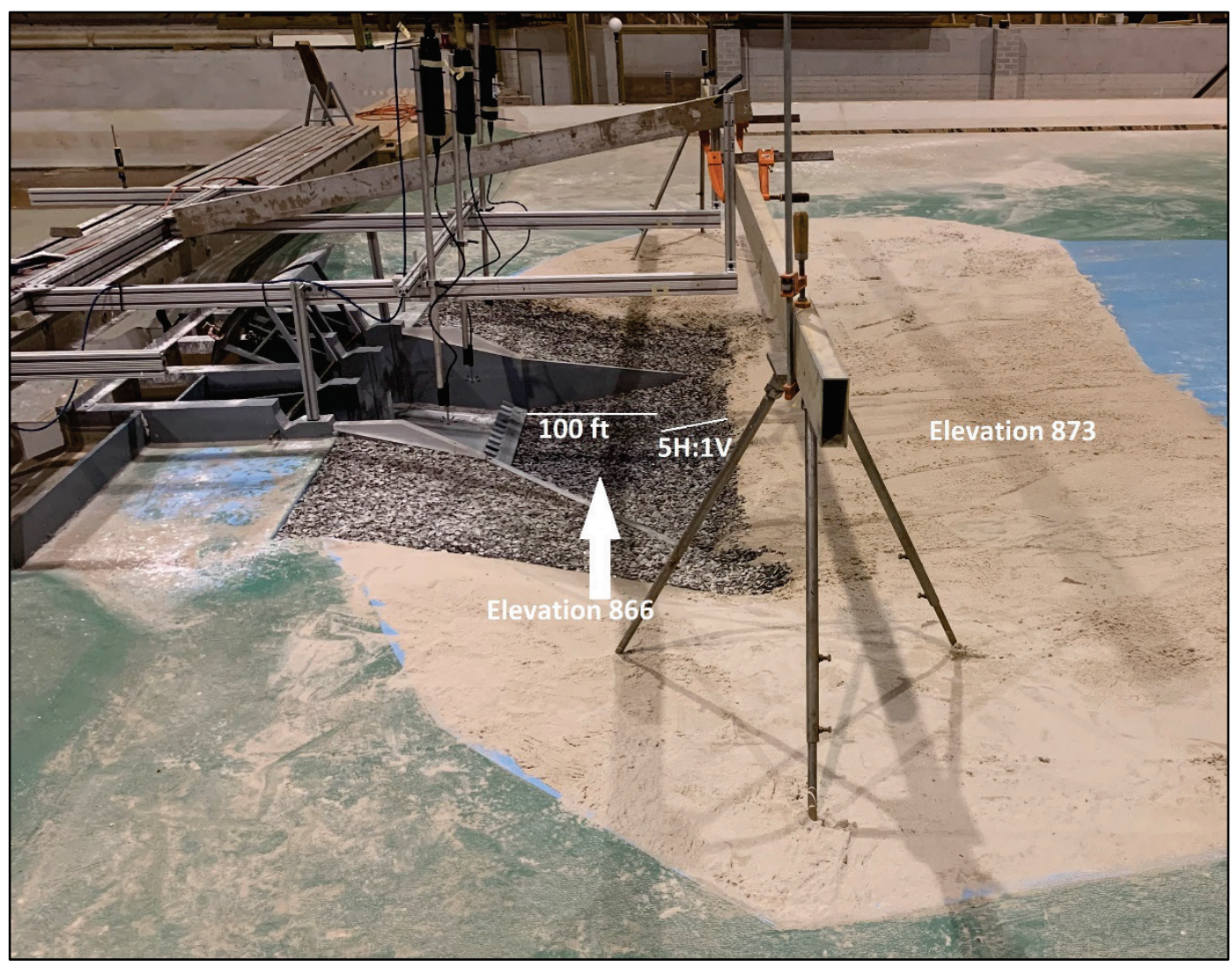


Figure 41. Modified approach wall configuration photos.

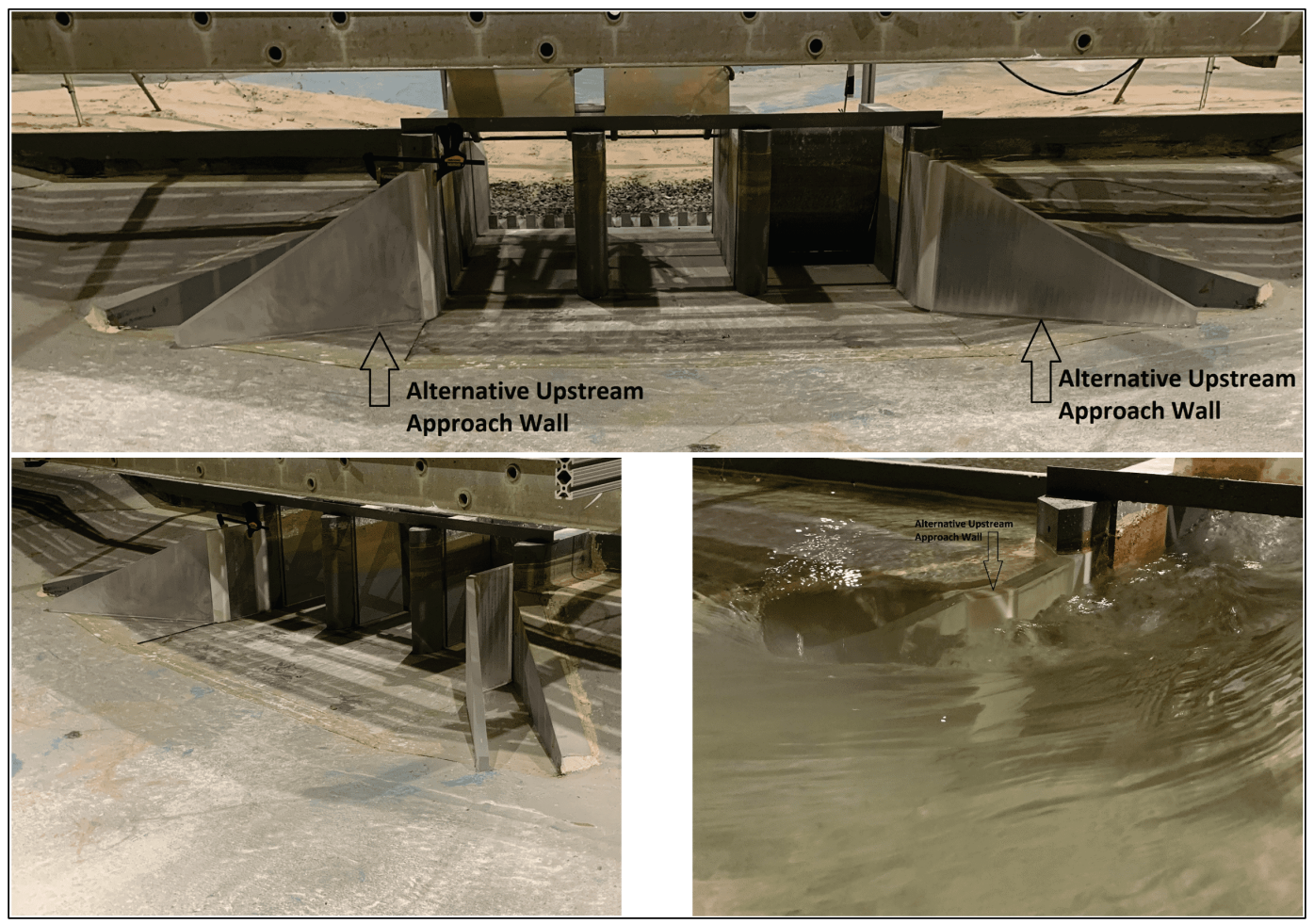

Figure 42. Modified approach wall configuration dimensions.

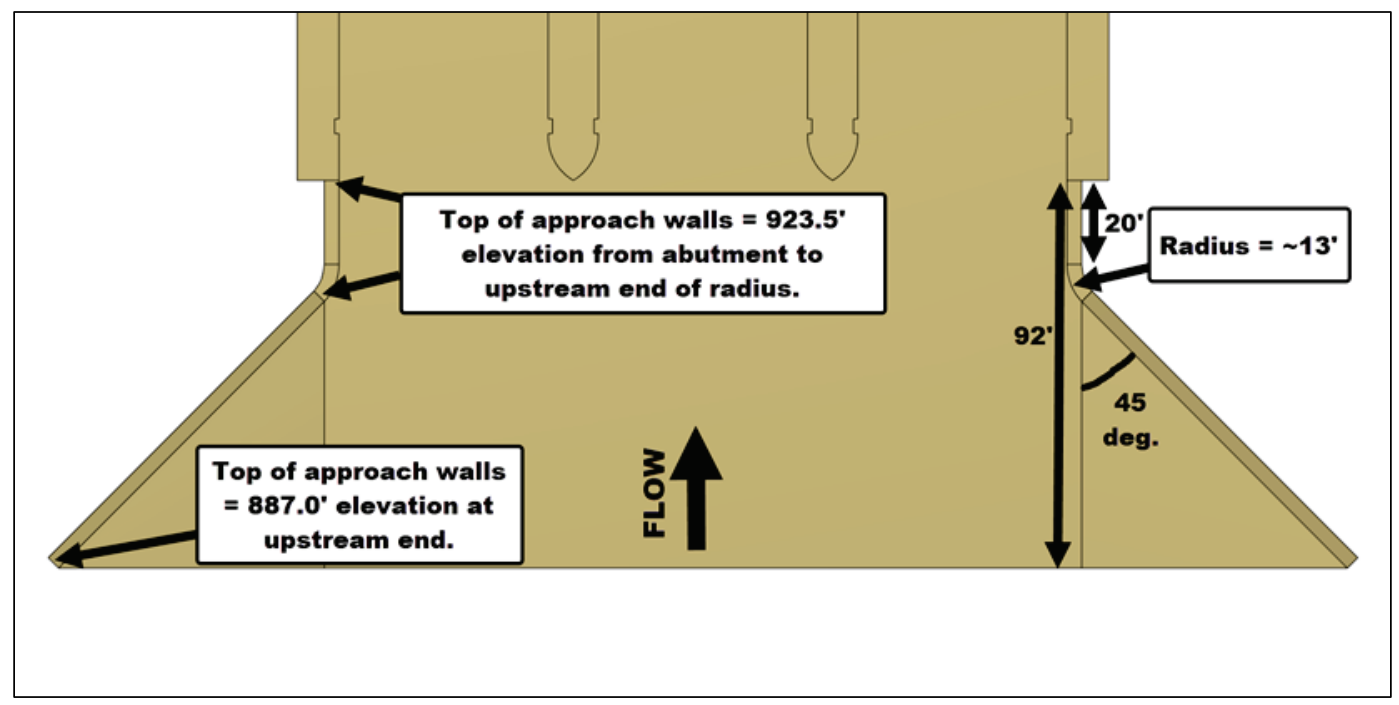

\subsubsection{Alternative 2 Design testing}

Table 11 details the simulations run for the Alternative 2 Design. Note that although LiDAR data was obtained for many of the tests, only the Maximum Controlled Releases LiDAR results are being reported for the reasons outlined in Section 4.2.2. 
Table 11. Alternative 2 Design testing boundary condition data.

\begin{tabular}{|c|c|c|c|c|c|c|c|}
\hline Scenario & $\begin{array}{l}\text { Target } \\
\text { Headwater } \\
\text { Elevation } \\
\text { (ft) }\end{array}$ & $\begin{array}{l}\text { Target } \\
\text { Tailwater } \\
\text { Elevation } \\
\text { (ft) }\end{array}$ & $\begin{array}{l}\text { Target } \\
\text { Discharge } \\
\text { (cfs) }\end{array}$ & $\begin{array}{l}\text { Model Headwater } \\
\text { Elevation }{ }^{1}(\mathrm{ft})\end{array}$ & $\begin{array}{l}\text { Model Tailwater } \\
\text { Elevation }^{2}(\mathrm{ft})\end{array}$ & $\begin{array}{c}\text { Model Discharge }{ }^{3} \\
\text { (cfs) }\end{array}$ & $\begin{array}{c}\text { Model Gate } \\
\text { Opening Height } \\
\text { (ft) }\end{array}$ \\
\hline $5 \%$ AEP Event & - & 910.1 & 10,700 & $910.2^{4}$ & 910.1 & 10,500 & Open \\
\hline 1\% AEP Event & 921.0 & 911.1 & 14,000 & 921.0 & 911.1 & 13,700 & 4.6 \\
\hline $0.2 \%$ AEP Event & 922.5 & 912.9 & 18,000 & 922.7 & 913.0 & 17,800 & 6.3 \\
\hline $\begin{array}{l}\text { Maximum Controlled } \\
\text { Releases }\end{array}$ & 923.5 & 912.9 & 18,000 & 923.3 & 913.0 & 17,500 & 6.2 \\
\hline 60,000 cfs Releases & 923.5 & 915.6 & 60,000 & 923.2 & 915.7 & 59,800 & 23.2 \\
\hline PMF & 923.5 & 917.5 & 104,300 & 923.6 & 918.0 & 104,200 & 36.1 \\
\hline $\begin{array}{c}\text { PMF Resiliency } \\
\text { (Descending Right Bank } \\
\text { Gate Completely Closed) }\end{array}$ & - & 917.0 & 89,700 & 924.6 & 917.1 & 89,100 & $\begin{array}{l}\text { Open (Descending } \\
\text { left bank and } \\
\text { middle) }\end{array}$ \\
\hline
\end{tabular}

1. Reported headwater elevations were the average of gages 2 and 4 over the course of the test. These gages were chosen to avoid the potential impact of drawdown effects located closer to the structure.

2. Reported tailwater elevations are from the average of measurements taken at gage 13 .

3. Flow measurements were averaged over the course of the experiment.

4. Reported headwater elevation is from the average of measurements taken at gage 5 (gages 2 and 4 were out of bank and flow was only in channel during this simulation/event). 
Velocity measurements were taken at the locations shown in Figure 43. Similar to Alternative 1 Design testing, ADVs were used for the locations downstream of the gates, and the Valeport was used for the locations upstream of the gates. Upstream velocity measurement results are shown in Figure 44. Note that the new upstream approach wall configuration had a minor impact on the approach velocities compared to the Alternative 1 Design upstream velocities.

Figure 43. Alternative 2 Design velocity measurement locations.

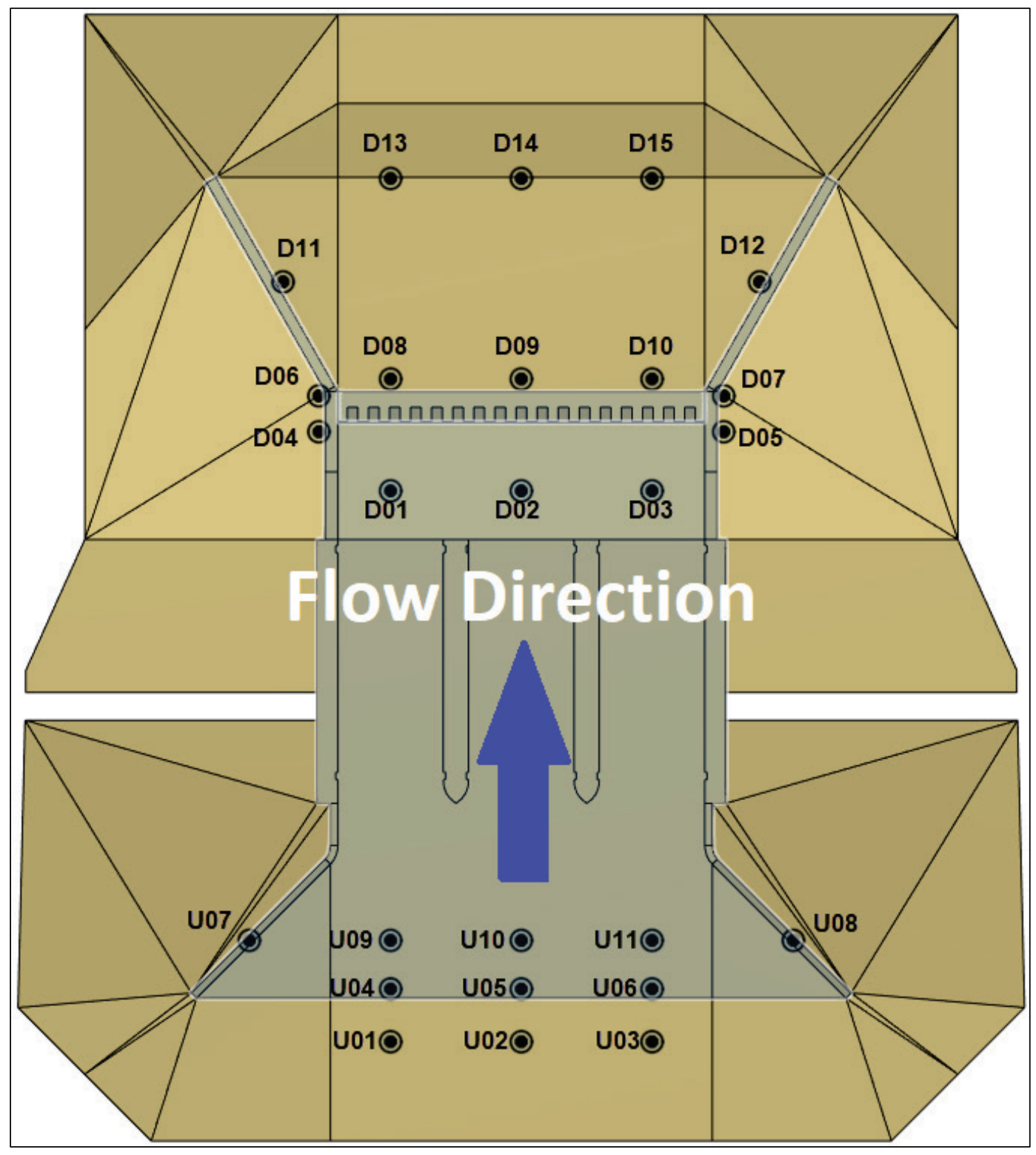


Figure 44. Upstream velocity results for Alternative 2 Design configuration.

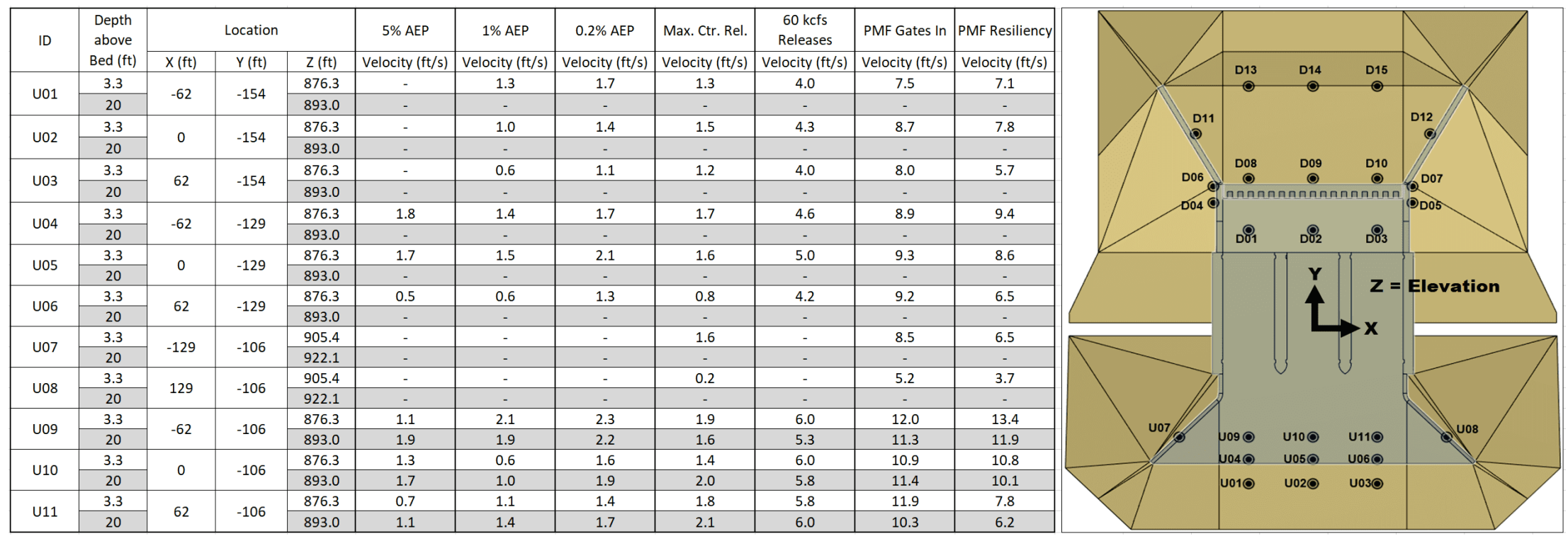


In Figure 45 through Figure 54, the velocity data collected using ADVs for the Alternative 2 Design are presented. Similar to the velocity

measurements from the Alternative 1 Design velocity data, the jet is forced upwards into the water column just past the dentated end sill. The new $5 \mathrm{H}: 1 \mathrm{~V}$ upslope face of the scaled riprap does not appear to have any major effects on the corresponding velocities compared to the $3 \mathrm{H}: 1 \mathrm{~V}$ slope. 
Figure 45. ADV velocity results for Alternative 2 Design testing.

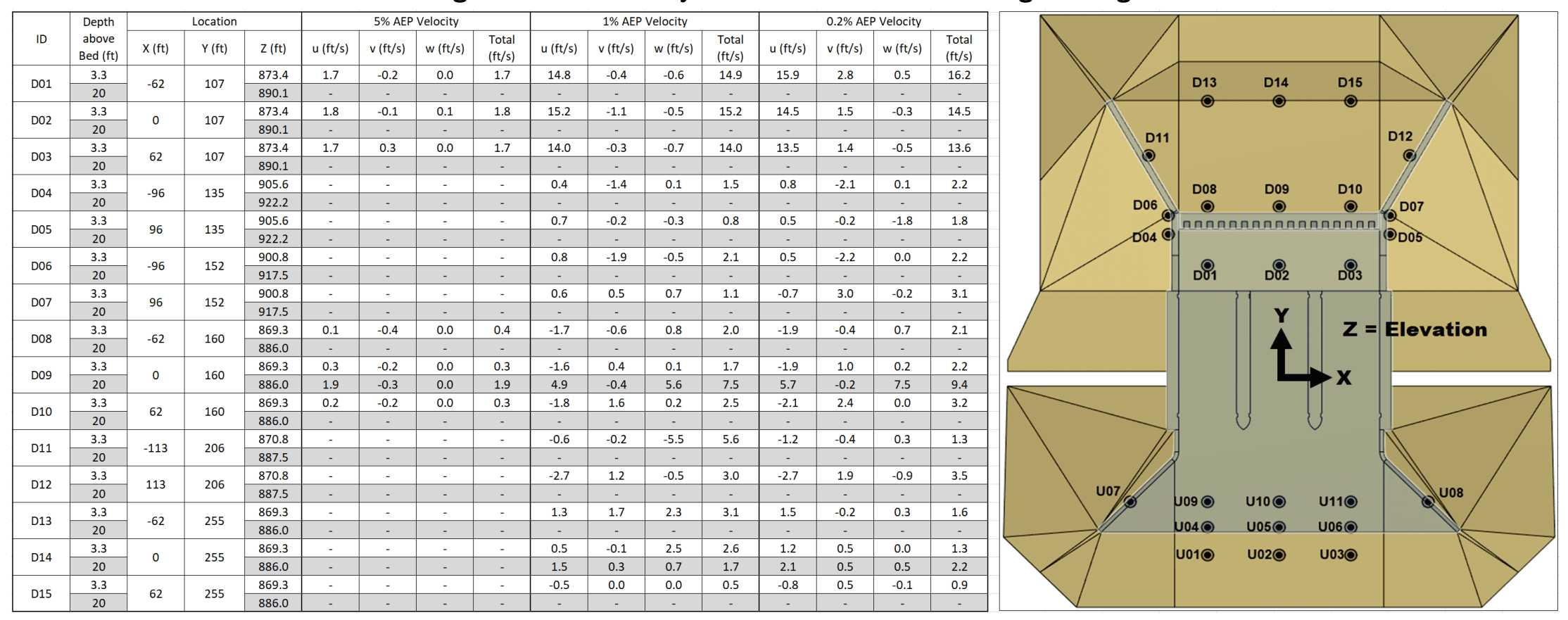


Figure 46. ADV velocity results for Alternative 2 Design testing.

\begin{tabular}{|c|c|c|c|c|c|c|c|c|c|c|c|c|}
\hline \multirow[b]{2}{*}{ ID } & \multirow{2}{*}{$\begin{array}{l}\text { Depth } \\
\text { above } \\
\text { Bed (ft) }\end{array}$} & \multicolumn{3}{|c|}{ Location } & \multicolumn{4}{|c|}{ Max. Ctrl. Rel. Velocity } & \multicolumn{4}{|c|}{60 kcfs Releases Velocity } \\
\hline & & $X(\mathrm{ft})$ & $Y(\mathrm{ft})$ & $z(\mathrm{ft})$ & $\mathrm{u}(\mathrm{ft} / \mathrm{s})$ & $v(\mathrm{ft} / \mathrm{s})$ & $w(\mathrm{ft} / \mathrm{s})$ & $\begin{array}{l}\text { Total } \\
(f \mathrm{ft} / \mathrm{s})\end{array}$ & $u(f t / s)$ & $v(\mathrm{ft} / \mathrm{s})$ & $w(f t / s)$ & $\begin{array}{l}\text { Total } \\
(\mathrm{ft} / \mathrm{s})\end{array}$ \\
\hline \multirow{2}{*}{ D01 } & 3.3 & \multirow{2}{*}{-62} & \multirow{2}{*}{107} & 873.4 & 16.6 & 0.1 & -0.8 & 16.6 & 23.6 & 0.3 & 0.4 & 23.6 \\
\hline & 20 & & & 890.1 & - & - & - & - & - & - & - & - \\
\hline \multirow{2}{*}{ D02 } & 3.3 & \multirow{2}{*}{0} & \multirow{2}{*}{107} & 873.4 & 18.4 & -0.5 & -1.2 & 18.5 & 23.7 & 0.9 & -0.2 & 23.7 \\
\hline & 20 & & & 890.1 & - & - & & & - & - & & - \\
\hline \multirow{2}{*}{ D03 } & 3.3 & \multirow{2}{*}{62} & \multirow{2}{*}{107} & 873.4 & 17.5 & -0.9 & -1.2 & 17.6 & 23.7 & 0.6 & 0.6 & 23.7 \\
\hline & 20 & & & 890.1 & - & - & & & - & - & & - \\
\hline \multirow{2}{*}{ D04 } & 3.3 & \multirow{2}{*}{-96} & \multirow{2}{*}{135} & 905.6 & 0.8 & -2.0 & 0.2 & 2.2 & 1.8 & -2.5 & 0.2 & 3.1 \\
\hline & 20 & & & 922.2 & - & - & - & - & - & - & - & - \\
\hline \multirow{2}{*}{ D05 } & 3.3 & \multirow{2}{*}{96} & \multirow{2}{*}{135} & 905.6 & 0.6 & -0.1 & -1.6 & 1.7 & -3.8 & 1.1 & -5.5 & 6.8 \\
\hline & 20 & & & 922.2 & - & - & & - & - & - & - & - \\
\hline \multirow{2}{*}{ D06 } & 3.3 & \multirow{2}{*}{-96} & \multirow{2}{*}{152} & 900.8 & 0.3 & -2.3 & -0.2 & 2.3 & 1.2 & -3.3 & -0.3 & 3.6 \\
\hline & 20 & & & 917.5 & - & - & - & - & - & - & - & - \\
\hline \multirow{2}{*}{ D07 } & 3.3 & \multirow{2}{*}{96} & \multirow{2}{*}{152} & 900.8 & -0.1 & 2.0 & 0.6 & 2.1 & -0.3 & 2.0 & -0.3 & 2.0 \\
\hline & 20 & & & 917.5 & - & - & - & - & - & - & - & - \\
\hline \multirow{2}{*}{ D08 } & 3.3 & -62 & 160 & 869.3 & -1.7 & -0.6 & 0.6 & 1.9 & $\begin{array}{l}-3.4 \\
\end{array}$ & 0.6 & 0.5 & 3.5 \\
\hline & 20 & -62 & & 886.0 & - & - & - & - & - & - & - & - \\
\hline & 3.3 & & & 869.3 & -1.9 & 0.9 & 0.2 & 2.2 & -2.2 & 2.0 & 1.2 & 3.2 \\
\hline D09 & 20 & 0 & 160 & 886.0 & 6.3 & 0.6 & 6.6 & 9.2 & 16.3 & -1.3 & 4.2 & 16.9 \\
\hline & 3.3 & & & 869.3 & -2.0 & 2.1 & -0.1 & 2.9 & -0.4 & 1.9 & 0.2 & 1.9 \\
\hline D10 & 20 & 62 & 160 & 886.0 & - & & - & & - & - & & - \\
\hline & 3.3 & & & 870.8 & 0.0 & 0.0 & 0.0 & 0.0 & 2.7 & 0.8 & -0.7 & 2.9 \\
\hline Di1 & 20 & -113 & 206 & 887.5 & - & - & - & - & - & - & - & - \\
\hline & 3.3 & & & 870.8 & -2.5 & 2.0 & -0.9 & 3.3 & -2.2 & 0.6 & -0.4 & 2.3 \\
\hline D12 & 20 & 113 & 206 & 887.5 & - & - & - & - & - & - & - & - \\
\hline & 3.3 & & & 869.3 & 1.5 & 0.1 & 0.2 & 1.5 & 5.7 & 0.3 & 1.0 & 5.8 \\
\hline D13 & 20 & -62 & 255 & 886.0 & - & - & - & - & - & - & - & - \\
\hline & 3.3 & & & 869.3 & 0.7 & 0.3 & 0.2 & 0.8 & 4.8 & 0.9 & 0.6 & 5.0 \\
\hline D14 & 20 & 0 & 255 & 886.0 & 1.8 & 1.1 & 0.7 & 2.2 & 8.1 & -0.3 & 1.1 & 8.2 \\
\hline & 3.3 & & & 869.3 & -0.7 & 0.2 & -0.1 & 0.7 & 5.5 & 1.2 & 0.5 & 5.6 \\
\hline D15 & & 02 & 235 & 886.0 & - & - & - & - & - & - & & - \\
\hline
\end{tabular}

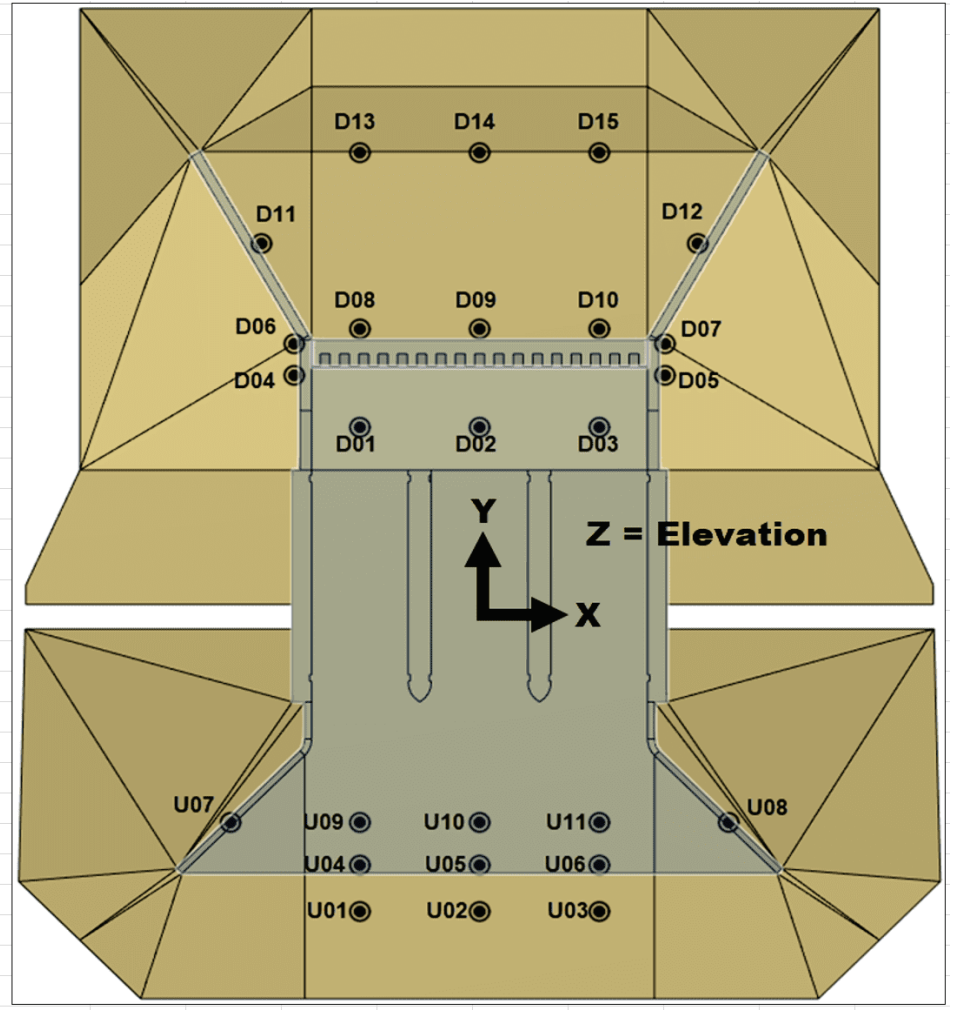


Figure 47. ADV velocity results for Alternative 2 Design testing.

\begin{tabular}{|c|c|c|c|c|c|c|c|c|c|c|c|c|}
\hline \multirow[b]{2}{*}{ ID } & \multirow{2}{*}{$\begin{array}{l}\text { Depth } \\
\text { above } \\
\text { Bed (ft) }\end{array}$} & \multicolumn{3}{|c|}{ Location } & \multicolumn{4}{|c|}{ PMF Gates In Velocity } & \multicolumn{4}{|c|}{ PMF Resiliency Velocity } \\
\hline & & $X(\mathrm{ft})$ & $Y(\mathrm{ft})$ & $Z(\mathrm{ft})$ & $u(\mathrm{ft} / \mathrm{s})$ & $v(\mathrm{ft} / \mathrm{s})$ & $w(f t / s)$ & $\begin{array}{l}\text { Total } \\
(\mathrm{ft} / \mathrm{s})\end{array}$ & $u(f t / s)$ & $v(\mathrm{ft} / \mathrm{s})$ & $w(\mathrm{ft} / \mathrm{s})$ & $\begin{array}{l}\text { Total } \\
(\mathrm{ft} / \mathrm{s})\end{array}$ \\
\hline \multirow{2}{*}{ D01 } & 3.3 & \multirow{2}{*}{-62} & \multirow{2}{*}{107} & 873.4 & 20.4 & 0.5 & -0.1 & 20.4 & 21.5 & -1.8 & -1.9 & 21.7 \\
\hline & 20 & & & 890.1 & - & - & - & - & 0.0 & 0.0 & 0.0 & - \\
\hline \multirow{2}{*}{ D02 } & 3.3 & \multirow{2}{*}{0} & \multirow{2}{*}{107} & 873.4 & 20.8 & 1.5 & 0.1 & 20.9 & 20.0 & 3.3 & -4.2 & 20.7 \\
\hline & 20 & & & 890.1 & - & - & - & - & - & - & - & - \\
\hline \multirow{2}{*}{ D03 } & 3.3 & \multirow{2}{*}{62} & \multirow{2}{*}{107} & 873.4 & 20.4 & 3.0 & -0.5 & 20.6 & -1.2 & 0.3 & -0.1 & 1.2 \\
\hline & 20 & & & 890.1 & - & - & - & - & - & - & - & - \\
\hline \multirow{2}{*}{ D04 } & 3.3 & \multirow{2}{*}{-96} & \multirow{2}{*}{135} & 905.6 & - & - & - & - & 0.3 & -0.3 & 0.1 & 0.4 \\
\hline & 20 & & & 922.2 & - & - & - & - & - & - & - & - \\
\hline \multirow{2}{*}{ D05 } & 3.3 & \multirow{2}{*}{96} & \multirow{2}{*}{135} & 905.6 & - & - & - & - & -0.4 & 0.1 & 1.1 & 1.2 \\
\hline & 20 & & & 922.2 & - & - & - & - & - & - & - & - \\
\hline \multirow{2}{*}{ D06 } & 3.3 & \multirow{2}{*}{-96} & \multirow{2}{*}{152} & 900.8 & - & - & - & - & 2.0 & -3.1 & -0.5 & 3.7 \\
\hline & 20 & & & 917.5 & - & - & - & - & - & - & - & - \\
\hline \multirow{2}{*}{ D07 } & 3.3 & \multirow{2}{*}{96} & \multirow{2}{*}{152} & 900.8 & - & - & - & - & -0.4 & 0.9 & 0.1 & 0.9 \\
\hline & 20 & & & 917.5 & - & - & - & - & - & - & - & - \\
\hline \multirow{2}{*}{ D08 } & 3.3 & & & 869.3 & 3.6 & -0.3 & -0.2 & 3.6 & 1.4 & -0.5 & -0.1 & 1.5 \\
\hline & 20 & -62 & 160 & 886.0 & - & - & - & - & - & - & - & - \\
\hline & 3.3 & & & 869.3 & 2.2 & 0.6 & -0.2 & 2.3 & 7.4 & 0.9 & 1.3 & 7.5 \\
\hline D09 & 20 & 0 & 160 & 886.0 & 17.8 & 3.8 & -0.9 & 18.2 & 22.1 & 0.9 & -0.1 & 22.2 \\
\hline & 3.3 & & & 869.3 & 5.5 & 2.1 & -1.2 & 6.0 & -1.5 & 0.6 & 0.2 & 1.6 \\
\hline D10 & 20 & 62 & 160 & 886.0 & - & - & - & - & - & - & - & - \\
\hline & 3.3 & & & 870.8 & 4.6 & 1.4 & 0.8 & 4.9 & 5.0 & 4.3 & -1.1 & 6.7 \\
\hline D11 & 20 & -113 & 206 & 887.5 & - & - & - & - & - & - & - & - \\
\hline & 3.3 & & & 870.8 & 1.3 & -0.5 & 0.1 & 1.4 & -1.4 & 0.6 & 0.3 & 1.5 \\
\hline D12 & 20 & 113 & 206 & 887.5 & - & 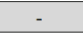 & - & & - & - & 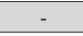 & \\
\hline & 3.3 & & & 869.3 & 9.9 & 3.3 & -1.4 & 10.5 & 8.0 & 0.5 & -0.7 & 8.1 \\
\hline D13 & 20 & -62 & 255 & 886.0 & - & - & - & - & - & - & - & - \\
\hline & 3.3 & & & 869.3 & 9.8 & 3.6 & -1.0 & 10.5 & 12.2 & 1.5 & -1.7 & 12.4 \\
\hline D14 & 20 & 0 & 255 & 886.0 & 12.4 & 3.2 & -3.6 & 13.3 & 15.3 & 2.7 & -3.6 & 16.0 \\
\hline & 3.3 & & & 869.3 & 8.8 & 3.5 & -1.5 & 9.6 & -0.7 & 0.2 & -0.1 & 0.7 \\
\hline D15 & 20 & 62 & 255 & 886.0 & - & - & - & - & - & - & - & \\
\hline
\end{tabular}

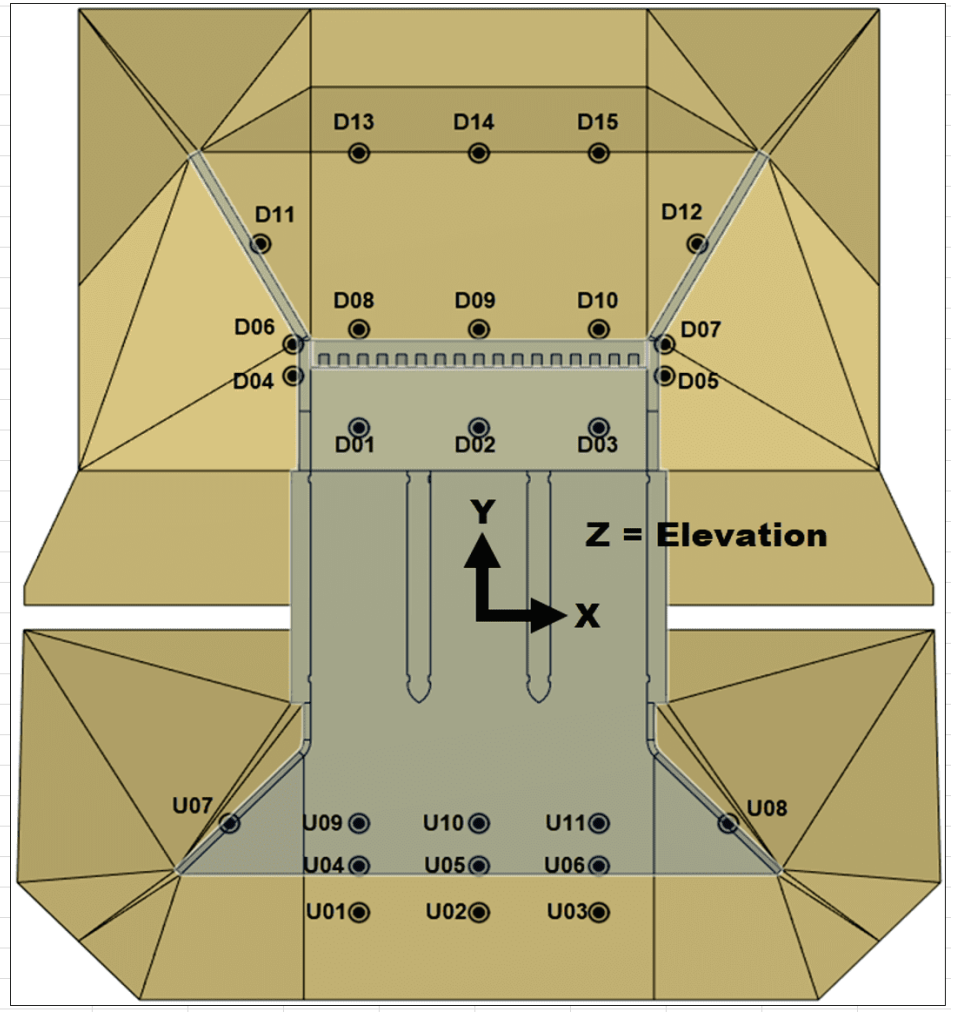


Figure 48. Alternative 2 Design 5\% AEP event ADV-derived velocity vectors.

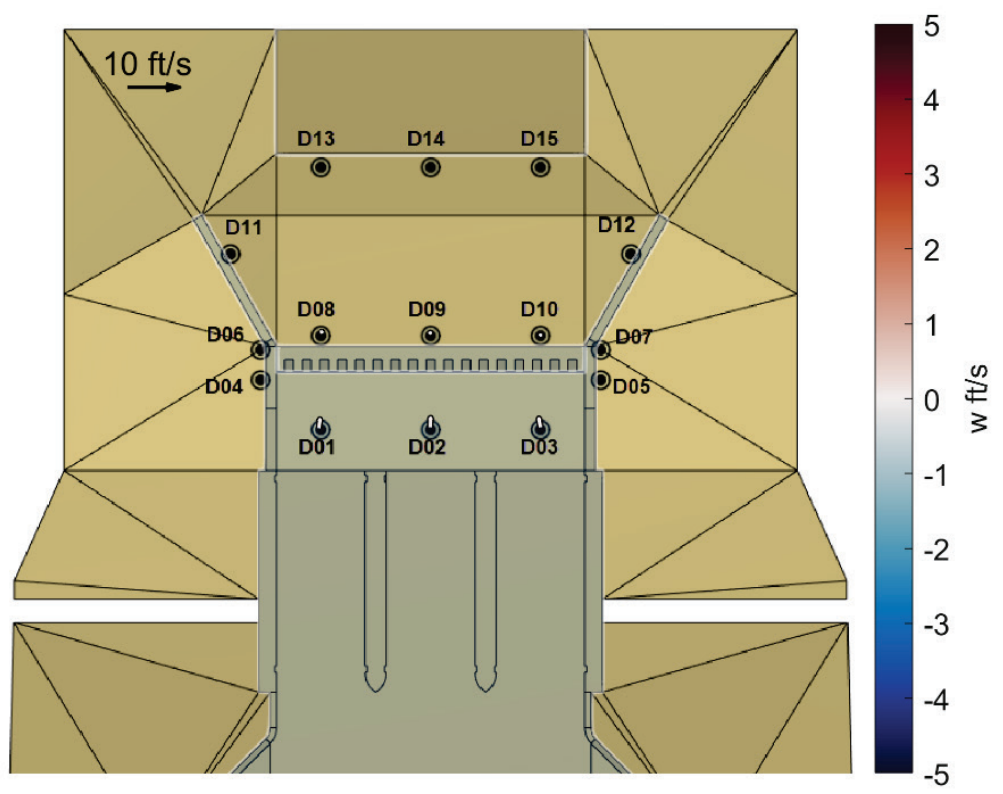

Figure 49. Alternative 2 Design 1\% AEP event ADV-derived velocity vectors.

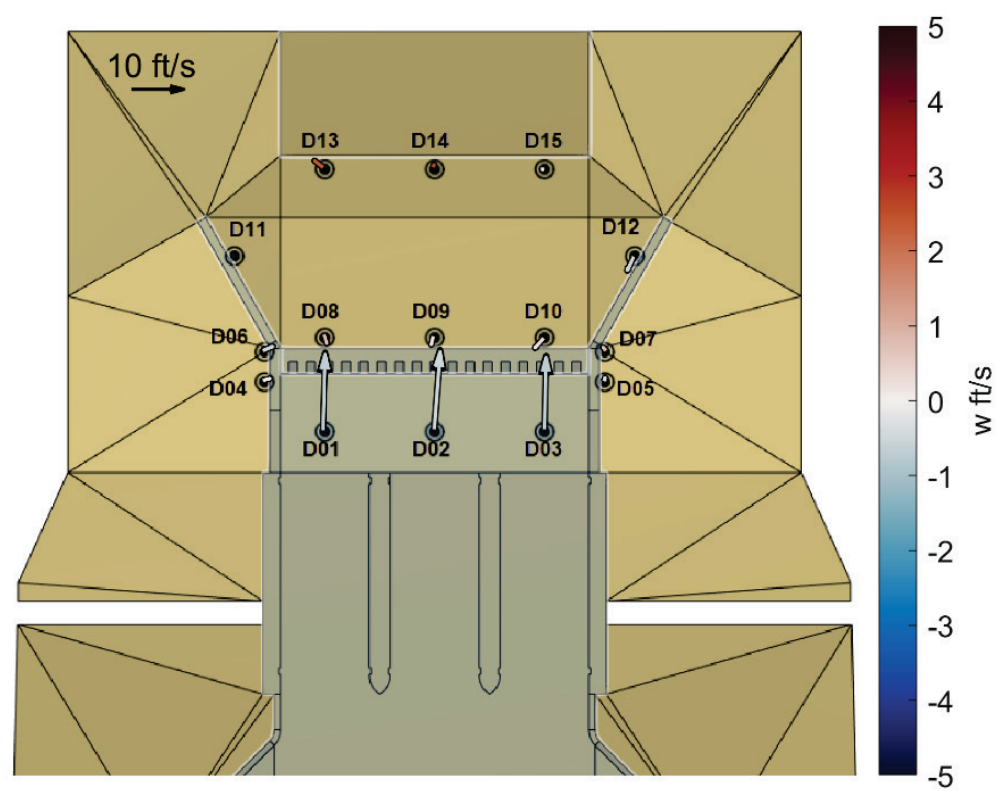


Figure 50. Alternative 2 Design $0.2 \%$ AEP event ADV-derived velocity vectors.

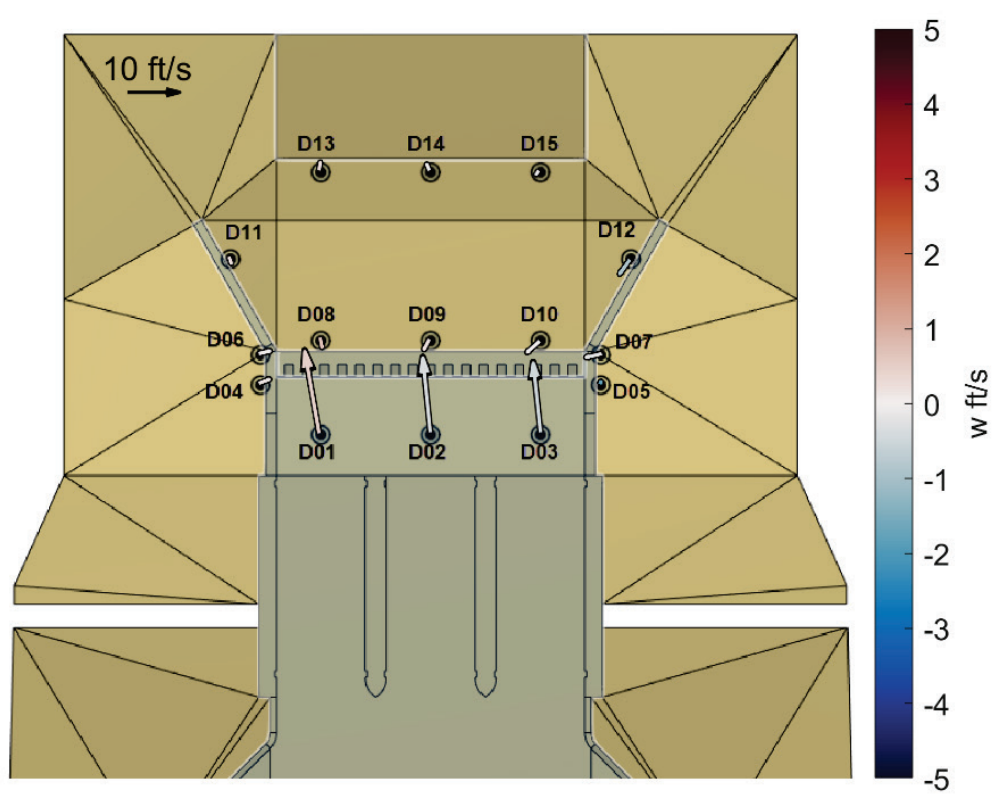

Figure 51. Alternative 2 Design maximum controlled releases ADV-derived velocity vectors.

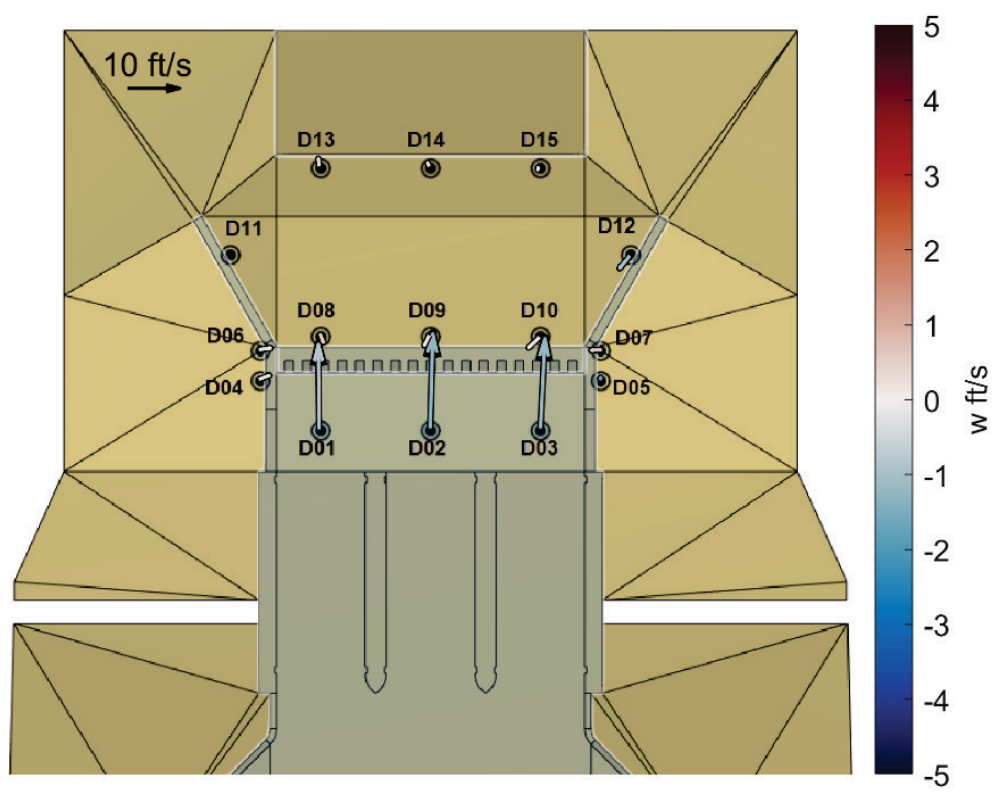


Figure 52. Alternative 2 Design 60,000 cfs releases ADV-derived velocity vectors.

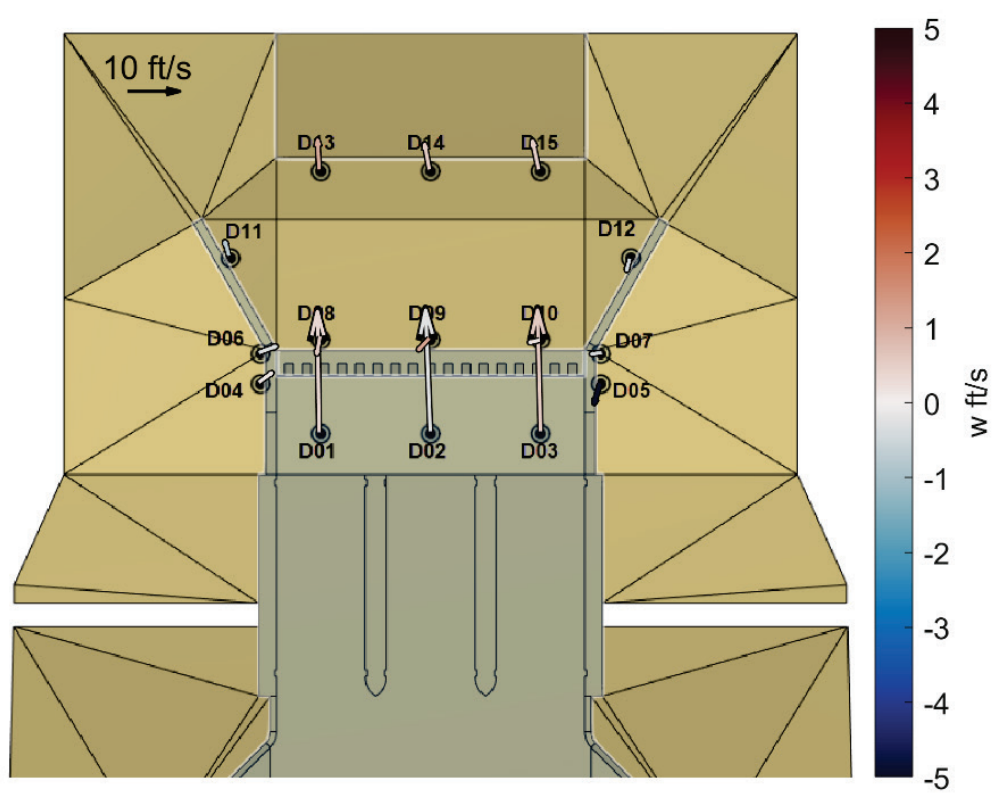

Figure 53. Alternative 2 Design PMF ADV-derived velocity vectors.

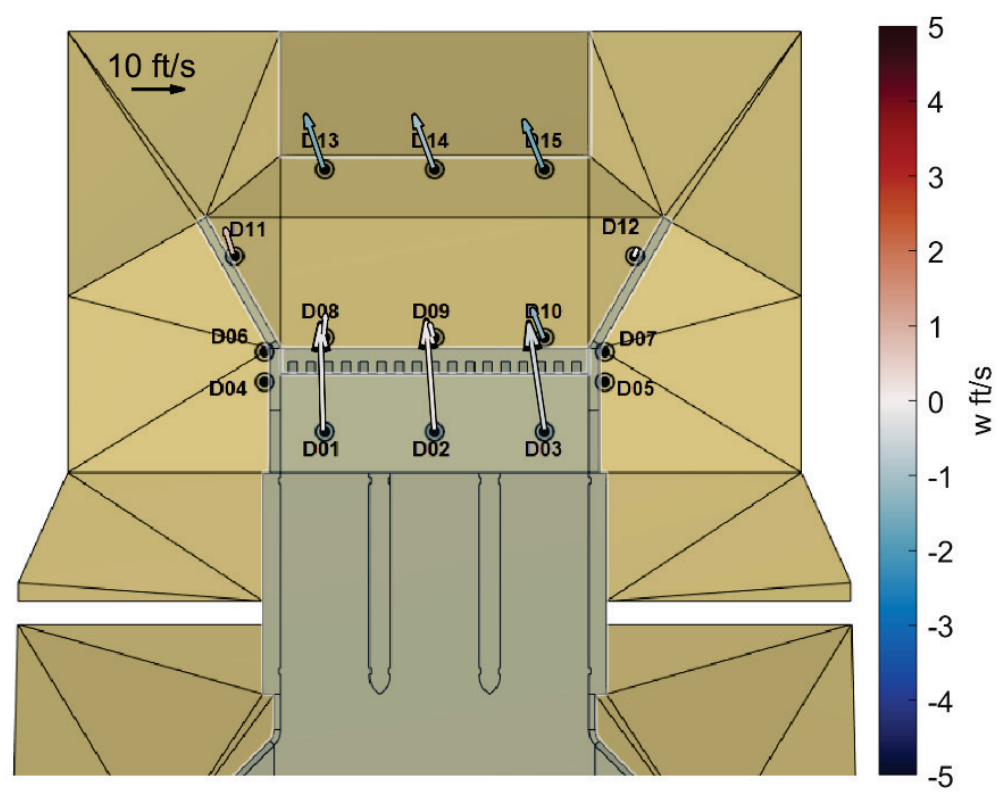


Figure 54. Alternative 2 Design PMF resiliency ADV-derived velocity vectors.

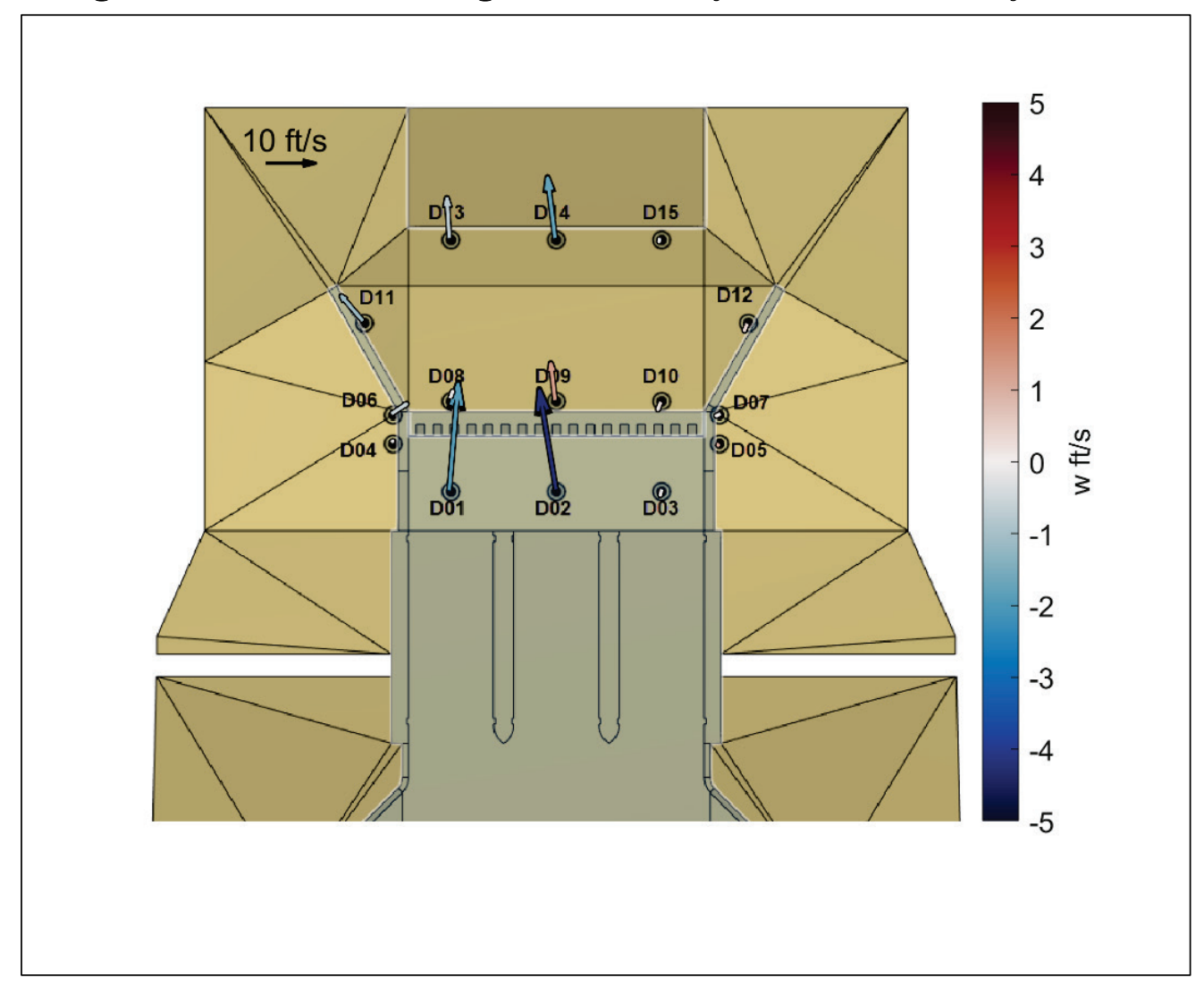

The model was filled with water at a very slow rate ( $\sim 0.25 \mathrm{cfs}$ inflow $)$ in order to not disturb the sand or scaled riprap before boundary conditions were met. Once the model reached the appropriate conditions for testing, the model was run for approximately $25-35$ hours (prototype) as per instruction of the St. Paul District. Afterwards, the model was de-watered by pumping out the scour hole, which sometimes caused some cutting of the sand material in the scour hole as water was drained from the model. A main design goal was to have no movement of riprap or bed material up through the Maximum Controlled Releases event. This was confirmed as successful by the resulting LiDAR data shown in Figure 55 and Figure 56. The model was scanned using a FARO Focus ${ }^{s} 350$ terrestrial laser scanner (ranging error of $\pm 1 \mathrm{~mm}$ or approximately $0.15 \mathrm{ft}$ prototype). Pre-scans were taken at multiple positions before the model testing. After the experiment and with the water drained out of the model, post-test scans were conducted at multiple positions in the model. The $3 \mathrm{D}$ data were tied to the project coordinate system by the use of spherical targets placed throughout the model (more information on LiDAR coordinate systems in physical models can be found in Bell et al. [2018]). The data were then scaled to prototype scale. The LiDAR data were interpolated to a 
consistent, highly resolved mesh for pre-test minus post-test comparisons. The LiDAR data show that there is little to no riprap movement between the retaining walls for this event. The circular areas in the data denote where the FARO Focus laser scanner was set up in multiple positions to ensure that enough bathymetry was collected. Note that there was no usage of any type of bedding or geofabric material between the riprap and sand. Also, in the channel area downstream of the structure, where the LiDAR data shows areas of deposition and scour (red to yellowish indicates scour; magenta to blue indicates deposition) in close proximities is due to very small amounts of sand being left in the channel bed after remolding the model and/or some water being in the channel after testing. Since the FARO laser scanner has a beam width near infrared, the water absorbs the laser's energy, thus not producing a return measurement in areas where water is present.

Figure 55. Pre-test minus post-test LiDAR for Maximum Controlled Releases test.

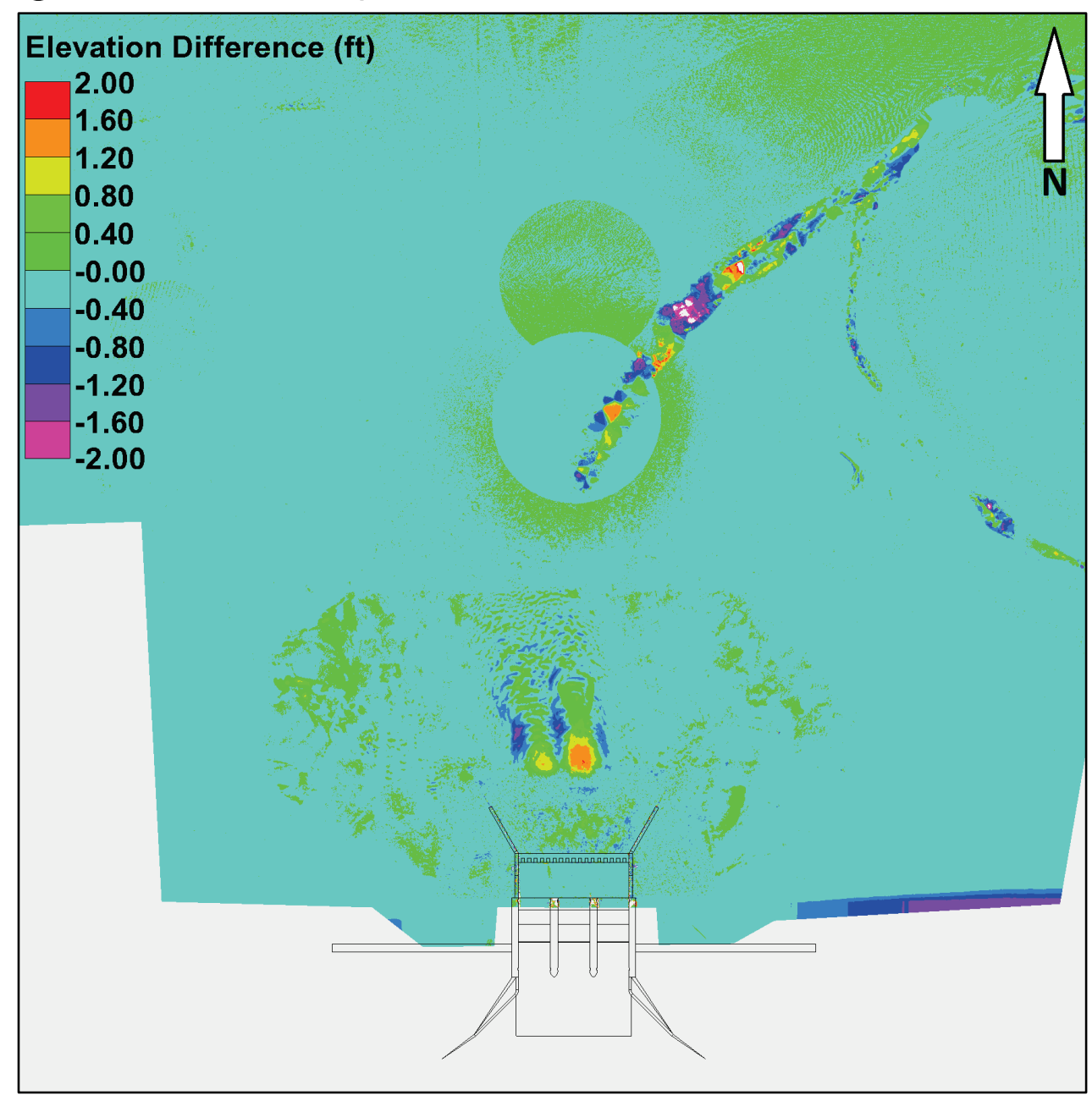


Figure 56. Pre-test (left) and post-test (right) pictures for Maximum Controlled Releases.

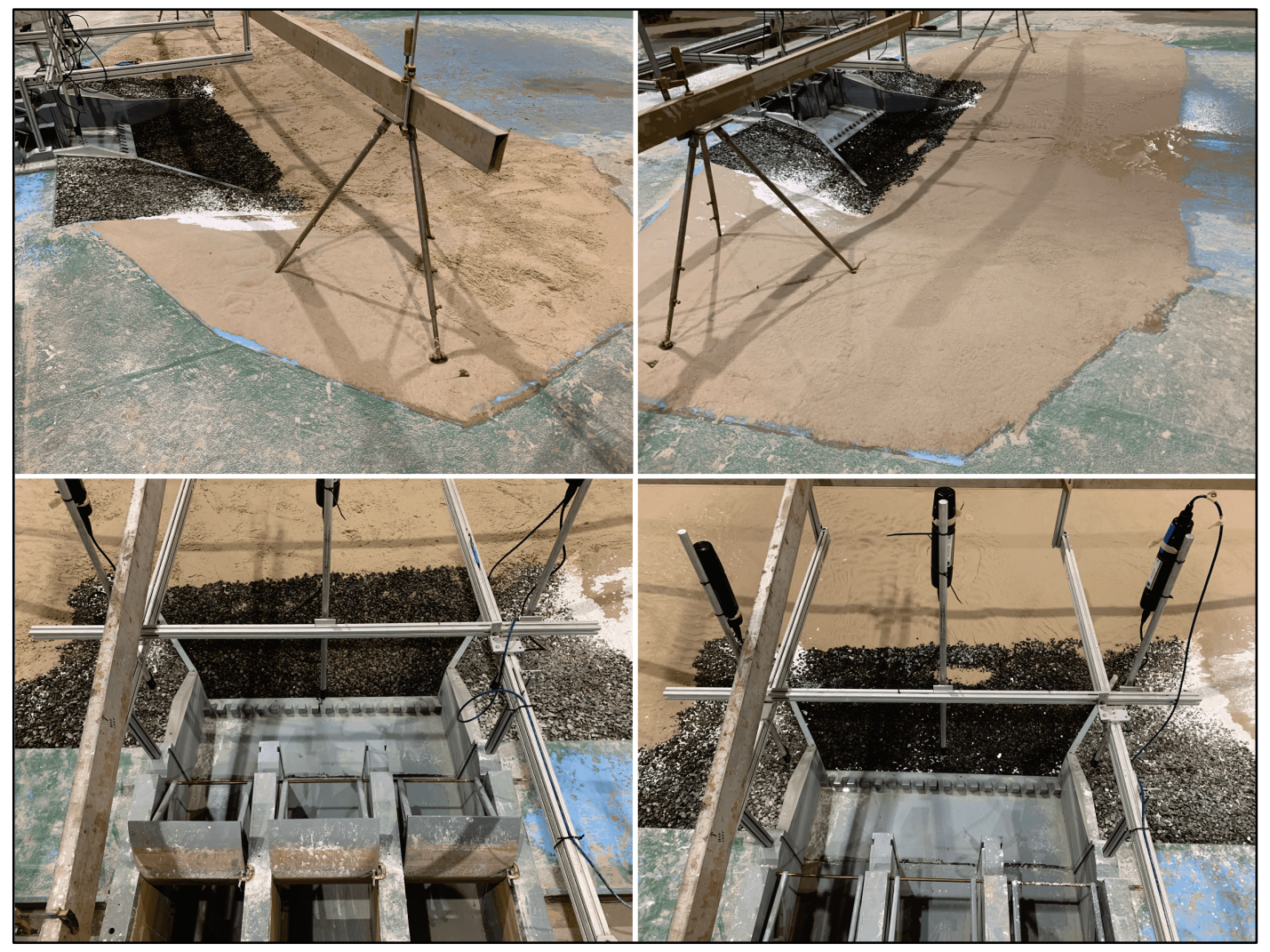

\subsubsection{Alternative 2 Design summary}

The modified approach walls were successful in that they maintained favorable hydraulic conditions near the dam embankment upstream of the structure. This was confirmed via visual inspection during physical model testing. Upstream velocities, obtained by the Valeport instrument, were slightly higher than the Alternative 1 Design due to a slight upstream adjustment of the contraction zone into the structure, but upstream riprap requirements are not impacted. Furthermore, the new $5 \mathrm{H}: 1 \mathrm{~V}$ upslope change did not impact the structure's capacity nor the scour characteristics.

\subsection{Alternative 3}

\subsubsection{Alternative 3 Design modifications}

The Alternative 3 Design maintained the downstream transition from elevation $866 \mathrm{ft}$ to $873 \mathrm{ft}$ over a $5 \mathrm{H}: 1 \mathrm{~V}$ upslope. However, the toe of the slope was relocated approximately $26 \mathrm{ft}$ upstream (towards the dentated 
end sill) from its previous position. The distance of flat-graded riprap was changed to $74 \mathrm{ft}$ compared to its previous length of $100 \mathrm{ft}$ (Figure 57). Scaled riprap could potentially move as the sand underneath the riprap layer was eroding because riprap bedding and geofabric were not included in the model. It is understood that the St. Paul District include both riprap bedding and geofabric into the final structure design to prevent this type of erosion from occurring.

Figure 57. Alternative 3 Design (pre-test for PMF scenario).

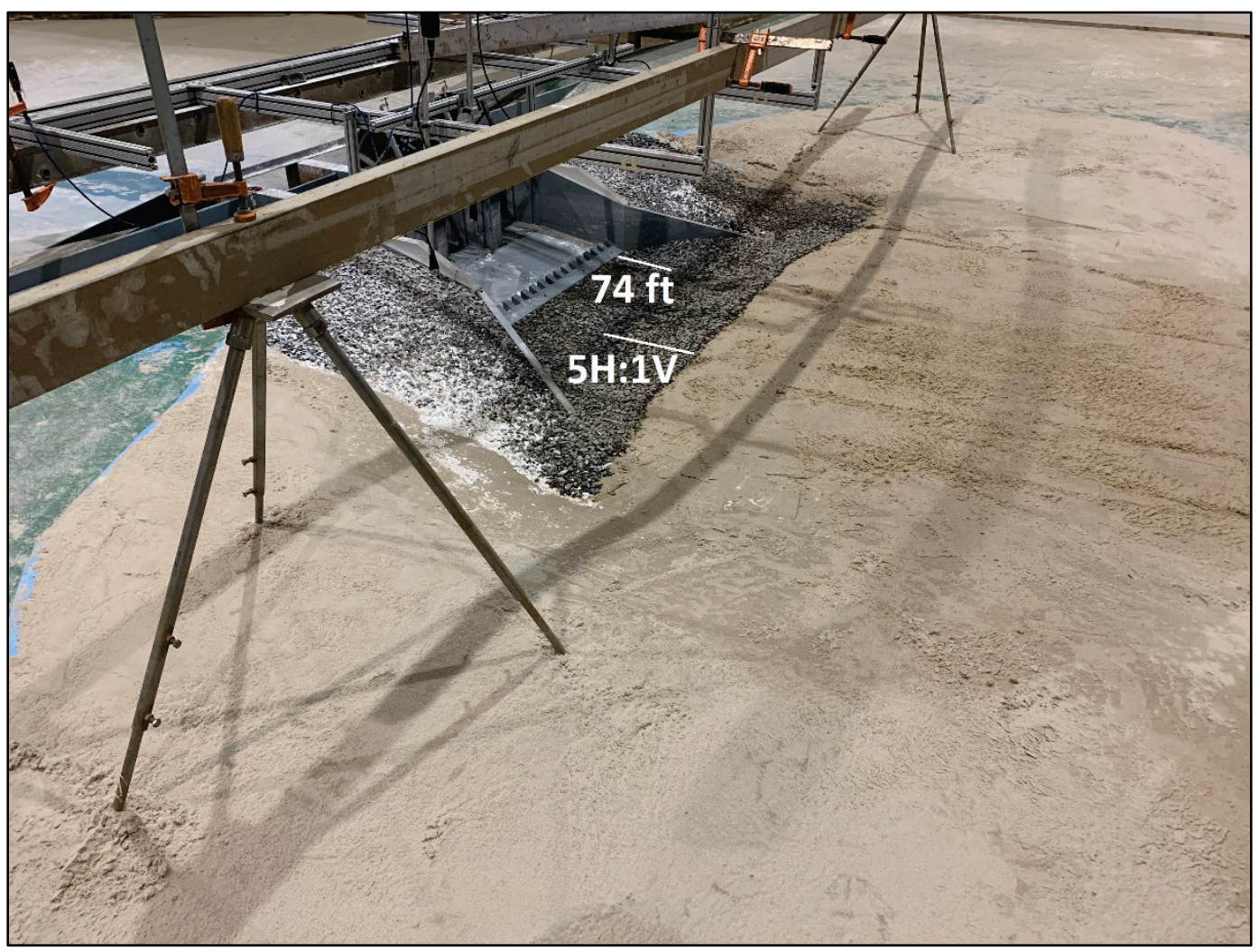

\subsubsection{Alternative 3 Design testing}

Table 12 gives the boundary condition data for Alternative 3 Design testing. 
Table 12. Alternative 3 Design testing boundary condition data.

\begin{tabular}{|c|c|c|c|c|c|c|c|}
\hline Scenario & $\begin{array}{c}\text { Target } \\
\text { Headwater } \\
\text { Elevation } \\
\text { (ft) }\end{array}$ & $\begin{array}{c}\text { Target } \\
\text { Tailwater } \\
\text { Elevation } \\
\text { (ft) }\end{array}$ & $\begin{array}{c}\text { Target } \\
\text { Discharge } \\
\text { (cfs) }\end{array}$ & $\begin{array}{c}\text { Model } \\
\text { Headwater } \\
\text { Elevation } \\
(\mathrm{ft})\end{array}$ & $\begin{array}{c}\text { Model } \\
\text { Tailwater } \\
\text { Elevation } \\
\text { (ft) }\end{array}$ & $\begin{array}{l}\text { Model } \\
\text { Discharge } \\
\text { (cfs) }\end{array}$ & $\begin{array}{l}\text { Model Gate Opening } \\
\text { Height (ft) }\end{array}$ \\
\hline $\begin{array}{c}\text { PMF Resiliency (Descending Right Bank Gate } \\
\text { Closed) }\end{array}$ & - & 917.0 & 89,700 & 924.8 & 917.2 & 89,600 & $\begin{array}{l}\text { Open (Descending left } \\
\text { bank and middle) }\end{array}$ \\
\hline PMF Test A & 923.5 & 917.5 & 104,300 & 923.5 & 917.9 & 104,000 & 36.1 \\
\hline PMF Test B, Upslope All Rock & 923.5 & 917.5 & 104,300 & 923.5 & 917.9 & 103,700 & 36.1 \\
\hline $\begin{array}{l}\text { PMF Resiliency (Descending Right Bank Gate } \\
\text { Closed) Test C, Upslope All Rock }\end{array}$ & - & 917.0 & 89,700 & 924.5 & 917.0 & 89,300 & $\begin{array}{l}\text { Open (Descending left } \\
\text { bank and middle) }\end{array}$ \\
\hline $\begin{array}{l}\text { PMF Resiliency (Descending Right Bank Gate } \\
\text { Closed) Test D, Upslope All Rock }\end{array}$ & - & 917.0 & 99,300 & 926.4 & 917.2 & 99,000 & $\begin{array}{l}\text { Open (Descending left } \\
\text { bank and middle) }\end{array}$ \\
\hline $\begin{array}{c}\text { PMF Resiliency (Descending Right Bank Gate } \\
\text { Closed) Test E }\end{array}$ & - & 917.0 & 99,300 & 926.5 & 917.0 & 99,500 & $\begin{array}{l}\text { Open (Descending left } \\
\text { bank and middle) }\end{array}$ \\
\hline
\end{tabular}


Velocity measurements were only taken for the PMF Resiliency test with the Alternative 3 Design and can be seen in Figure 58. Figure 59 displays the upstream velocity measurements.

Figure 58. Alternative 3 Design velocity measurement locations.

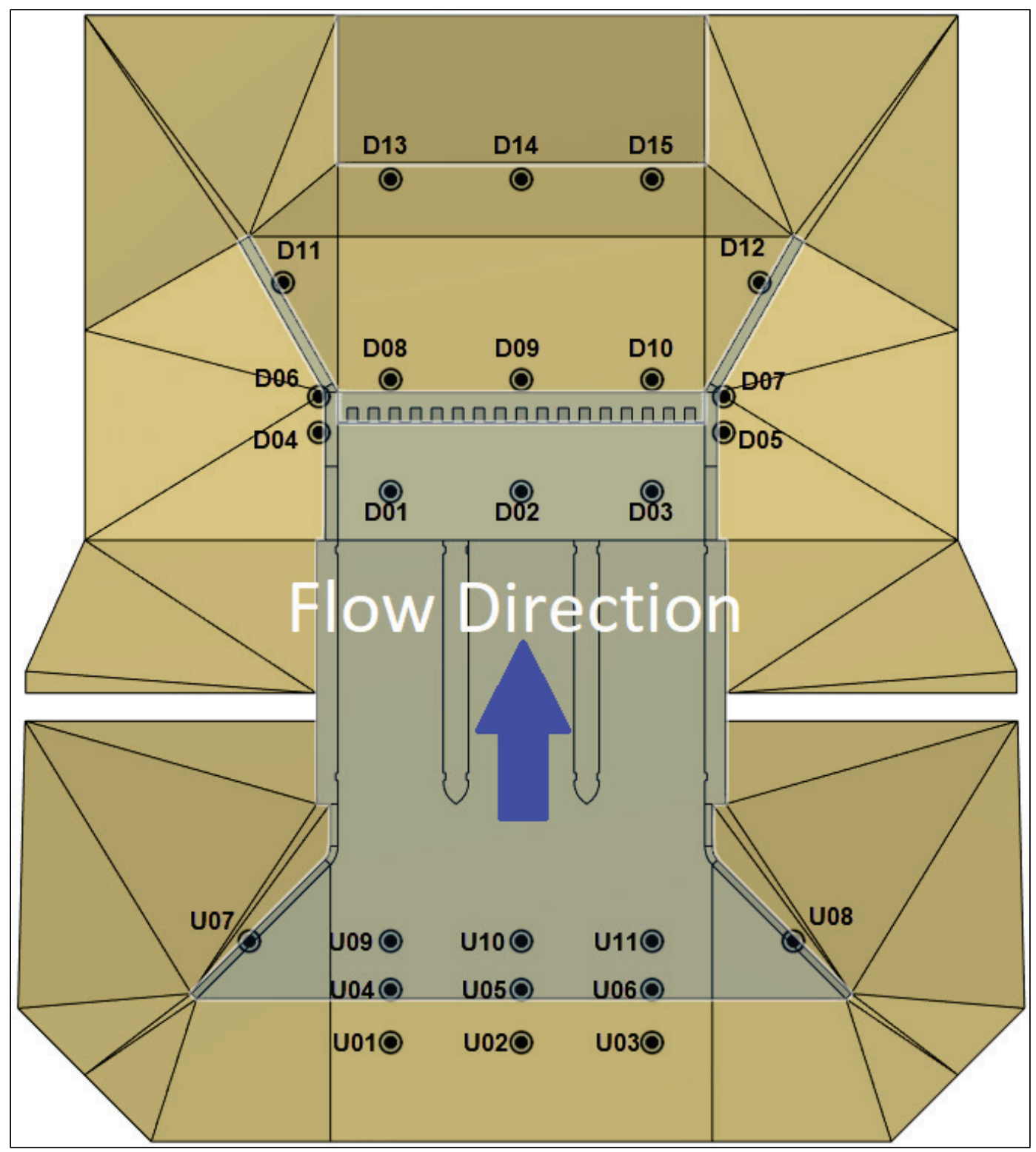


Figure 59. Upstream velocity results for Alternative 3 Design PMF Resiliency.

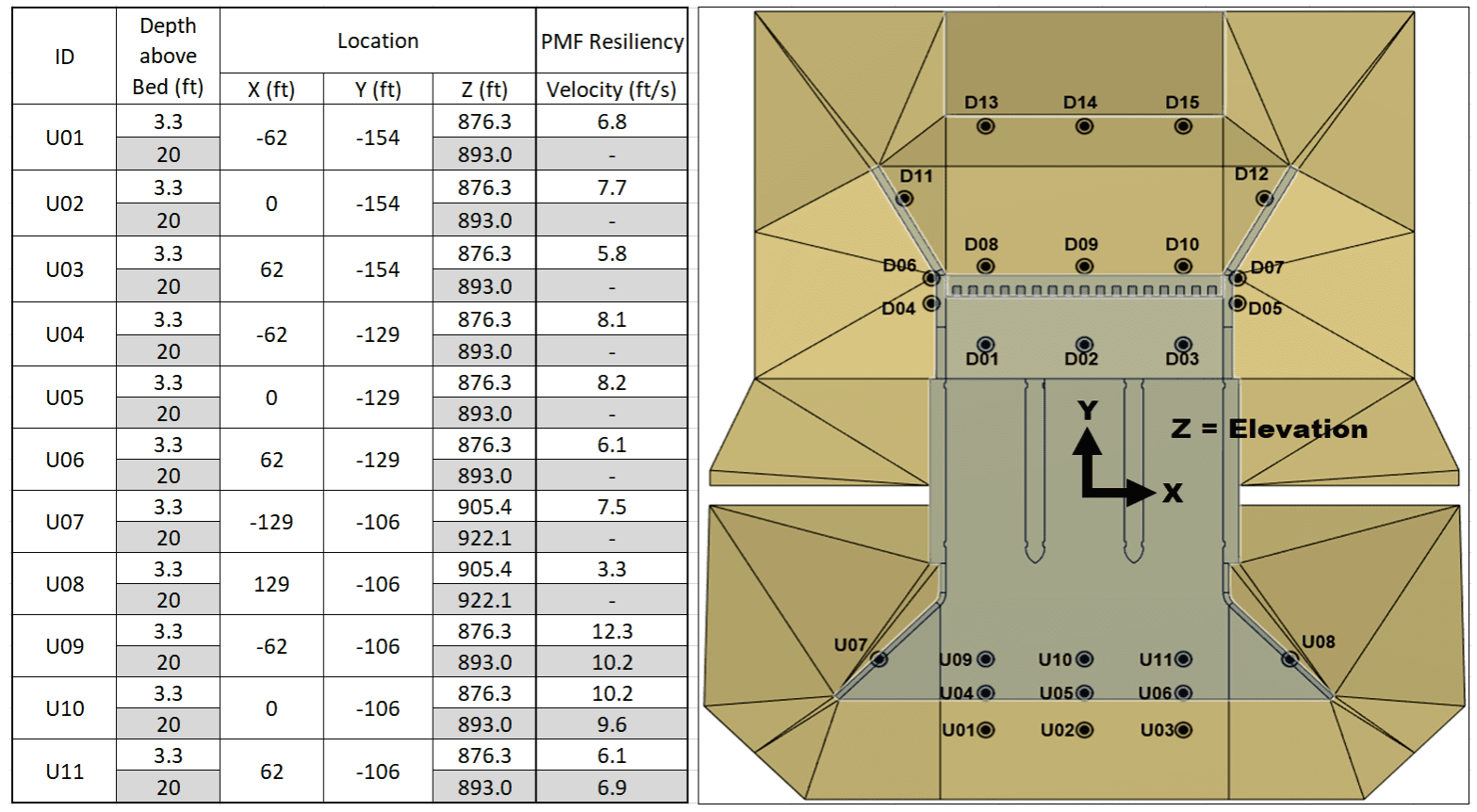

The downstream ADV velocity data can be seen in Figure 60 and Figure 61.

Figure 60. ADV velocity results for Alternative 3 Design PMF Resiliency testing.

\begin{tabular}{|c|c|c|c|c|c|c|c|c|}
\hline \multirow[b]{2}{*}{ ID } & \multirow{2}{*}{$\begin{array}{l}\text { Depth } \\
\text { above } \\
\text { Bed (ft) }\end{array}$} & \multicolumn{3}{|c|}{ Location } & \multicolumn{4}{|c|}{ PMF Resiliency Velocity } \\
\hline & & $x(\mathrm{ft})$ & $Y(\mathrm{ft})$ & $\mathrm{Z}(\mathrm{ft})$ & $\mathrm{u}(\mathrm{ft} / \mathrm{s})$ & $v(\mathrm{ft} / \mathrm{s})$ & $\mathrm{w}(\mathrm{ft} / \mathrm{s})$ & $\begin{array}{l}\text { Total } \\
(\mathrm{ft} / \mathrm{s})\end{array}$ \\
\hline \multirow{2}{*}{ D01 } & 3.3 & \multirow{2}{*}{-62} & \multirow{2}{*}{107} & 873.4 & 22.0 & -0.3 & -1.4 & 22.1 \\
\hline & 20 & & & 890.1 & - & - & - & - \\
\hline \multirow{2}{*}{ D02 } & 3.3 & \multirow{2}{*}{0} & \multirow{2}{*}{107} & 873.4 & 21.1 & 5.5 & -1.6 & 21.8 \\
\hline & 20 & & & 890.1 & - & - & - & - \\
\hline \multirow{2}{*}{ D03 } & 3.3 & \multirow{2}{*}{62} & \multirow{2}{*}{107} & 873.4 & -1.3 & 0.2 & -0.1 & 1.3 \\
\hline & 20 & & & 890.1 & - & - & - & - \\
\hline \multirow{2}{*}{ D04 } & 3.3 & \multirow{2}{*}{-96} & \multirow{2}{*}{135} & 905.6 & 1.1 & -2.3 & 0.0 & 2.6 \\
\hline & 20 & & & 922.2 & - & - & - & - \\
\hline \multirow{2}{*}{ D05 } & 3.3 & \multirow{2}{*}{96} & \multirow{2}{*}{135} & 905.6 & -0.3 & 1.0 & -0.2 & 1.1 \\
\hline & 20 & & & 922.2 & - & - & - & - \\
\hline \multirow{2}{*}{ D06 } & 3.3 & \multirow{2}{*}{-96} & \multirow{2}{*}{152} & 900.8 & 2.6 & -3.1 & -0.5 & 4.1 \\
\hline & 20 & & & 917.5 & - & - & - & - \\
\hline \multirow{2}{*}{ D07 } & 3.3 & \multirow{2}{*}{96} & \multirow{2}{*}{152} & 900.8 & 0.1 & 1.9 & 0.0 & 1.9 \\
\hline & 20 & & & 917.5 & - & - & - & - \\
\hline \multirow{2}{*}{ D08 } & 3.3 & \multirow{2}{*}{-62} & \multirow{2}{*}{160} & 869.3 & 3.1 & -1.2 & 1.2 & 3.5 \\
\hline & 20 & & & 886.0 & - & - & - & - \\
\hline \multirow{2}{*}{ D09 } & 3.3 & & & 869.3 & 8.4 & 2.1 & -0.1 & 8.7 \\
\hline & 20 & 0 & 160 & 886.0 & 22.7 & -1.1 & 1.0 & 22.7 \\
\hline D10 & 3.3 & 62 & 160 & 869.3 & -1.5 & 0.7 & -0.2 & 1.6 \\
\hline Div & 20 & 02 & 100 & 886.0 & - & - & - & - \\
\hline$D 11$ & 3.3 & -113 & 206 & 875.8 & - & - & - & - \\
\hline UII & 20 & -113 & 206 & 892.5 & - & - & - & - \\
\hline 212 & 3.3 & & & 875.8 & -1.9 & 0.6 & -0.2 & 1.9 \\
\hline U12 & 20 & 113 & 206 & 892.5 & - & - & - & - \\
\hline 113 & 3.3 & 62 & & 874.8 & 11.8 & 1.4 & -0.2 & 11.9 \\
\hline D13 & 20 & -62 & 253 & 891.4 & - & - & - & - \\
\hline 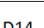 & 3.3 & . & & 874.8 & 11.8 & 1.1 & -0.4 & 11.9 \\
\hline D14 & 20 & 0 & 255 & 891.4 & 18.6 & 3.8 & -0.9 & 19.0 \\
\hline 015 & 3.3 & & & 874.8 & -1.0 & -0.4 & 0.0 & 1.1 \\
\hline U15 & 20 & 62 & 255 & 891.4 & - & & & \\
\hline
\end{tabular}

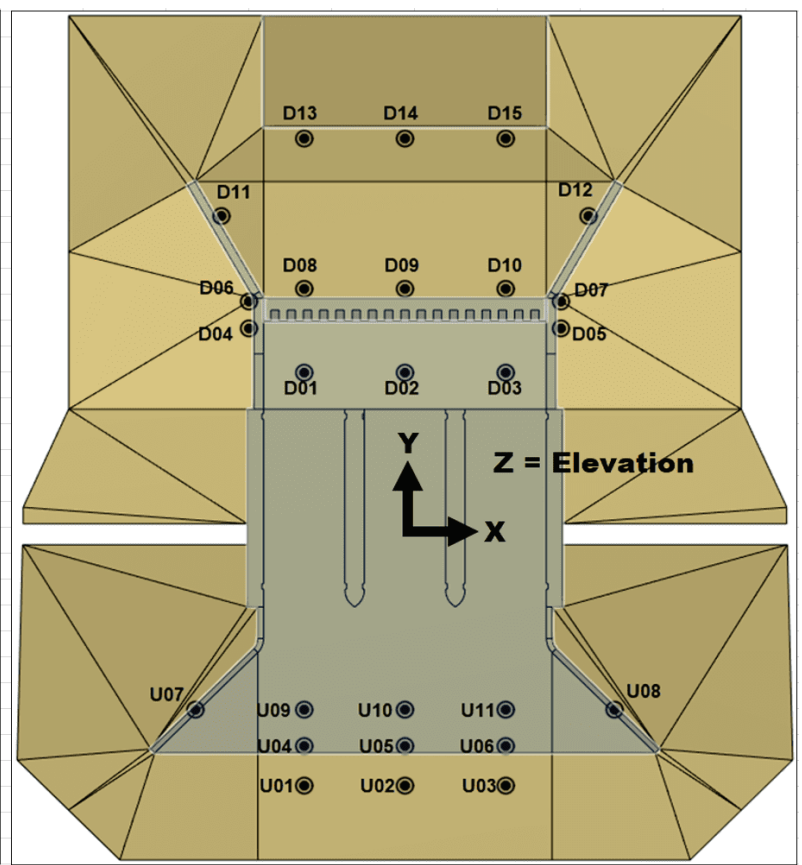


Figure 61. Alternative 3 Design PMF resiliency ADV-derived velocity vectors.

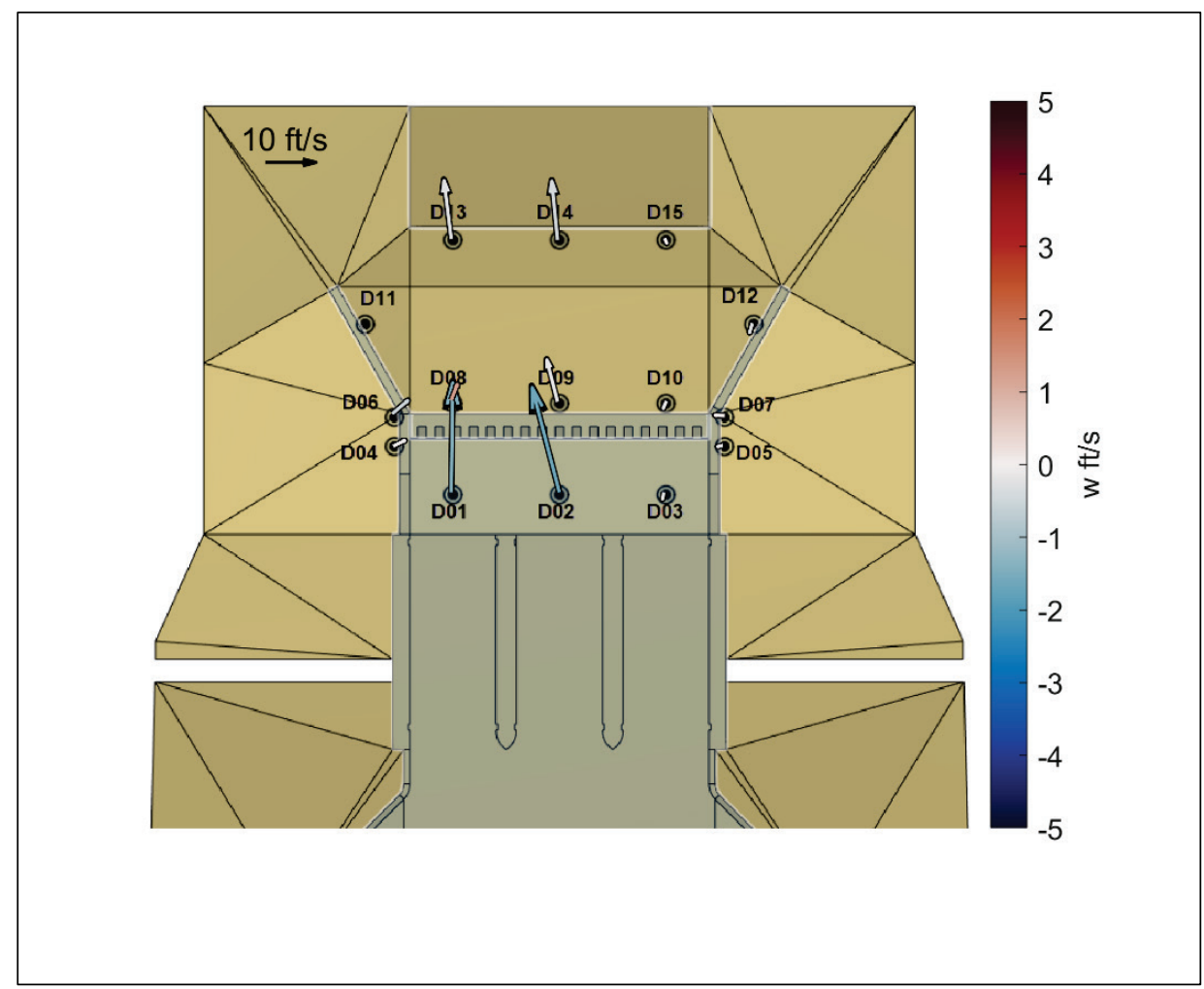

A total of five tests were conducted where velocity measurements were not collected so that there would be no interference with the hydrodynamics downstream of the gates during testing. It was believed that enough velocity data had been acquired up to this point and the potential scour of R470 riprap downstream of the structure needed to be examined. By not obstructing the flow downstream of the gates, the LiDAR data are now acceptable to use. The tests where LiDAR data were evaluated are labeled Test A - E in Table 11. Note that for each test, there was no usage of any type of bedding or geofabric material between the riprap and sand. Again, red to yellowish areas represent areas of scour while blue to magenta areas represent deposition. In the following figures, the yellow/orange/red areas indicate scour, and the blue/grey areas represent deposition. Test A (PMF) results can be seen in Figure 62 and Figure 63. 
Figure 62. Pre-test minus post-test LiDAR for Test A PMF.

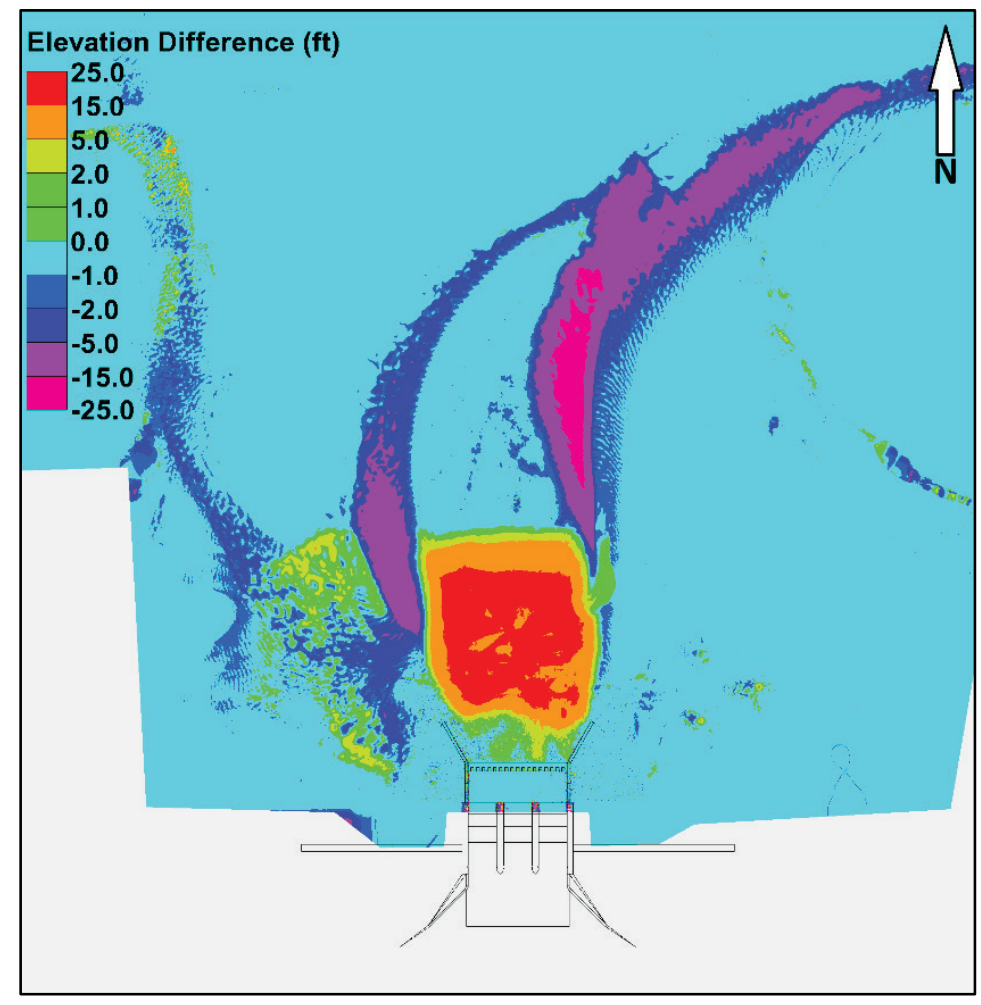

Figure 63. Pre-test (left) and post-test (right) pictures for Test A PMF.
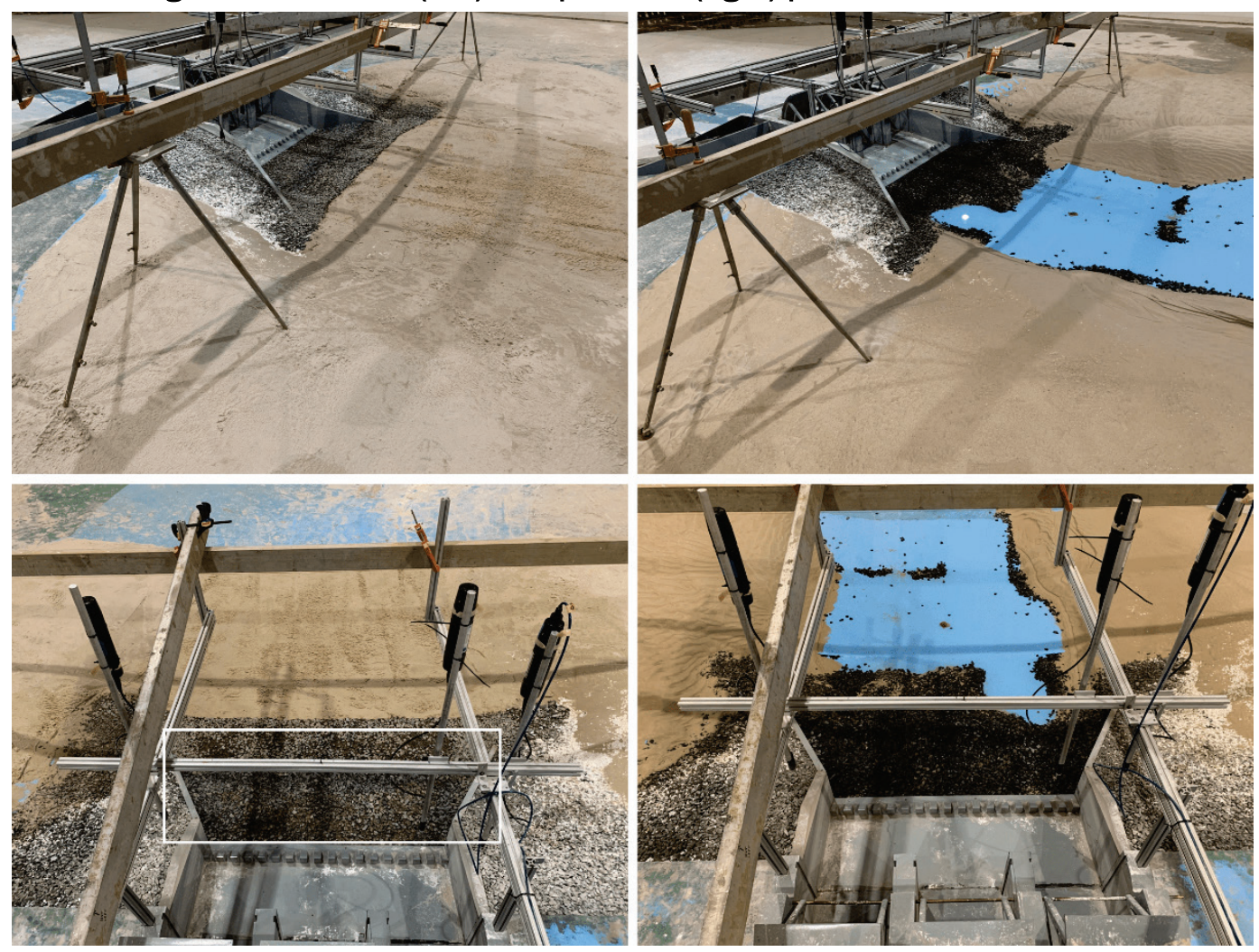
The main concern during these tests was the scour/movement of riprap in the area in between the retaining walls downstream of the end sill (area shown by the white box in the bottom left image in Figure 63). The amount of riprap scour that occurred on the descending right bank side indicated additional analysis was needed to better understand the true scour potential, especially considering that the blue areas shown in the post-test figures are the bed of the model (fixed bed) and thus additional scour could have been possible beyond what the model captured.

Conversations with the St. Paul District indicated that the actual design calls for both geofabric and rock bedding to be added underneath the riprap that would create a barrier between the native material and the riprap. Because the physical model did not have this barrier, it allowed for an unrealistic movement of sand beneath the scaled riprap in the model, which in turn caused the riprap to move downstream. Thus, these model conditions were concluded to not be representative of prototype conditions in terms of maximum scour depth. Furthermore, the uniformly graded sand is a conservative material in terms of critical shear stress. The actual bed material that is in the prototype is cohesive clay/hard-pan material and is expected to have higher resistance to scour than the sandy material used in the physical model.

For Test A (PMF), the area of riprap just downstream from the end sill and in between the retaining walls was molded such that it was all uniformly graded sand except for the top layer, which was scaled R470 stone at a prototype depth of 54 in.

Test B (PMF) was constructed such that the scaled R470 stone would completely fill the depth downstream of the stilling basin all the way to the physical model base instead of using a sand fill with riprap on top. The results can be seen in Figure 64 and Figure 65. It is clear that the amount of riprap scour noted from Test A has been greatly reduced. 
Figure 64. Pre-test minus post-test LiDAR for Test B PMF.

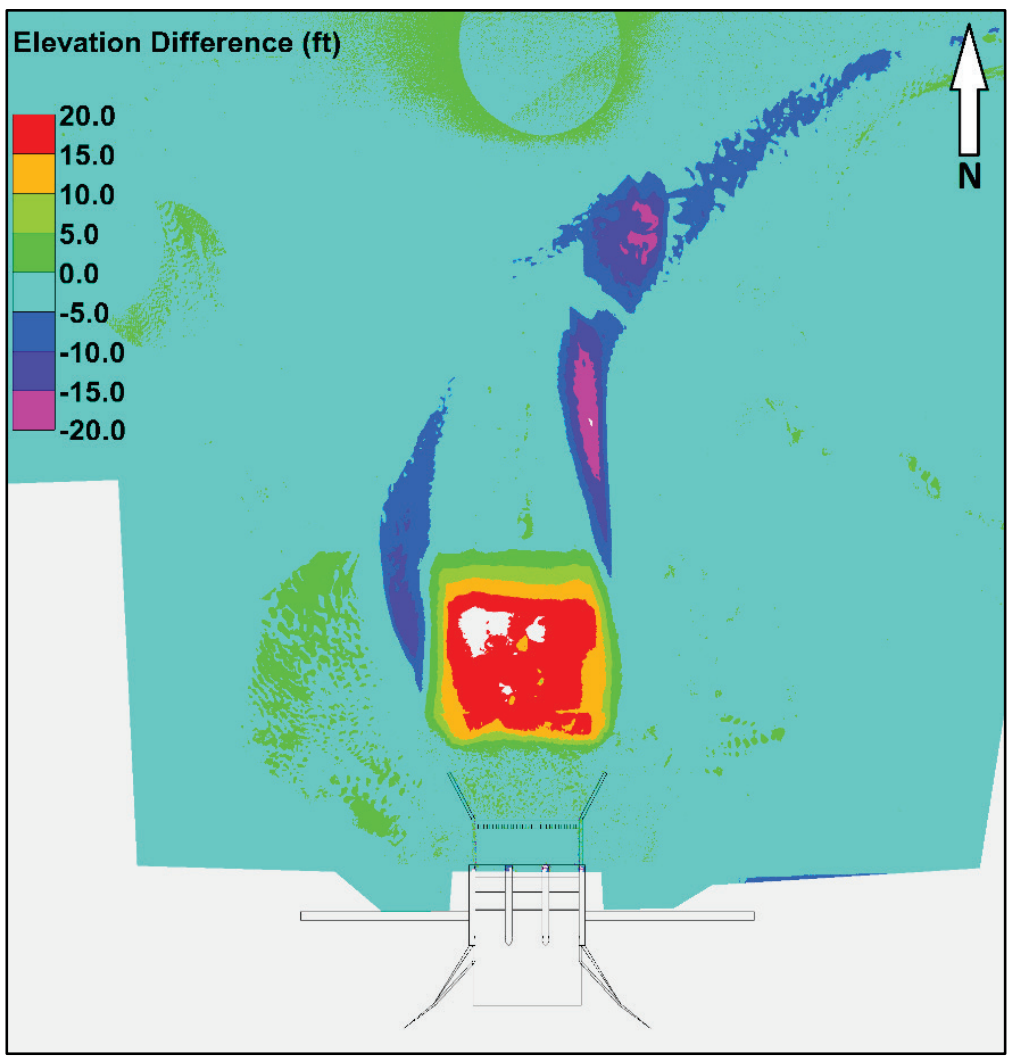

Figure 65. Pre-test (left) and post-test (right) pictures for Test B PMF.

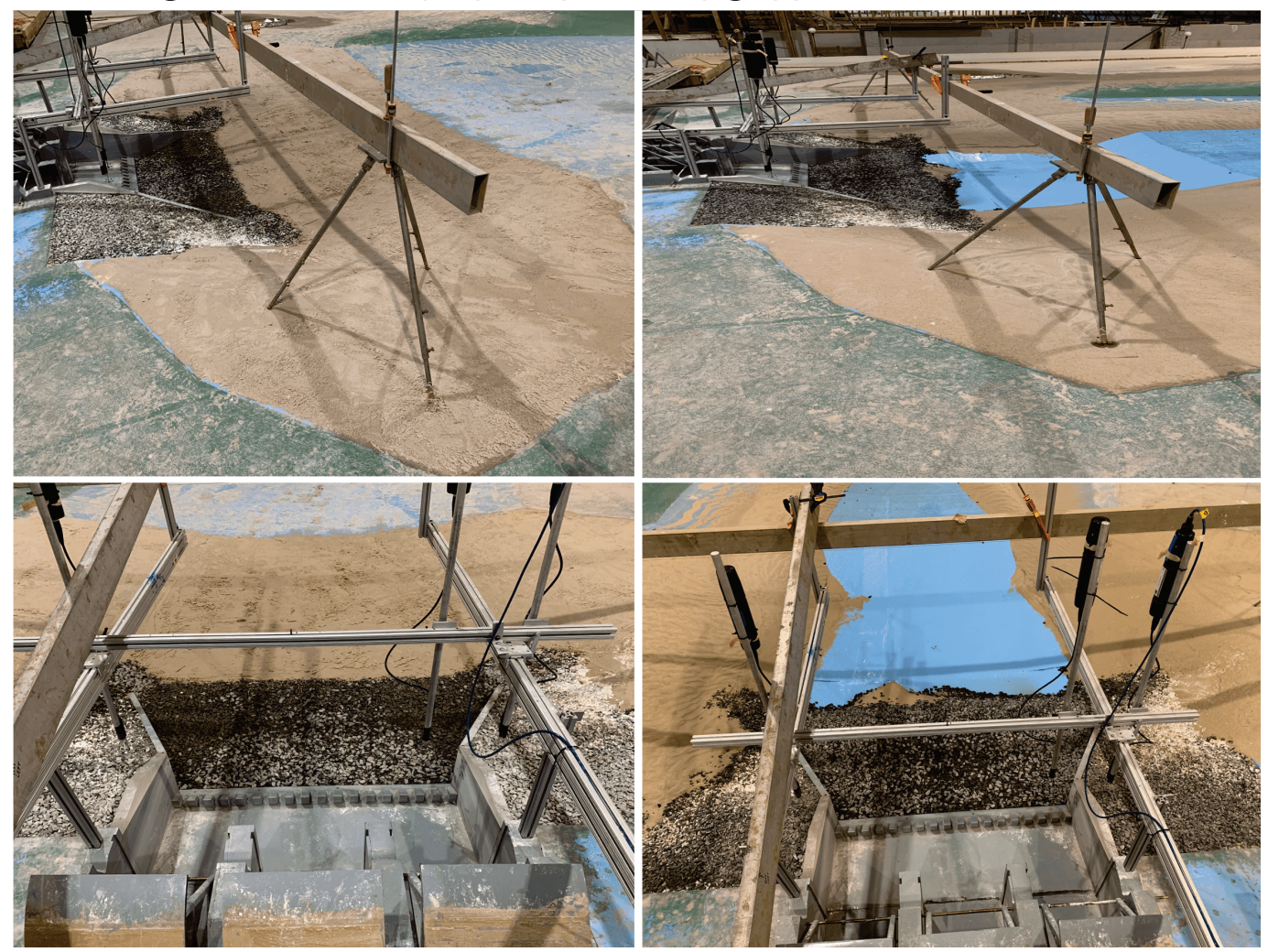


Tests $\mathrm{C}$ through $\mathrm{E}$ were constructed the same as Test $\mathrm{B}$ in regards to the riprap downstream of the stilling basin. Test $\mathrm{C}$ was tested under a flow of 89,700 cfs for the PMF resiliency scenario, which has the descending right bank gate completely closed. Tests D and E were tested under 99,300 cfs for the PMF resiliency scenario. The goal was to confirm if and how much riprap between the retaining walls moved under these high-flow conditions. The results can be seen in Figure 66 through Figure 71. Note that the PMF resiliency Test $\mathrm{D}$ was conducted without a re-mold of the sand/riprap. The test was performed with the resulting bathymetry from the PMF resiliency Test $\mathrm{C}$ and thus used the post LiDAR data from Test $\mathrm{C}$ as the pre-test data for Test $\mathrm{D}$. This was intended to save time as the test was completed to see if more riprap would scour in between the retaining walls when the flow was increased by approximately 10,000 cfs. Tests D and $\mathrm{E}$ results can be seen in Figure 68 through Figure 71. Test $\mathrm{E}$ has the same flow conditions as Test D, but the setup differed in that the sand was reformed in the model downstream of the riprap in Test $\mathrm{E}$ while this sand was not reformed in Test D.

Figure 66. Pre-test minus post-test LiDAR for Test C PMF resiliency $(89,700 \mathrm{cfs})$.

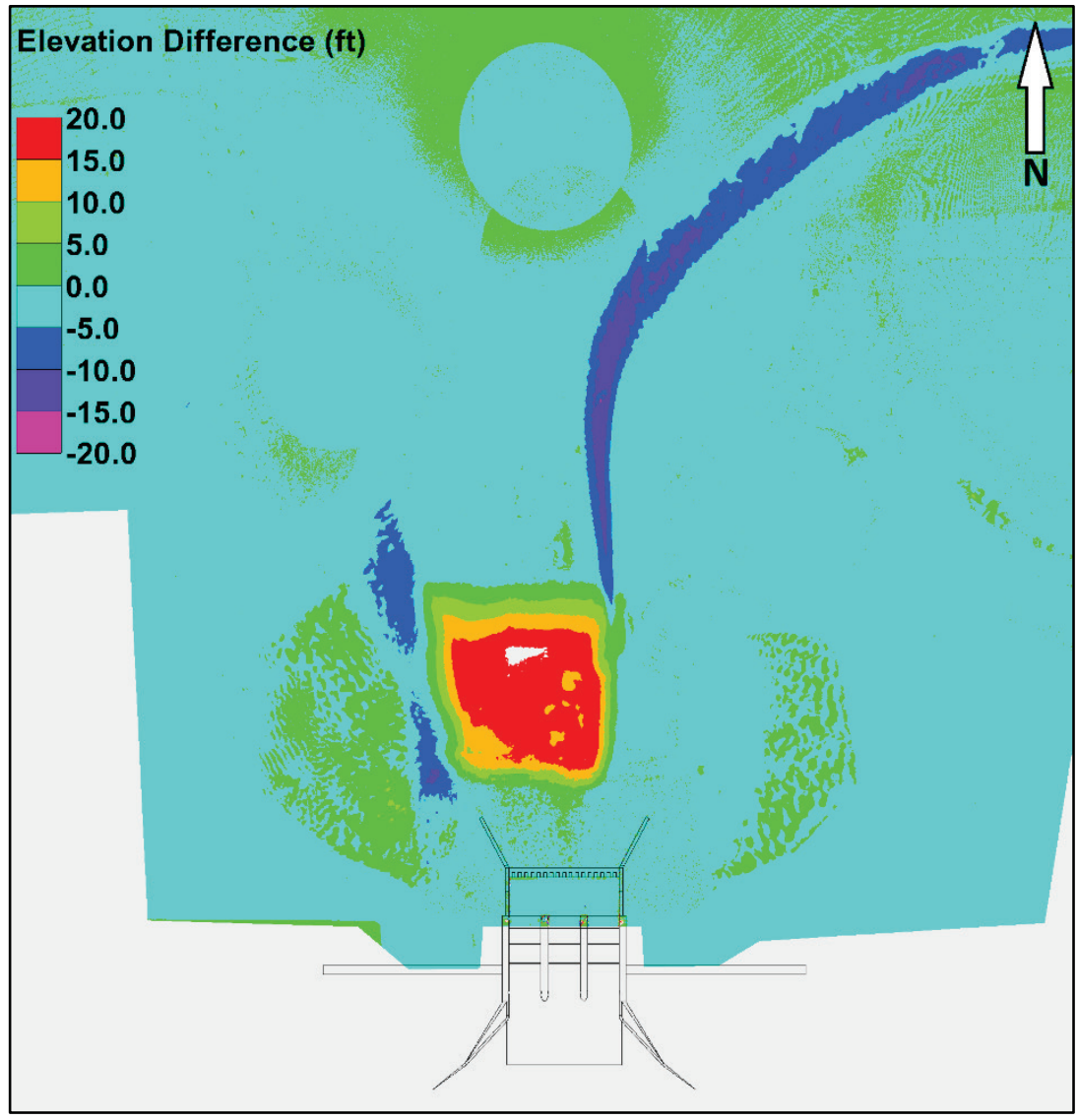


Figure 67. Pre-test (left) and post-test (right) pictures for Test C PMF resiliency $(89,700 \mathrm{cfs})$.

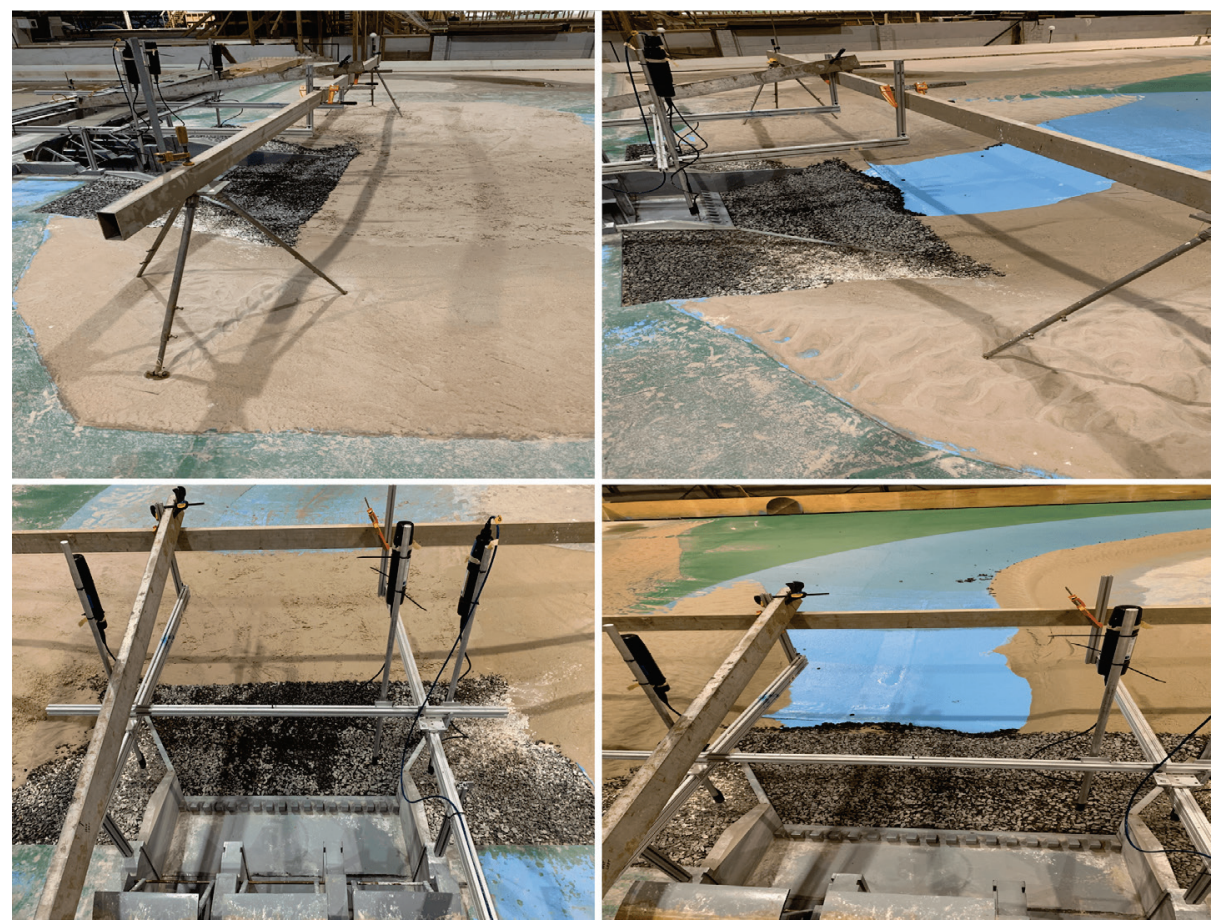

Figure 68. Pre-test minus post-test LiDAR for Test D PMF resiliency $(99,300 \mathrm{cfs})$.

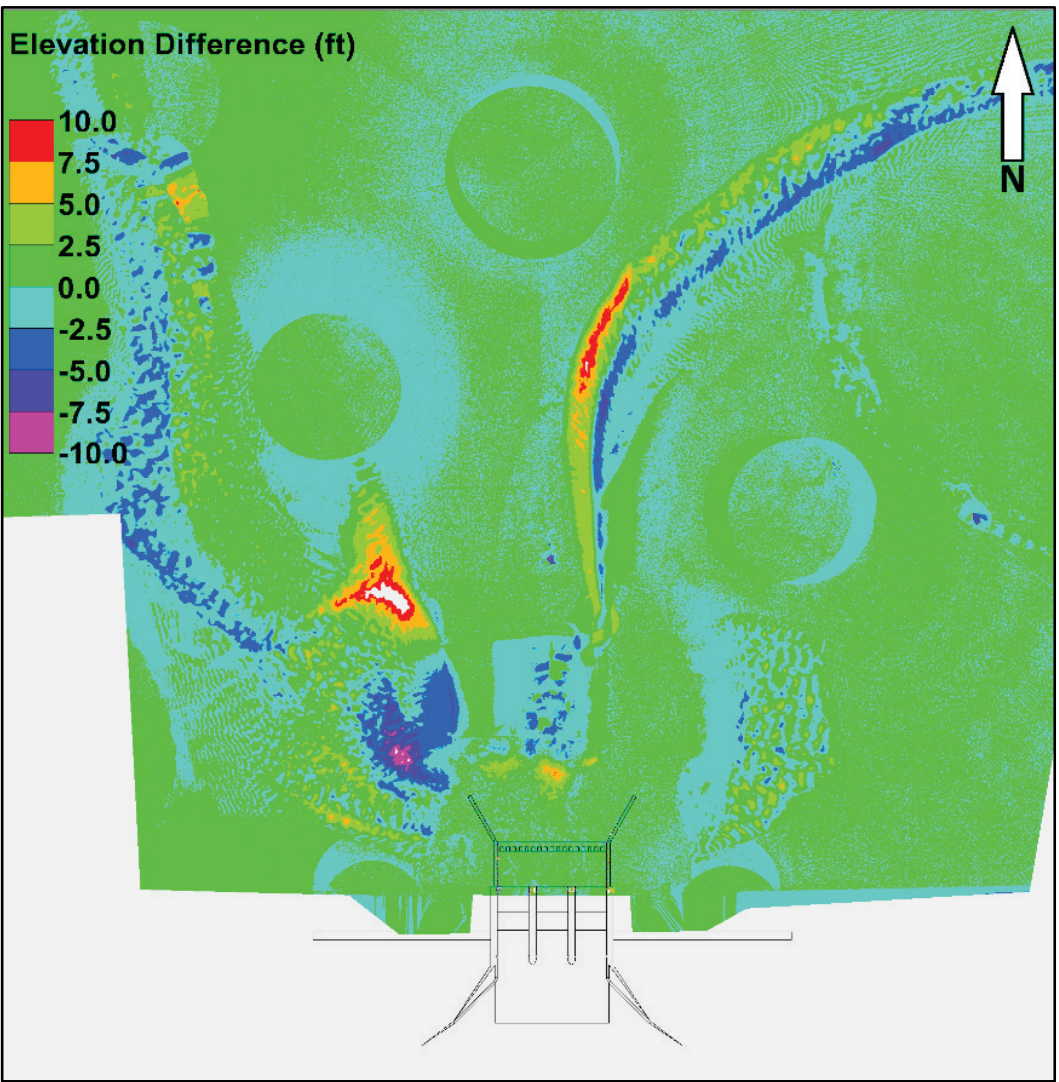


Figure 69. Pre (left) and post-test (right) pictures for Test D PMF resiliency (99,300 cfs).

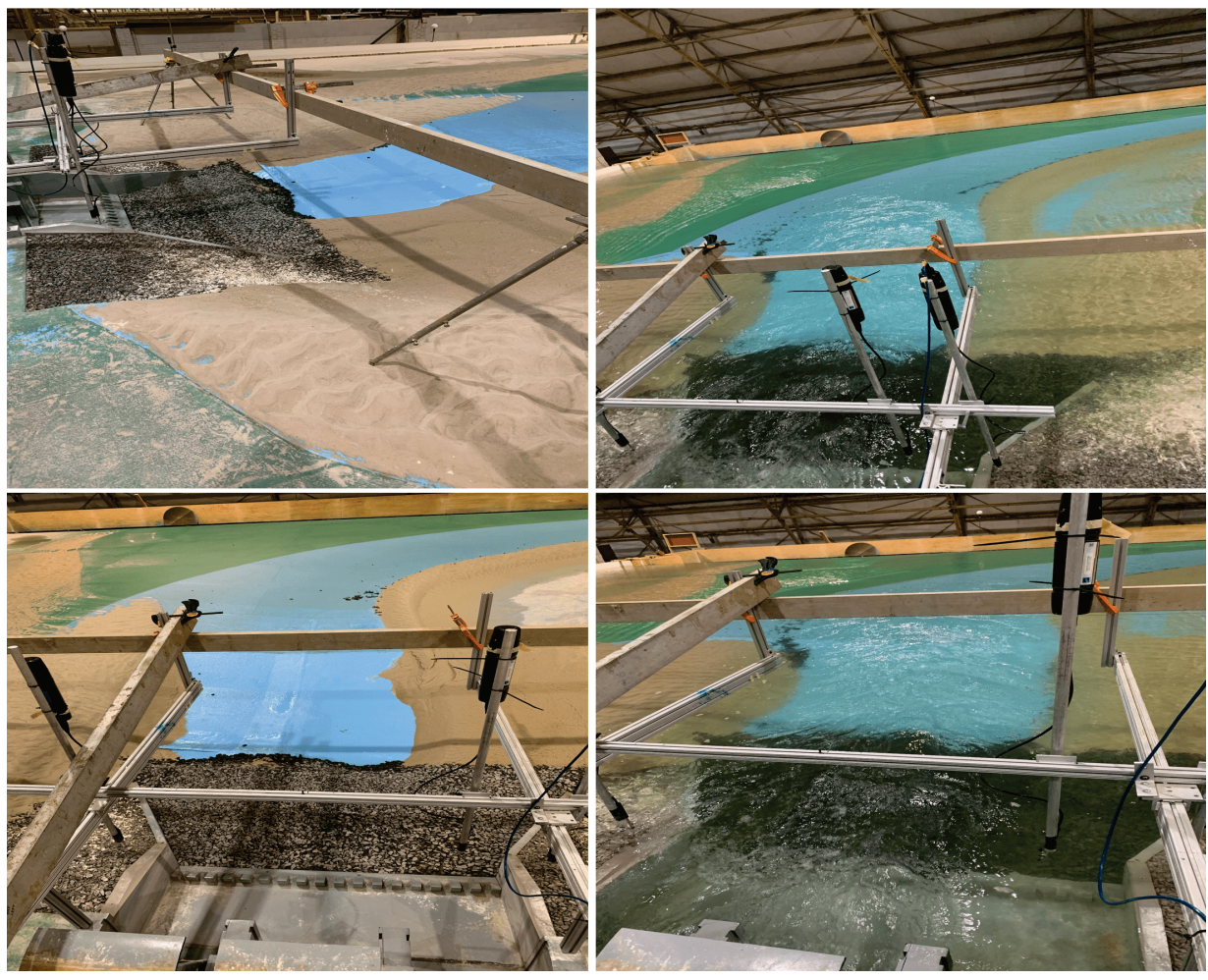

Figure 70. Pre minus post-test LiDAR for Test E PMF Resiliency $(99,300 \mathrm{cfs})$.

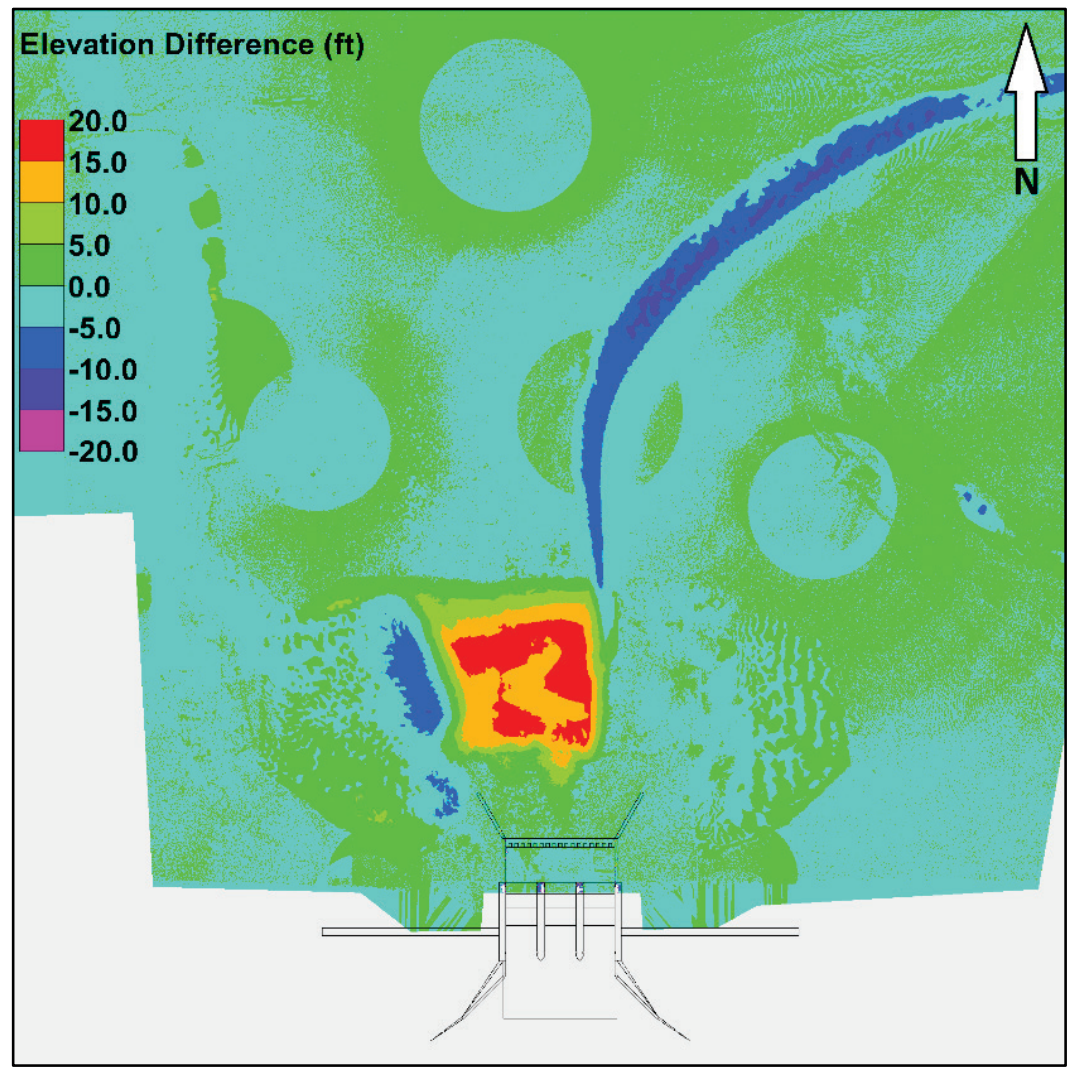


Figure 71. Pre-test (left) and post-test (right) pictures for Test E PMF resiliency $(99,300 \mathrm{cfs})$.

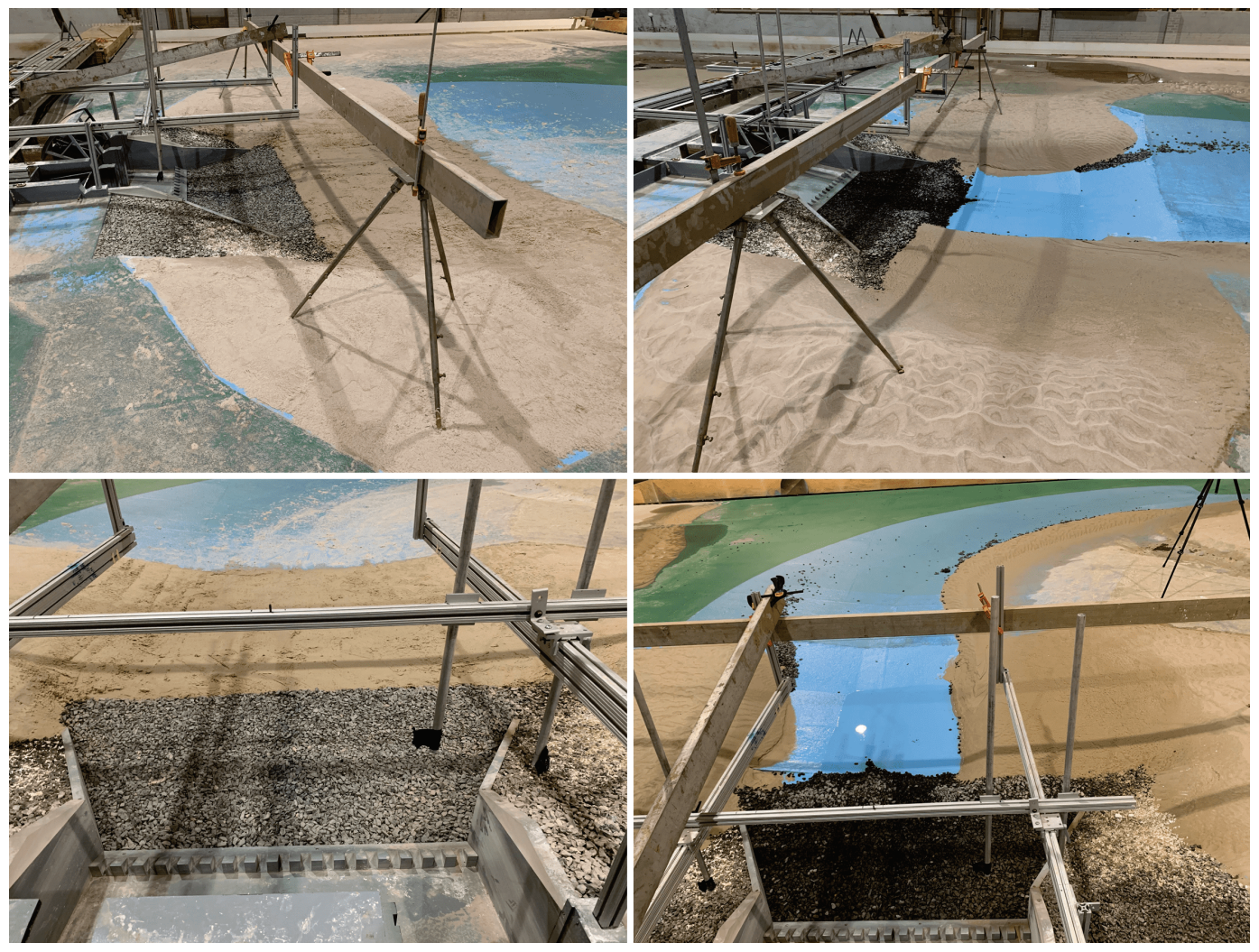

\subsubsection{Alternative 3 Design summary}

It was determined that the $74 \mathrm{ft}$ distance of the flat riprap area in between the retaining walls was effective and met the design goal of minimal riprap movement during both the PMF and PMF resiliency tests. 


\section{Conclusions and Recommendations}

The proposed RRS design has been confirmed to successfully pass the PMF while staying at or under the target headwater elevation of $923.5 \mathrm{ft}$. The approach structure, gate width, control structure length, stilling basin length, stilling basin wall height, dentated end sill configuration, engineered channel design, and other features have been confirmed to be appropriate for passing the PMF while minimizing erosion of riprap downstream of the stilling basin.

At the conclusion of the Base Design testing, it was confirmed that the pre-formed scour hole could be reduced or eliminated. The uniformly graded sand was used to simulate a reduction in the scour hole's footprint. The capacity of the proposed structure was not notably impacted by the presence of a pre-formed scour hole. Additionally, the pre-formed scour hole was not needed to minimize erosion of riprap downstream of the stilling basin. The Alternative 1, 2, and 3 Designs did not incorporate a pre-formed scour hole.

The physical modeling effort resulted in a stilling basin wall, retaining wall, and end sill geometry/configuration where erosive conditions were not observed outside and adjacent to the stilling basin. The stilling basin wall inserts proved to be successful in creating hydraulic conditions that would not lead to scour of the scaled R470 riprap in the near vicinity of the structure. The sloped stilling basin insert proved to be an acceptable and effective design feature. The water jet was still propelled upwards into the water column, and the area downstream of the end sill was protected from scour. The dentated end sill proved to be efficient in thrusting the water jet up into the water column thus protecting the area immediately downstream of the end sill from potential erosion. Properly designed riprap proved to be successful in protecting the proposed RRS from potential scour downstream of the stilling basin. The recommended riprap layer consists of the St. Paul District R470 gradation, having a thickness of $4.5 \mathrm{ft}$ and designed with the properly bedding/filter to prevent bed material from being drawn up through the riprap. The scaled R470 riprap also proved successful in protecting the retaining walls and stilling basin walls from potential scour. Dropping the stilling basin by $7 \mathrm{ft}$ (first introduced in Alternative 1) over a down-sloping length was successful in preventing erosion of downstream riprap. Furthermore, the modified approach wall design proved to be successful in creating safe approach 
flow conditions as well as acceptable flow separation patterns. Alternative 3 was the most successful geometry in terms of preventing erosion in the near vicinity of the stilling basin. It is recommended that Alternative 3 be the design used going forward.

While the facility is available, ERDC recommends any additional desired testing be conducted with the general physical model. 


\section{References}

Bell, Gary, Jeremy Sharp, Tate McAlpin, Anthony Jackson, and George Herring. 2018. Laboratory Techniques and Procedures Using Lidar. CHETN-VII-18. Vicksburg, MS: U.S. Army Engineer Research and Development Center.

ERDC (U.S. Army Engineer Research and Development Center). 2017. Adaptive Hydraulics 2D Shallow Water (AdH-SW2D) User Manual (Version 4.6).

Martin, V., T. Fisher, R. Millar, and M. Quick. 2004. ADV Data Analysis for Turbulent Flows: Low Correlation Problem. Hydraulic Measurements and Experimental Methods Specialty Conference 2002.

https://ascelibrary.org/doi/10.1061/40655\%282002\%29101

USACE MVP (U.S. Army Corps of Engineers, St. Paul District). 2019. Fargo-Moorhead Metropolitan Area Flood Risk Management Project. Wild Rice River Structure. Engineering and Design Phase. 


\section{Appendix: ERDC/CHL LR-19-15}

[Note: The authors of the following document have given permission for its inclusion in this technical report.] 


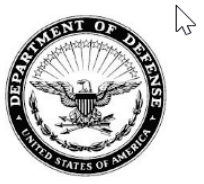

DEPARTMENT OF THE ARMY

U.S. ARMY CORPS OF ENGINEERS, ENGINEER RESEARCH AND DEVELOPMENT CENTER COASTAL AND HYDRAULICS LABORATORY

WATERWAYS EXPERIMENT STATION, 3909 HALLS FERRY ROAD

VICKSBURG, MISSISSIPPI 39180-6199

CEERD-HFR

23 December 2019

MEMORANDUM FOR Commander, U.S. Army Corps of Engineers, St. Paul District (Mr. Kevin Deen), $1805^{\text {th }}$ St E, St Paul, MN 55101

SUBJECT: Physical Model Study: Verification of the Proposed Red River Structure's Flow Capacity Letter Report.

1. The U.S. Army Engineer Research and Development Center, Coastal and Hydraulics Laboratory, was tasked by the U.S. Army Corps of Engineers St. Paul District to assist in the hydraulic evaluation of the proposed Red River Structure (RRS). This model's performance in regards to the structure's capacity is documented in the letter report entitled "Red River Structure Physical Model Study: Verification of the Proposed Structure's Flow Capacity" (ERDC/CHL LR-19-15) and is provided here.

2. If you have any questions, please contact Mr. Gary Bell at 601-634-4621 or Gary.L.Bell@usace.army.mil.

Encl

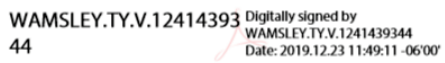
Date: 2019.12.23 11:49:11-06

TY V. WAMSLEY, PhD, SES

Director, Coastal and Hydraulics Laboratory 


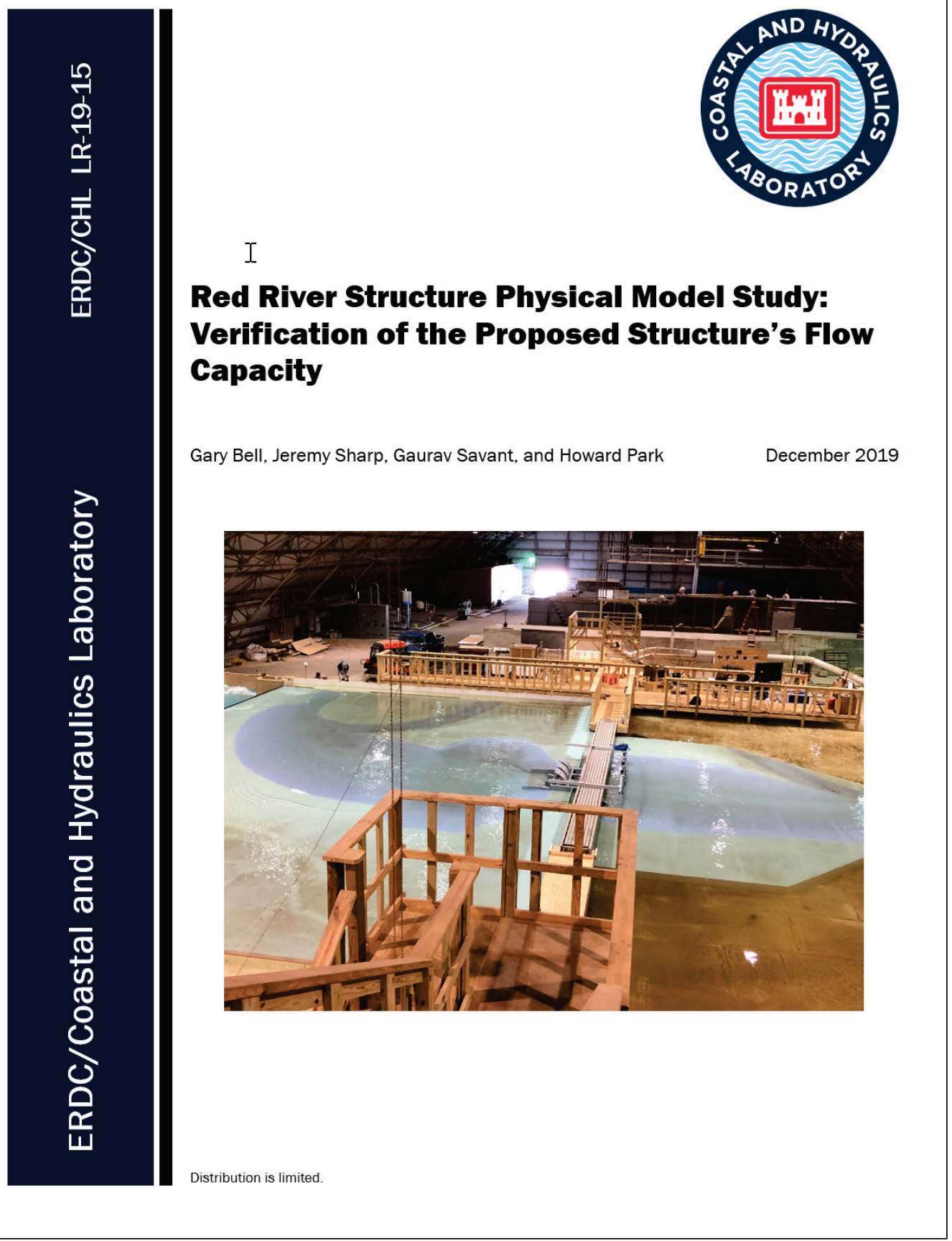




\section{Red River Structure Physical Model Study: Verification of the Proposed Structure's Flow Capacity}

Gary Bell, Jeremy Sharp. Gaurav Savant, and Howard Park

Coastal and Hydraulics Laboratory

U.S. Army Engineer Research and Development Center

3909 Halls Ferry Road

Vicksburg, MS 39180-6199

Final Letter Report

Prepared for St. Paul District, U.S. Army Corps of Engineers

Saint Paul, MN 55101 
ERDC/CHL LR-19-15

Abstract: This Coastal \& Hydraulics Laboratory (CHL) Letter Report describes the evaluation of the Red River Structure's (RRS) capacity to pass the Probable Maximum Flood (PMF). The proposed RRS is located on the Red River just south of Fargo, ND. Data from the physical model study were used to determine that the proposed structure possessed the capacity to pass the PMF while maintaining headwater elevations of less than 923.5 feet.

DISCLAIMER: The contents of this report are not to be used for advertising, publication, or promotional purposes. Citation of trade names does not constitute an official endorsement or approval of the use of such commercial products. All product names and trademarks cited are the property of their respective owners. The findings of this report are not to be construed as an official Department of the Army position unless so designated by other authorized documents.

DESTROY THIS REPORT WHEN NO LONGER NEEDED. DO NOT RETURN IT TO THE ORIGINATOR. 
s

ERDC/CHL LR-19-15

\section{Contents}

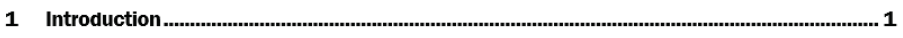

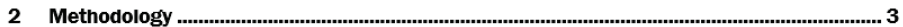

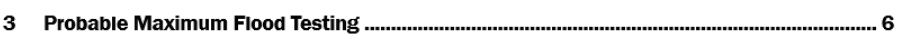

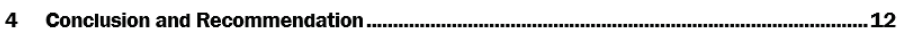

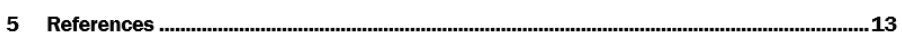




\section{Introduction}

The United States Army Corps of Engineers (USACE) St. Paul District (MVP) and non-federal sponsors (City of Fargo, ND; City of Moorhead, MN; Cass County, ND; Clay County, MN; and the Cass County Joint Water Resources District) are designing and constructing a flood risk management project that will reduce the risk of flooding in the FargoMoorhead metropolitan area. There is a 30-mile long diversion channel around the west side of the city of Fargo as well as staging temporary floodwater storage area that will be formed upstream of a 25-mile long dam (referred to as the Southern Embankment) that collectively includes an earthen embankment with three gated structures: the Diversion Inlet Structure (DIS), the Wild Rice River Structure (WRRS), and the Red River Structure (RRS). Construction of the DIS began in December of 2016. Detailed design of the WRRS is complete. Detailed design of the RRS commenced June 17, 2019.

An undistorted free-surface Froude-scaled physical model has been implemented to evaluate the capacity potential of the RRS. Using St. Paul District-provided data for the desired lowest flow to be tested; Coastal and Hydraulics Laboratory (CHL) personnel determined a geometric scale of Length ratio $\left(\mathrm{L}_{r}\right)$ 1:40 is sufficient. At the selected scale and for the selected range of flow conditions, the model is fully turbulent and surface tension is not a factor. An overview of the entire project can be seen in Figure 1. 


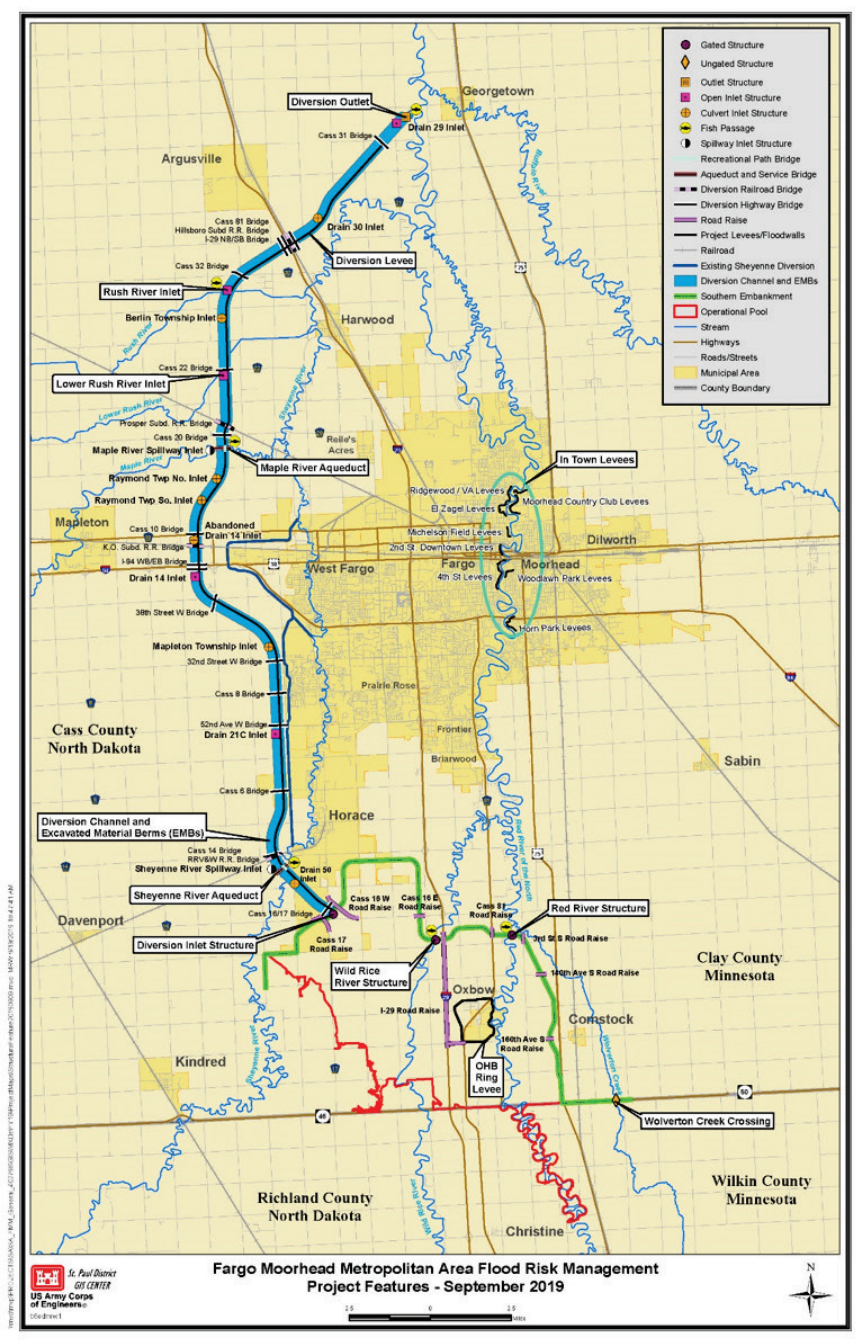

Figure 1. Flood Risk Management Project Overview 


\section{Methodology}

To determine the extents of the physical model boundaries, a twodimensional Adaptive Hydraulics model ( $\mathrm{AdH}$ ) was used (Adaptive Hydraulics, 2017). A base model was created that extended to Highway 75 and Interstate 29 for the East and West boundaries, respectively, with downstream and upstream boundaries at 2.15 miles and 5.5 miles from the proposed RRS, respectively. The intent of the large base model domain was to eliminate boundary effects near the structure. The base model was used to compare alternative reduced boundary extents for the physical model layout. The domain for the base model and location of the proposed RRS can be seen in Figure 2.

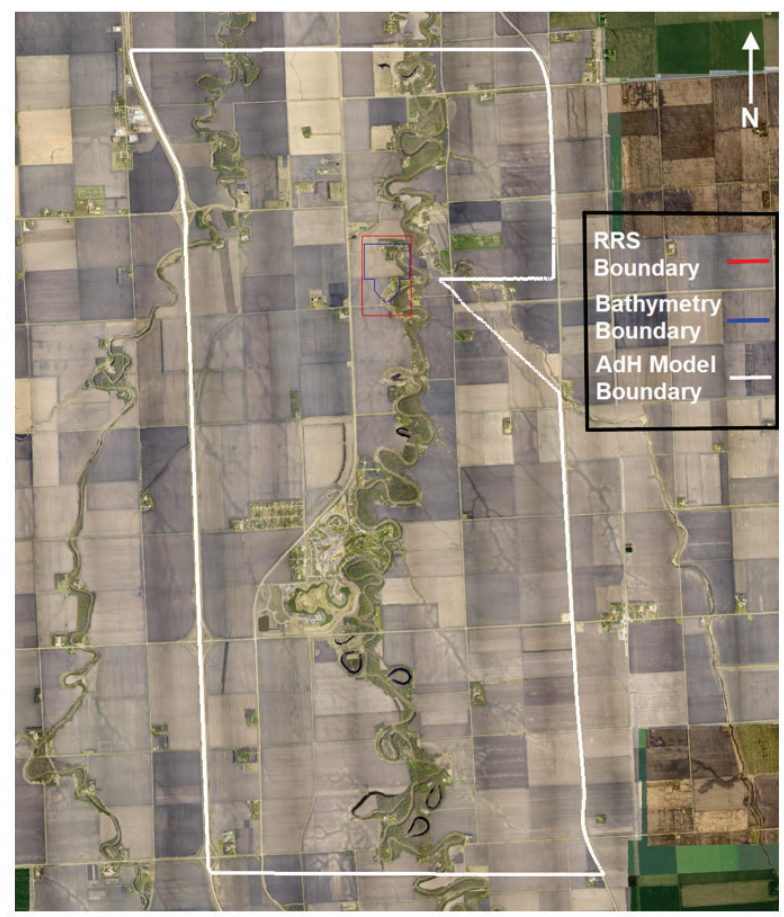

Figure 2. AdH Base Model Domain. 
After multiple numerical model simulations with varying boundaries, a final domain was created (Figure 3). The red line outlines the wall of the physical model, while the blue line represents where the bathymetry/topography ends. The final physical model extents were defined as the smallest extents that did not disturb the velocity field entering the RRS.

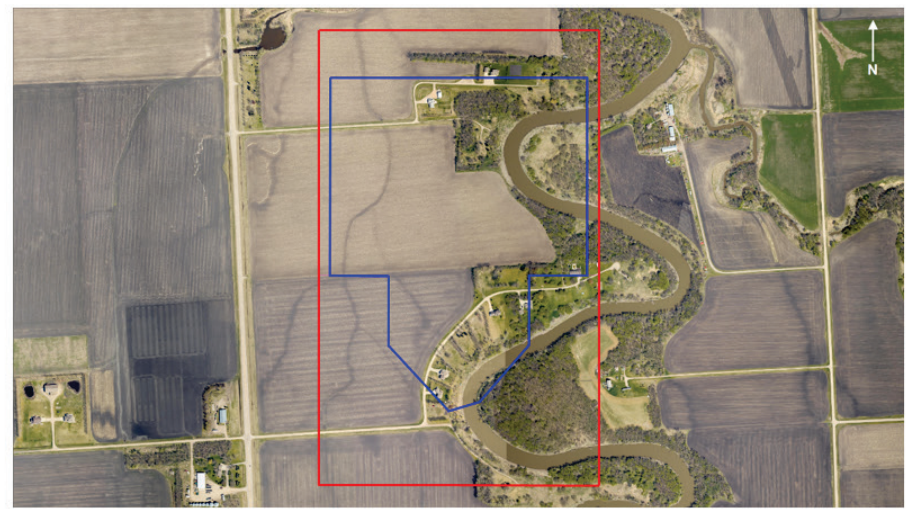

Figure 3. Final Model Domain.

Physical model construction was completed mid-November of 2019. This included the bathymetry/topography, structure, paint, observation deck, data collection instrumentation center, stilling well basin, structural framework for Nortek Vectrino velocity probes, upstream baffle wall, downstream flap gates and weirs, etc. Figure 4 shows the un-finished upstream portion (left) and finished downstream portion (right) of the RRS physical model. Figure 5 displays the observation deck, data collection center, upstream baffle wall, and stilling well basin. 
A
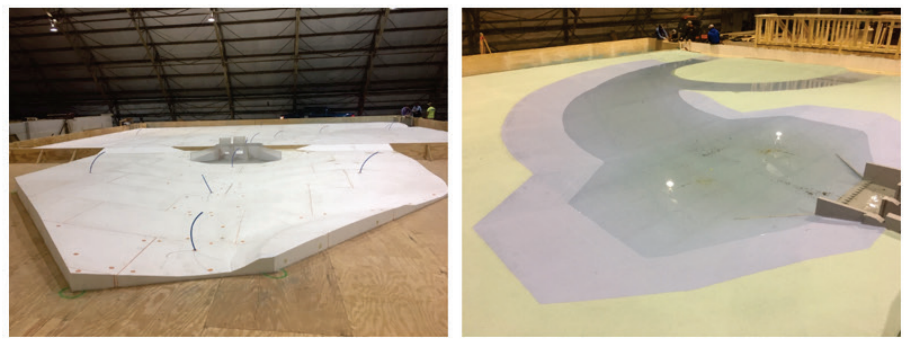

Figure 4. Physical Model Construction
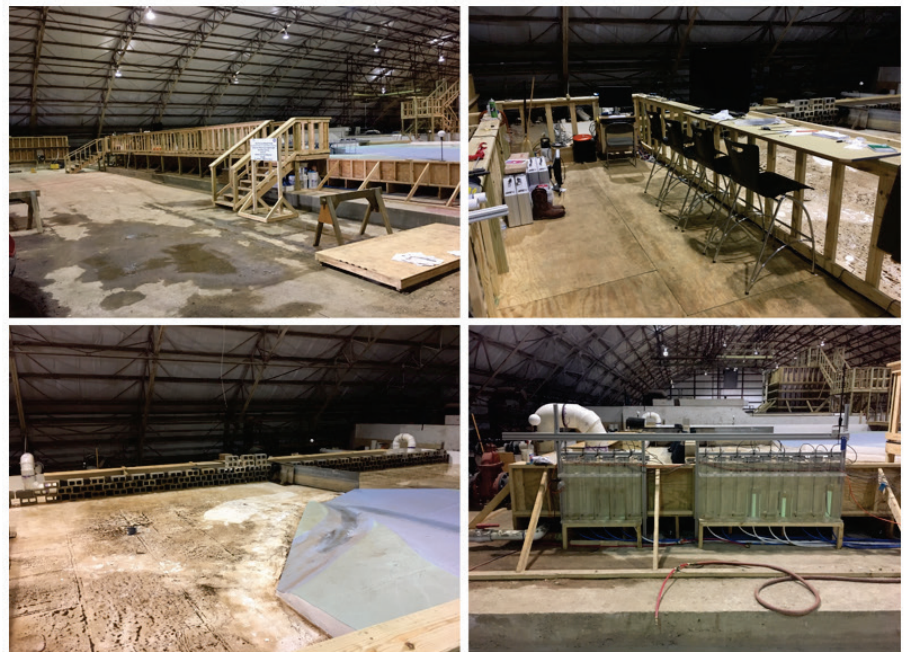

Figure 5. Physical Model Construction Showing (Clockwise from Upper Left) the Observation Deck, Data Collection Center, Stilling Well Basin, and Upstream Baffle Wall. 


\section{Probable Maximum Flood Testing}

The proposed RRS physical model was evaluated for the Probable Maximum Flood (PMF) flow scenario to determine the ability of the structure to pass the flow. The PMF scenario is comprised of an inflow of 104,300 cubic feet per second (cfs) (note results are reported at prototype scale). Some $\mathrm{L}_{\mathrm{r}}$ conversions are shown in Table 1 . Typical model tests were set up as follows: the inflow was set using gate valves and measured with two ultrasonic flowmeters from EESIFLO International (each on a separate 12 " pipe). The downstream boundary water surface elevation (WSE) was set to 917.5 feet ( $\mathrm{ft}$ ) by adjusting weirs and vertical flap gates. The flow and downstream boundary conditions were defined from onedimensional Hydrologic Engineering Center River Analysis System (HECRAS) numerical modeling using a St. Paul District-modified version of the Conditional Letter of Map Revision model dated December 4, 2019. WSEs throughout the physical model were monitored by 14 Akamina capacitance gages and were measured using digital point gages referenced to a bench mark on the frame of the stilling well basin (Figure 6).

Table 1. Length Ratio Conversions.

\begin{tabular}{|c|c|}
\hline Variable & $\begin{array}{c}\text { Froudian Simili- } \\
\text { tude Scale }\end{array}$ \\
\hline Length & $\mathrm{L}_{\mathrm{r}}$ \\
\hline Velocity & $\mathrm{L}_{\mathrm{r}} \wedge .5$ \\
\hline Discharge & $\mathrm{L}_{\mathrm{r}}{ }^{\wedge} 2.5$ \\
\hline
\end{tabular}


外

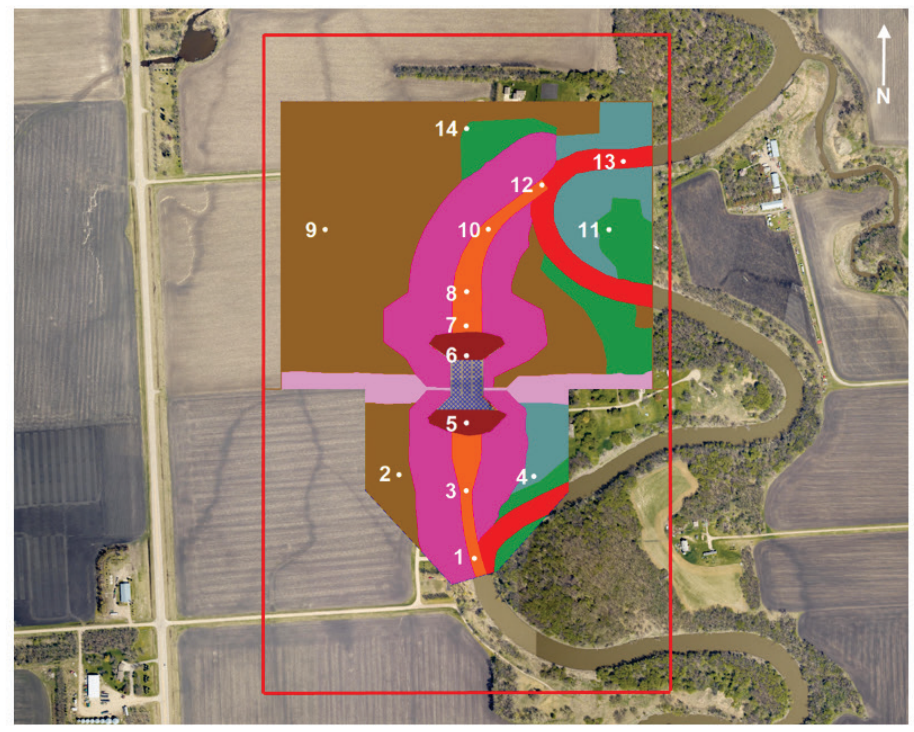

Figure 6. Gage Locations.

Two tests were conducted for the PMF flow condition: (i) using the expected downstream boundary condition of $917.5 \mathrm{ft}$ and (ii) using a higher downstream boundary condition of $918.5 \mathrm{ft}$ to test the RRS capacity sensitivity to the downstream boundary condition. Each test was repeated to ensure result reproducibility. Data collected for each test included WSE measurements at each gage and inflow pipe discharge measurements. WSE and flow data collected as part of the PMF flow with $917.5 \mathrm{ft}$ downstream boundary condition are shown in Table 2. Figure 7 displays the average WSEs ( $\mathrm{ft}$ ) at each gage location for the PMF event. 
Table 2. Model Test Results for the PMF Condition.

\begin{tabular}{|c|c|c|c|}
\hline Gage Number & $\begin{array}{c}11 / 19 / 2019 \\
\text { WSE, ft }\end{array}$ & $\begin{array}{c}12 / 12 / 2019 \\
\text { WSE, ft }\end{array}$ & $\begin{array}{c}\text { Average, } \\
\text { ft }\end{array}$ \\
\hline 1 & 921.8 & 921.9 & 921.8 \\
\hline 2 & 921.6 & 921.8 & 921.7 \\
\hline 3 & 921.7 & 921.9 & 921.8 \\
\hline 4 & 921.7 & 921.8 & 921.8 \\
\hline 5 & 921.2 & 921.3 & 921.3 \\
\hline 6 & 916.2 & 916.3 & 916.3 \\
\hline 7 & $918.6 *$ & 918.5 & 918.5 \\
\hline 8 & 916.2 & 915.8 & 916.0 \\
\hline 9 & 917.6 & 917.6 & 917.6 \\
\hline 10 & 917.3 & 917.4 & 917.4 \\
\hline 11 & 917.3 & 917.4 & 917.4 \\
\hline 12 & 917.3 & 917.3 & 917.3 \\
\hline 13 & 917.3 & 917.4 & 917.3 \\
\hline 14 & 918.1 & 917.7 & 917.9 \\
\hline Flow (cfs) & 103,824 & 104,229 & 104,027 \\
\hline
\end{tabular}

*11/19/2019 gage reading discarded due to erroneous measurement. Measurement recorded is from an additional test performed on $12 / 16 / 2019$ to verify WSE data. 


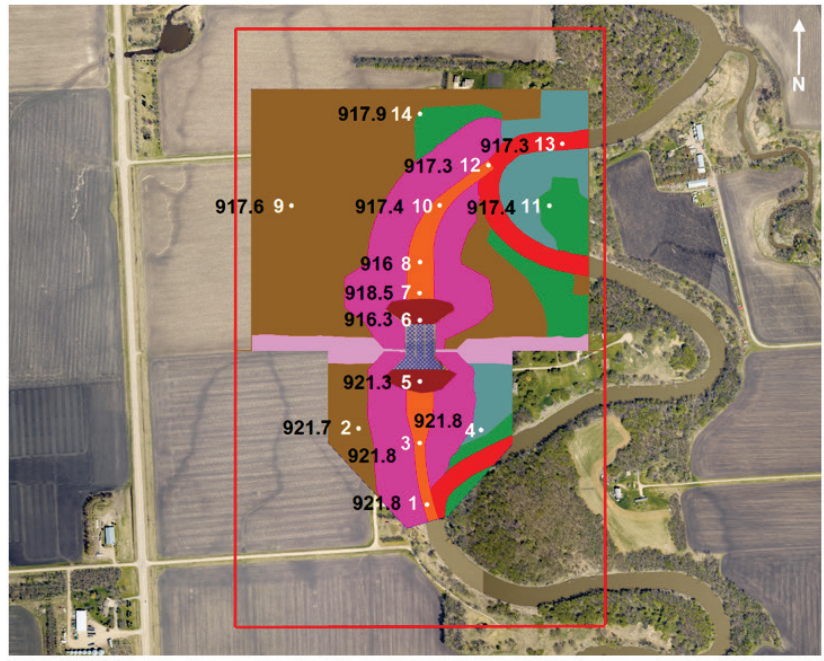

Figure 7. PMF Results

WSE and flow data collected as part of the PMF flow with the higher downstream boundary condition of $918.5 \mathrm{ft}$ is shown in Table 3 . Figure 8 displays the average WSEs ( $\mathrm{ft}$ ) at each gage location for the PMF Sensitivity event.

Table 3. Model Results for the PMF Sensitivity Test.

\begin{tabular}{|c|c|c|c|}
\hline Gage Number & $\begin{array}{c}11 / 20 / 2019 \\
\text { WSE, ft }\end{array}$ & $\begin{array}{c}12 / 12 / 2019 \\
\text { WSE, ft }\end{array}$ & $\begin{array}{c}\text { Average, } \\
\mathrm{ft}\end{array}$ \\
\hline 1 & 922.4 & 922.4 & 922.4 \\
\hline 2 & 922.3 & 922.3 & 922.3 \\
\hline 3 & 922.4 & 922.4 & 922.4 \\
\hline 4 & 922.4 & 922.4 & 922.4 \\
\hline 5 & 921.9 & 921.8 & 921.9 \\
\hline 6 & 916.9 & 917.1 & 917.0 \\
\hline 7 & $*$ & 919.2 & 919.2 \\
\hline 8 & 916.8 & 916.5 & 916.7 \\
\hline 9 & 918.5 & 918.5 & 918.5 \\
\hline 10 & 918.1 & 918.1 & 918.1 \\
\hline 11 & 918.0 & 918.1 & 918.1 \\
\hline
\end{tabular}




\begin{tabular}{|c|c|c|c|}
\hline 12 & $*$ & 918.1 & 918.1 \\
\hline 13 & 918.0 & 918.1 & 918.1 \\
\hline 14 & 919.7 & 919.0 & 919.4 \\
\hline Flow (cfs) & 105,038 & 103,723 & 104,381 \\
\hline
\end{tabular}

${ }^{*}$ Gage reading discarded due to erroneous measurement.

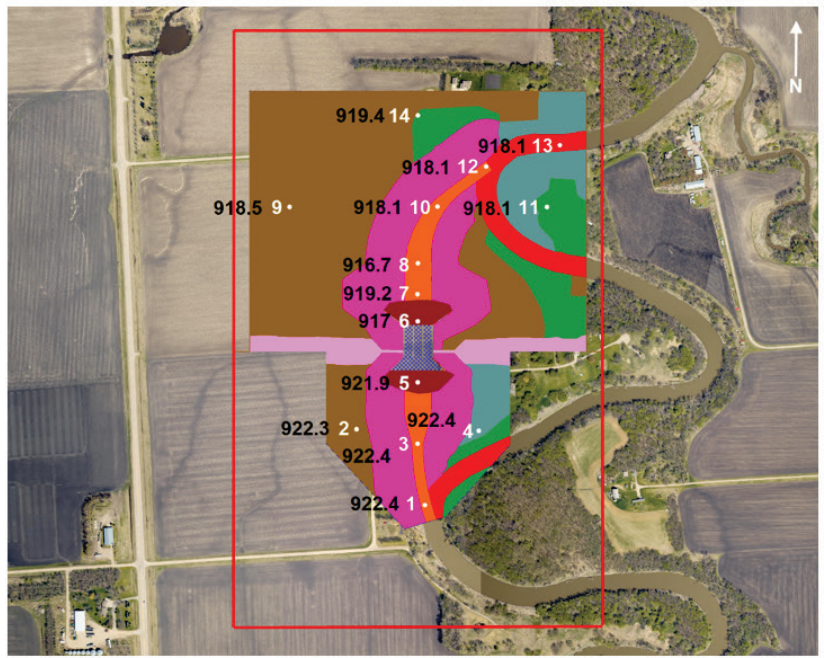

Figure 8. PMF Sensitivity Results.

WSE readings from gages 2 and 4 are considered representative of the pool elevations. The St. Paul District's plan anticipates a maximum pool elevation of $923.5 \mathrm{ft}$ during the PMF event. Therefore, readings equal to or less than $923.5 \mathrm{ft}$ at gages 2 and 4 during the tests indicate the RRS as currently designed has sufficient capacity to pass the PMF event. Table 4 summarizes the measurements for gages 2 and 4 for each test. As shown in the table, all measurements for both tests and for both downstream boundary condition scenarios have WSEs less than $923.5 \mathrm{ft}$. Therefore, the RRS has sufficient capacity to pass the PMF flow conditions based on the physical modeling effort and boundary condition information provided by the St. Paul District. 
4

Table 4. Model Results for the PMF and PMF Sensitivity Tests.

\begin{tabular}{|c|c|c|c|c|c|}
\hline \multirow{2}{*}{$\begin{array}{c}\text { Gage } \\
\text { Number }\end{array}$} & $\begin{array}{c}\text { Maximum } \\
\text { Allowable } \\
\text { WSE, ft }\end{array}$ & $\begin{array}{c}11 / 19 / 19 \\
\text { WSE, ft }\end{array}$ & $\begin{array}{c}12 / 12 / 19 \\
\text { WSE, ft }\end{array}$ & $\begin{array}{c}11 / 20 / 19 \text { Sensitivity } \\
\text { WSE, ft }\end{array}$ & $\begin{array}{c}\text { 12/12/19 Sensitivity } \\
\text { WSE, ft }\end{array}$ \\
\hline 2 & 923.5 & 921.6 & 921.8 & 922.3 & 922.3 \\
\hline 4 & 923.5 & 921.7 & 921.9 & 922.4 & 922.4 \\
\hline Flow (cfs) & - & 103,824 & 104,229 & 105,038 & 103,723 \\
\hline
\end{tabular}

It is noted that in evaluating the data for the tests, the physical model appears to be creating an artificial backwater effect near gage 14. In early 2020 , this will be mitigated by extending the tail bay that receives the downstream flow to eliminate this artificial backwater effect. The effect at this small area in the end of the channel will not affect the RRS's ability to pass the PMF. 


\section{Conclusion and Recommendation}

Based on the model testing results discussed previously, the physical model indicates that the proposed RRS has the capacity to pass the PMF

flow. This is based on headwater WSE values being lower than $923.5 \mathrm{ft}$, which is the maximum allowable elevation as defined by the St. Paul District. 


\section{References}

Engineer Research and Development Center, US Army Corps of Engineers, 2017. Adaptive Hydraulics 2D Shallow Water (AdH-SW2D) User Manual (Version 4.6). 
ADDITIONAL INFORMATION: This letter report was prepared by Gary Bell, Research Hydraulic Engineer at the US Army Corps of Engineers, Engineer Research and Development Center, Coastal \& Hydraulics Laboratory. Questions about this letter report can be addressed to Author at 601-634-4621 or Gary.L.Bell@usace.army.mil. 


\section{Unit Conversion Factors}

\begin{tabular}{|l|l|l|}
\hline Multiply & By & To Obtain \\
\hline feet & 0.3048 & meters \\
\hline inches & 0.0254 & meters \\
\hline miles (U.S. statute) & $1,609.347$ & meters \\
\hline
\end{tabular}




\section{Acronyms and Abbreviations}

$\begin{array}{ll}\text { 2D } & \text { two-Dimensional } \\ \text { 3D } & \text { three-dimensional } \\ \text { AdH } & \text { Adaptive Hydraulics } \\ \text { ADV } & \text { acoustic Doppler velocimeter } \\ \text { AEP } & \text { annual exceedance probability } \\ \text { CHL } & \text { Coastal and Hydraulics Laboratory } \\ \text { DIS } & \text { Diversion Inlet Structure } \\ \text { ERDC } & \text { U.S. Army Engineer Research and Development Center } \\ \text { Lr } & \text { Length ratio } \\ \text { PMF } & \text { Probable Maximum Flood } \\ \text { RSS } & \text { Red River Structure } \\ \text { SNR } & \text { Signal to Noise Ratio } \\ \text { WRRS } & \text { Wild Rice River Structure } \\ \text { WSE } & \text { water surface elevations }\end{array}$




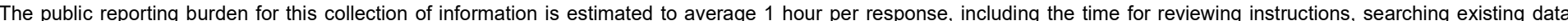

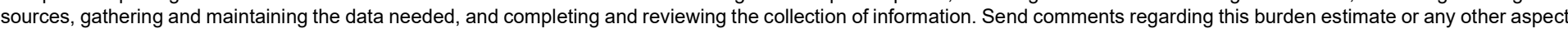

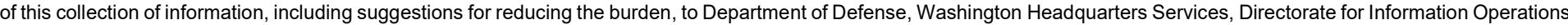

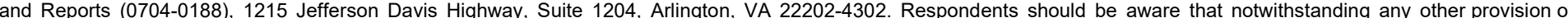
law, no person shall be subject to any penalty for failing to comply with a collection of information if it does not display a currently valid OMB control number. PLEASE DO NOT RETURN YOUR FORM TO THE ABOVE ADDRESS.

\begin{tabular}{l|l|l} 
1. REPORT DATE & $\begin{array}{l}\text { 2. REPORT TYPE } \\
\text { Final Report }\end{array}$ & 3. DATES COVERED (From - To) \\
September 2020 & \begin{tabular}{l} 
Final \\
\hline
\end{tabular}
\end{tabular}

\section{TITLE AND SUBTITLE}

Red River Structure Physical Model Study 5a. CONTRACT NUMBER

5b. GRANT NUMBER

5c. PROGRAM ELEMENT NUMBER

5d. PROJECT NUMBER

\section{AUTHOR(S)}

Gary L. Bell, Jeremy A. Sharp, Locke M. Williams, Howard E. Park, Duncan B. Bryant, and Gaurav Savant 5e. TASK NUMBER

5f. WORK UNIT NUMBER

8. PERFORMING ORGANIZATION REPORT NUMBER

ERDC/CHL TR-20-20

10. SPONSOR/MONITOR'S ACRONYM(S) USACE MVP

\section{SPONSOR/MONITOR'S} REPORT NUMBER(S)

\section{DISTRIBUTION/AVAILABILITY STATEMENT}

Approved for public release; distribution is unlimited.

\section{SUPPLEMENTARY NOTES}

MIPR W81G6591564227

\section{ABSTRACT}

A proposed Red River Structure (RRS), intended to function as one of three gated structures comprising the Fargo-Moorhead Metropolitan Area Flood Risk Management Project, was tested in a general physical model. A 1:40 Froude-scale was applied to model the structure, engineered channels, existing bathymetry/topography in the Red River and overbank areas, and the proposed Southern Embankment. The physical model was used to ensure that the RRS could pass at least 104,300 cfs during the Probable Maximum Flood while maintaining a maximum pool water surface elevation of $923.5 \mathrm{ft}$. The physical model was also utilized to optimize the approach structure, stilling basin, retaining walls, and erosion protection designs. The physical modeling effort resulted in an optimized stilling basin wall, retaining wall, and end sill geometry/configuration where erosive conditions were not observed outside and adjacent to the stilling basin. Properly designed riprap (St. Paul District's R470 gradation) proved to be successful in protecting the proposed RRS from potential scour downstream. The modified approach wall design proved to be successful in creating safe approach flow conditions as wel as acceptable flow separation patterns. It is recommended that Alternative 3 be the design used going forward.

\section{SUBJECT TERMS}

Fargo (N.D.), Flood control, Hydraulic gates, Hydraulic models, Moorhead (Minn.), Red River of the North

16. SECURITY CLASSIFICATION OF:

\begin{tabular}{|l|l|l|}
\hline a. REPORT & b. ABSTRACT & c. THIS PAGE \\
Unclassified & Unclassified & Unclassified \\
\hline
\end{tabular}

17. LIMITATION OF ABSTRACT

SAR

\section{NUMBER} OF PAGES

109 19a. NAME OF RESPONSIBLE PERSON Gary L. Bell

19b. TELEPHONE NUMBER (Include area code) 601-634-4621 